University of Montana

ScholarWorks at University of Montana

Graduate Student Theses, Dissertations, \&

Professional Papers

2004

\title{
Automated External Defibrillators in collegiate athletic training programs
}

Starr Junelyn Wharton

The University of Montana

Follow this and additional works at: https://scholarworks.umt.edu/etd Let us know how access to this document benefits you.

\section{Recommended Citation}

Wharton, Starr Junelyn, "Automated External Defibrillators in collegiate athletic training programs" (2004). Graduate Student Theses, Dissertations, \& Professional Papers. 6213.

https://scholarworks.umt.edu/etd/6213

This Thesis is brought to you for free and open access by the Graduate School at ScholarWorks at University of Montana. It has been accepted for inclusion in Graduate Student Theses, Dissertations, \& Professional Papers by an authorized administrator of ScholarWorks at University of Montana. For more information, please contact

scholarworks@mso.umt.edu. 


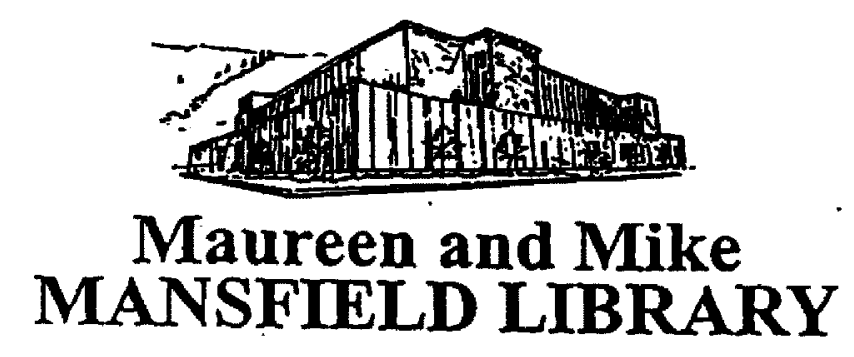

\section{The University of Montana}

Permission is granted by the author to reproduce this material in its entirety, provided that this material is used for scholarly purposes and is properly cited in published works and reports.

**Please check "Yes" or "No" and provide signature**

Yes, I grant permission

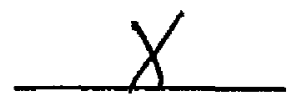

No, I do not grant permission

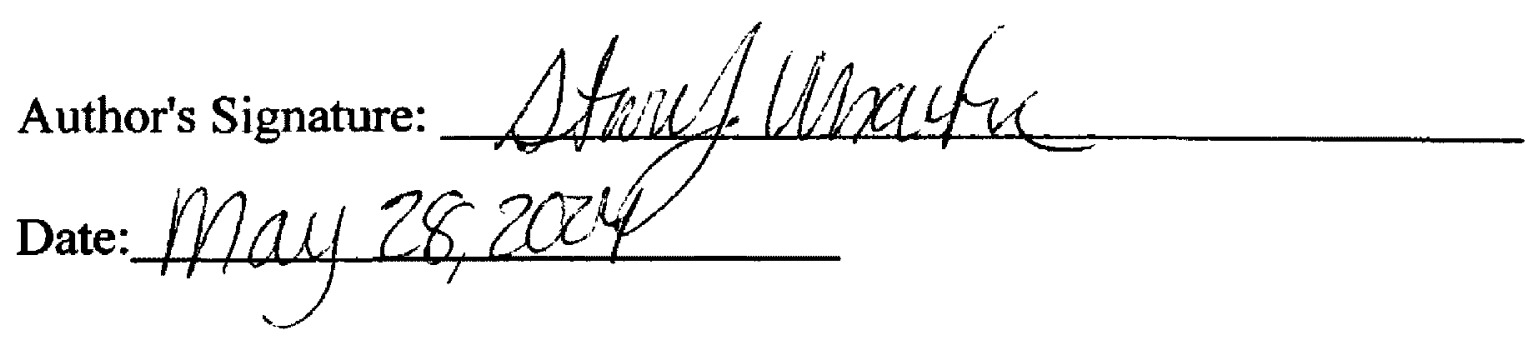

Any copying for commercial purposes or financial gain may be undertaken only with the author's explicit consent. 


\section{AUTOMATED EXTERNAL DEFIBRILLATORS IN \\ COLLEGIATE ATHLETIC TRAINING PROGRAMS}

by

Starr Junelyn Wharton

B.S.Ed University of Idaho, USA, 2000

presented in partial fulfillment of the requirements

for the degree of

Master of Science

The University of Montana

May 2004
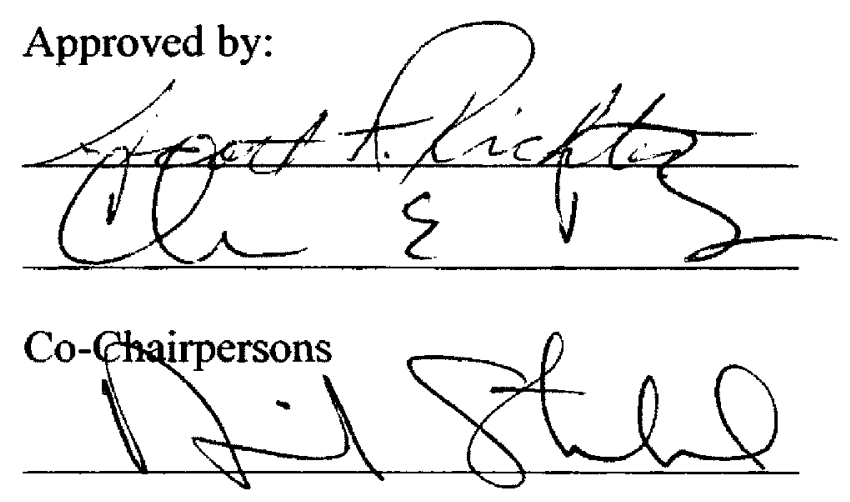

Dean, Graduate School

$$
6-1-04
$$

Date 
UMI Number: EP37014

All rights reserved

\section{INFORMATION TO ALL USERS}

The quality of this reproduction is dependent upon the quality of the copy submitted.

In the unlikely event that the author did not send a complete manuscript and there are missing pages, these will be noted. Also, if material had to be removed, a note will indicate the deletion.

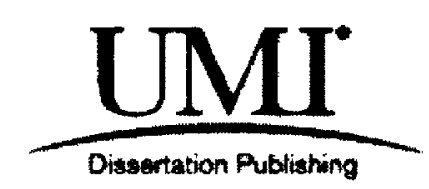

UMI EP37014

Published by ProQuest LLC (2013). Copyright in the Dissertation held by the Author.

Microform Edition (C) ProQuest LLC.

All rights reserved. This work is protected against unauthorized copying under Title 17, United States Code

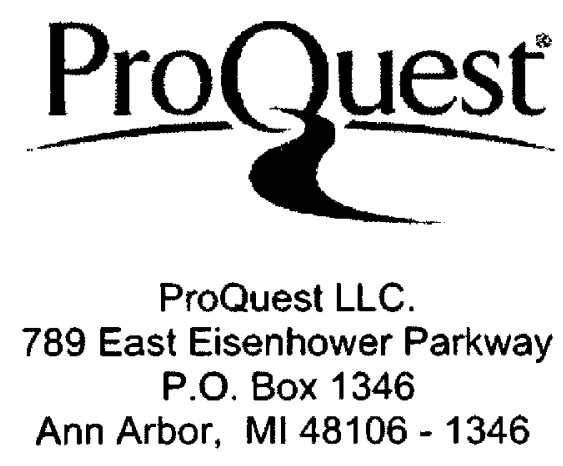


Automated External Defibrillators in Collegiate Athletic Training Programs

$C \& B$
Co-Chairpersons: Clarence E. Burns and Scott T. Richter
$S T R$

PURPOSE: The purpose of this project was (a) to establish a descriptive picture of Automated External Defibrillator (AED) ownership and use, and (b) determine the predictability of ownership and use based upon factors identified from the data obtained in collegiate athletic training programs. METHODS: Head certified athletic trainers (ATCs) at 325 National Collegiate Athletic Association (NCAA) Division I institutions were asked to complete an online survey: Automated External Defibrillators (AEDs) in Collegiate Athletic Training Programs to investigate the existence, use, and perceived need for AEDs within the athletic training room setting. The survey included the topics of the athletic training profession, emergency care by the training staff, cardiovascular preparticipation screenings, and AEDs use and placement in training rooms. RESULTS: Consistent differences were found between AED ownership and 1) Division membership, 2) preparticipation screening protocol, 3 ) who conducts the screenings, 4) cardiopulmonary emergencies, 5) emergency protocol, and 6) intent to purchase. Consistent differences were found between willingness to purchase and 1) emergency protocol, 2) belief of benefits, 3) funding barrier, 4) who should purchase, and 5) AED ownership. No single criterion variable was predictive of AED ownership. When combined, the eight variables did show an important level of predictability $(71 \%)$. CONCLUSIONS: This research provides a descriptive picture of the ownership and utilization of AEDs in Division I Collegiate Athletic Training Programs, but it also illustrates the underlying debate regarding AEDs. The variables that predict AED ownership are extremely broad and do not exist singularly. The NCAA and the National Athletic Trainer's Association (NATA) should use this research to educate ATCs and support future legislation for AEDs in collegiate athletic training programs. 


\section{ACKNOWLEGEMENTS}

To my wonderful committee members: Gene Burns, Laura Dybdal, Merle Farrier, and Scott Richter. Thank you for sticking with me and supporting me through graduate school. Because of you, I have become a passionate owner of my research, a more critical investigator, a statistical magician (who now understands the meaning of parsimonious), and have a better understanding on what I truly want to do.

To my family: You heard me say that I would get my Masters, and now I have. I guess that's one down, maybe another to go? Thank you for supporting my dreams, as wild as they may get, and never letting me forget them. You remind me that I can do whatever I want and give me the independence to do it.

To my friends: You know who you are...Thank you for appreciating my craziness. I treasure each and every one of you and hope that we can all stay as close as we are now forever.

"Life is too brief and fragile to let its gifts pass you by. Follow your heart and soul and do what makes you happy."

This project has special meaning to me because of an extraordinary individual, Chris Hanly. Chris died from sudden cardiac arrest August 15, 2002 at the age of 24. He was talented in everything he did and committed himself $100 \%$ to his family and friends. I consider myself lucky to have had him in my life for even an instant.

Chris, I never told you how much you have inspired me... and continue to do so. You are part of my heart and soul forever.

"Do not follow where the path may lead. Go instead where there is no path and leave a trail." 


\section{TABLE OF CONTENTS}

Abstract

Acknowledgements $\quad$ iii

List of Tables $\quad$ vi

List of Figures $\quad$ vii

\section{Chapter 1: Introduction}

Statement of the Problem 1

Purpose of the Study 4

Research Question $\quad 5$

Definitions $\quad 6$

Chapter 2: Review of Literature

Cardiovascular Disease $\quad 8$

$\begin{array}{ll}\text { Sudden Cardiac Arrest } & 10\end{array}$

Hypertrophic Cardiomyopathy 14

Marfan's Syndrome $\quad 16$

Congenital Defects 17

Arrhythmogenic Right Ventricular Cardiomyopathy $\quad 18$

Commotio Cordis $\quad 18$

Ergogenic Aids and Supplement Use $\quad 19$

Myocarditis 20

Other Conditions $\quad 21$

Preparticipation Screenings $\quad 21$

Emergency Planning $\quad 27$

The Cardiac Chain of Survival 29

Automated External Defibrillators (AEDs) 32

History of Defibrillation 33

Current Research $\quad 34$

AED Legislation $\quad 36$

AEDs in Health and Fitness Facilities $\quad 37$

AEDs in Collegiate Athletic Programs 38

\section{Chapter 3: Methodology}

Research Question $\quad 40$

$\begin{array}{ll}\text { Purpose } & 40\end{array}$

$\begin{array}{ll}\text { Procedures } & 40\end{array}$

Participant Selection $\quad 40$

Instrumentation $\quad 41$

Data Collection $\quad 41$

Confidentiality and Reliability $\quad 42$

Statistical Procedures $\quad 43$

Null Hypothesis $\quad 43$

A Priori Statements $\quad 43$ 
$\begin{array}{ll}\text { Statistic } & 43\end{array}$

Limitations $\quad 44$

Delimitations $\quad 44$

$\begin{array}{ll}\text { Assumptions } & 45\end{array}$

Chapter 4: Results

Data Collection 46

Summary Data

Head Certified Athletic Trainer Profile $\quad 50$

Preparticipation Screening Profile 51

Cardiopulmonary Emergencies Profile $\quad 52$

Emergency Planning and AED Profile 53

Statistics - Cross-tabs $\quad 55$

Statistics - Discriminate Function Analysis $\quad 59$

\section{Chapter 5: Discussion}

Institution and Program Profile $\quad 61$

Head Certified Athletic Trainer Profile $\quad 62$

Preparticipation Screening Profile $\quad 63$

Cardiovascular Emergency Profile 64

Emergency Planning and AED Profile

Emergency Protocol $\quad 65$

AED Beneficial? $\quad 66$

Barriers to Purchasing $\quad 66$

Afford to Purchase? $\quad 67$

Who Should Purchase? $\quad 68$

Who Owns an AED? $\quad 69$

Null Hypothesis $\quad 70$

Recommendations for Future Research $\quad 70$

$\begin{array}{ll}\text { Conclusion } & 71\end{array}$

Automated External Defibrillators (AEDs) In Collegiate Athletic

Training Programs Survey 73

Appendix A: Summary Data Tables $\quad 89$

$\begin{array}{ll}\text { References } & 103\end{array}$ 


\section{LIST OF TABLES}

Table 1:

\# Institutions with emergency personnel/vehicles @ athletic competitions

Table 2:

Preparticipation screening profile

\section{Table 3:}

Cardiopulmonary emergencies and deaths by group

\section{Table 4:}

Cross-tab Results: AED Ownership x Variables

Table 5:

Cross-tab Results: Willingness to Purchase $\mathrm{x}$ Variables

Table 6:

Discriminate Function Analysis (DFA) Results

Table 7:

Who should purchase AED, explanation 


\section{LIST OF FIGURES}

Figure 1:

Respondents by NCAA Division

Figure 2:

Respondents by NATA District

Figure 3:

Required Certifications

Figure 4:

Barriers to ownership

Figure 5:

Amount program can afford to purchase an AED 


\section{INTRODUCTION}

\section{Statement of the Problem}

Heart disease is the leading cause of death in the United States (American Heart Association [AHA], 2003). Heart attacks are occurring more frequently in those under age 40 than a decade ago (AHA, 2003). This age group includes the competitive collegiate athlete.

While heart attacks are generally preceded by symptoms, cardiac arrest is the sudden stopping of the heartbeat, with no presenting symptoms. This event is defined as Sudden Cardiac Arrest (SCA) and is often related to coronary heart disease. SCA is caused by a heart attack that results in an irregular rhythm (ventricular fibrillation, ventricular tachycardia, or bradycardia) that causes the heart to suddenly stop pumping blood. Causes of SCA can include, but are not limited to, diagnosed or undiagnosed cardiovascular disease, prescription medication, illicit drug use, respiratory arrest, electrocution, drowning, choking, and trauma (AHA, 2003). Death from SCA is properly known as Sudden Cardiac Death (SCD).

In the competitive collegiate athlete, $\mathrm{SCA}$ is most commonly associated with underlying cardiovascular anomalies classified as congenital heart defects (Maron, Shirani, Poliac, Mathenge, Roberts, and Mueller, 1996). At least thirty-five distinct types of defects are recognized, ranging from simple murmurs to complex malformations. Recent studies have shown that $36 \%$ of young athletes who die suddenly have probable or definitive hypertrophic cardiomyopathy (HCM), a common genetic cardiac disease, making it the most common cause of sudden cardiac death in young competitive athletes 
(Maron, et. al, 1996). Another genetic condition, Marfan's syndrome, is commonly recognized as an indicator for underlying cardiac conditions.

The interest of the media and the more accurate reporting of SCA events have been factors in estimating the true number of sudden cardiac deaths in athletes. Currently, the American Heart Association estimates the risk to be 1:200,000 (2003). The number of deaths caused from specific conditions is currently unknown due to the possible etiologies leading to the event.

A cardiovascular evaluation in the preparticipation evaluation (PPE) of athletes is standard practice in collegiate athletic training rooms. This evaluation generally performs a risk assessment by collecting a history of the athlete, family background, and any exercise-induced symptoms. In addition, the clinician will perform a physical assessment of the athlete. At the present time, a number of screening modules have been developed, but there is a lack of uniformity between schools, states, and organizations. The American Heart Association (1996) asserts that a history and physical examination alone is not sufficient to properly detect cardiovascular abnormalities in athletes. This assertion has lead to the incorporation of electrocardiography, echocardiography, and exercise stress testing into preparticipation screening protocols in some organizations, with controversy (Schnirring, 2001).

Sudden cardiac death due to SCA is largely preventable. Early detection and recognition of risk factors, and early advanced care to those in arrest are the pillars for prevention of sudden cardiac death in any population (AHA, 2003; American Red Cross [ARC], 2003). Treatment of cardiopulmonary emergencies is fairly standard among collegiate athletic training rooms. The athletic training team serves as the first responder 
to any athletic emergency, and utilizes protocols specifically for cardiac emergencies. The American Heart Association and the American Red Cross, two leading agencies in the training of individuals in First Aid/Cardiopulmonary Resuscitation (CPR) and advanced emergency care, have developed a recommended protocol for treatment of cardiac emergencies- the Cardiac Chain of Survival. This "Chain" consists of the steps to follow in a cardiac emergency: Early Response, Early CPR, Early Defibrillation, and Early Advanced Life Support, which are generally provided by the Emergency Medical Technicians (EMTs) or in the hospital setting. While athletic training rooms have an emergency protocol that includes $\mathrm{CPR}$, more programs are beginning to include an Automated External Defibrillator (AED) in their cardiac care arsenal (Hunt, 2002).

The AED was introduced in 1979 as an alternative to the bulky, heavy "crash cart" used by emergency personnel (including EMTs, law enforcement, and fire crews). While EMTs have continued to use a larger model of the AED, other emergency personnel have placed the newer versions in their vehicles since the mid-1990s. The AED is lightweight, portable, battery operated, and can be used by the lay rescuer with minimal training (AHA, 2003; ARC, 2003). The AED analyzes the heart's rhythm and, if necessary, will advise the delivery of an electric shock to the cardiac muscle. This shock can disrupt the abnormal rhythm and allow a normal rhythm to resume.

Survival from SCA is directly linked to the amount of time between the onset of SCA and defibrillation. When compared to CPR which, when used alone has a 10-15\% success rate, $\mathrm{CPR}$ in combination with defibrillation within minutes of the arrest provides up to a $70 \%$ chance of survival (AHA 2003; ARC, 2003). Recent legislation has incorporated the AED as a tool for the Good Samaritan and has endorsed the 
development of Public Access Defibrillation (PAD) Programs in the community, such as shopping malls, athletic and fitness facilities, airports, rural law enforcement agencies, and schools (Community AED Act, 2001).

The incorporation of AEDs in collegiate athletic training room emergency protocols is accompanied by controversy. Cost, availability to adequate training, insurance and malpractice concerns, and the perceived need for this equipment when EMTs are readily available, comprise some of the most common concerns identified by Hunt (2002). To balance these concerns, there are the issues of keeping touch with current technologies, setting an example for high school programs, and providing the athletes with the highest standard of care possible.

To this date, there has been limited data collected through the collegiate athletic training rooms to indicate the prevalence and incidence of sudden death due to SCA; only that done through the National Center for Catastrophic Sport Injury Research, or reported to the National Collegiate Athletic Association (NCAA) Injury Surveillance System (ISS). No data on the type(s) and extent of cardiovascular evaluation in the PPE, and the inclusion of AEDs in the emergency protocol has been conducted. In addition, there is no data to indicate how many training rooms currently have an AED and if they have used it in the prevention of sudden cardiac death.

\section{Purpose of the Study}

The purpose of this research will be (a) to establish a descriptive picture of AED ownership and use, and (b) determine the predictability of ownership and use based upon factors identified from the data obtained in collegiate athletic training programs. These 
data will help to set a baseline for the current and future implications for AEDs in collegiate athletic training programs.

\section{Research Question}

The primary research question will be as follows: What factors, if any, are associated with the determination of Automated External Defibrillator (AED) ownership and use in collegiate athletic training programs? 


\section{Definitions}

Acute Myocardial Infarction: Commonly referred to as a heart attack.

Arrhythmia: Loss of rhythm commonly occurring with irregularity of the heart beat.

Arteriosclerosis: Hardening of the arteries; also know as atherosclerosis.

Athletic Trainer: An individual skilled in the prevention, evaluation, treatment, and rehabilitation of athletic injuries.

Athletic Training Program: The staff, students, and facilities that serve the clinical needs of the institution's collegiate athletics program. May include a clinical education program. Also referred to as the athletic training department.

Automated External Defibrillator (AED): A machine that delivers an external electrical shock to restore normal rhythm in the heart.

Cardiopulmonary emergency: A situation where the individual has respiratory difficulty or cessation, with cardiac involvement inevitable.

Cardiopulmonary resuscitation (CPR): The attempt to restore normal cardiopulmonary function to an individual in arrest through the circulation of oxygenated blood to the vital organs.

Cardiovascular Disease: Disease of the heart and/or blood vessels of the heart.

Congenital Heart Disorder/Disease: Malfunctions in the physical traits or functions of the heart from hereditary influence or due to influence during gestation.

Coronary Heart Disease: Disease of the blood vessels of the heart.

Defibrillation: An electrical mechanism used to force the cardiac muscle to cease the current rhythm (atrial or ventricular) and re-establish a normal rhythm.

Dysrrhythmia: An abnormal cardiac rhythm. 
Hypertrophic Cardiomyopathy (HCM): Enlargement of unknown cause, thought to be genetic, that impairs the left ventricle filling, emptying, or both.

Myocarditis: Inflammation of the muscular walls of the heart.

NATA: National Athletic Trainer's Association. The governing body for certified athletic trainers.

NCAA: National Collegiate Athletic Association. The governing body of collegiate athletics.

Preparticipation screening: History and physical evaluation completed on athletes prior to training or competition.

Sudden Cardiac Arrest (SCA): Complete cessation of the cardiac activity; may be electric, mechanical or both.

Sudden Cardiac Death (SCD): Death resulting from a sudden cardiac arrest.

Ventricular Fibrilliation (VF): The most common arrhythmia, characterized by fine, rapid movements of the ventricular muscle that replaces normal rhythm. 


\section{REVIEW OF LITERATURE}

\section{Cardiovascular Disease}

\section{History}

At the turn of the 20th Century, heart disease was the fourth most common cause of death in the United States, behind pneumonia, tuberculosis, and diarrheal disease (National Center for Health Statistics, 1995; Braunwald, 1997). By 1910, it had steamrolled into first place and has maintained that position to the present (with a brief hiatus to the great influenza epidemic of 1920). By 1950, cardiovascular disease accounted for more than half of all deaths in the United States (National Center for Health Statistics, 1995). According to Braunwald (1997), as the incidence of cardiovascular diseases increased in all age groups, races, and both sexes, the medical community began to pinpoint the risk factors, possible causes of, diagnostic criteria, and treatment options for cardiovascular disease (CVD). The National Heart Institute (now known as the National Heart, Lung, and Blood Institute) was created with a $\$ 500,000$ appropriation from Congress whereby it created the Framingham Heart Study in 1949 (Dawber et al., 1951). The Framingham Heart Study is widely recognized as "...one of the cornerstones of cardiac epidemiology" (Braunwald, 1997; Dawber et al., 1951). In 1961, a follow-up to the Framingham Heart Study defined the concepts of risk and contributing factors for heart disease. The National Heart Institute and the American Heart Association immediately developed national campaigns to disseminate information on the risk factors, including smoking, which was reinforced by the 1964 Surgeon General's Report: Reducing the Health Consequences of Smoking. 
In 1912, acute myocardial infarction was defined, and by the end of World War II, was the most common cause of death in the United States. Over the last 50 years, the incidence of death from acute myocardial infarction, and the corresponding CVD death rate, has declined largely due to the development of prevention and treatment procedures for ventricular fibrillation (Braunwald, 1997). Braunwald (1997) identified three separate endeavors that may be contributed to decline:

1) A deeper understanding of cardiac electrophysiology and the ability this related to treating life-threatening ventricular arrhythmias,

2) Development of the external defibrillator (1957) and,

3) A radical reorganization of clinical care to place patients with acute myocardial infarction at a single site in the hospital, to be cared for by specially trained staff. In this site, the unit nurse was designated to treat ventricular fibrillation on an emergency basis if a physician was not present.

\section{General Population}

In the United States, CVD is responsible for the death of approximately 950,000 Americans per year (Centers for Disease Control and Prevention [CDC], 2003). Heart disease and stroke are the first and third leading causes of death in the United States, accounting for $40 \%$ of all deaths and will cost the United States a projected $\$ 350$ billion in health care expenses and lost productivity (CDC, 2003). While advances in pharmacology, engineering, and electronics post World War II have helped people to live with CVD, they have not explained, nor prevented, sudden cardiac arrest in young, seemingly healthy individuals. 


\section{Sudden Cardiac Arrest}

Sudden cardiac arrest (SCA) is a complete loss of heart function usually due to an abnormal heart rhythm, an arrhythmia, causing the cessation of the heart's pumping action. According to the American Heart Association [AHA] (2003), the majority of these arrhythmias are classified as ventricular fibrillation (quivering of the heart's ventricles), or pulseless ventricular tachycardia (extremely rapid, ineffective beating of the heart's ventricles). Statistics for the exact number of SCAs that occur each year are unknown at this time, but the AHA (2003) and American Red Cross [ARC] (2003) estimate approximately 250,000 Americans each year will be victims of out-of-hospital SCA. That number accounts for nearly one death every two minutes and approximately half of all coronary heart disease deaths in the United States yearly (AHA, 2003; ARC, 2003).

Death from SCA is properly known as sudden cardiac death. Sudden cardiac death can be attributed to a number of conditions, including, but not limited to, diagnosed or undiagnosed cardiovascular disease, prescription medication, illicit drug use, respiratory arrest, electrocution, drowning, choking, and trauma (AHA, 2003). Death can also occur without any known cause.

The average age of sudden cardiac death is 60 years, although it may occur at any age. (Zheng et al., 2001). Between 1989 and 1996, the yearly total of sudden cardiac deaths in the 15-34 age group rose from 2,719 to 3,000. The rates were higher in African Americans and increased by $30 \%$ in young women (Zheng et al., 2001). 


\section{Athletic Population}

Of the approximately five million young athletes that compete each year, approximately four million of them are high school, 500,000 college, and 5000 professional, not including middle school, youth, and master's level (numbers unknown) (AHA, 1996). In the 2000-2001 academic year, 210,989 men and 150,186 women competed at the collegiate level (National Collegiate Athletic Association [NCAA], 2003). Thompson (1996) and VanCamp, et al. (1995) estimates the risk of sudden cardiac death in this population at 1:133,000 for men and 1:769,000 for women. MacAuley (1998) cited one in ten sudden cardiac deaths in young individuals is associated with athletics.

Futterman and Myerburg (1998) define exercise-related sudden cardiac death by symptoms that arise within one hour of participation. The major mechanisms of death are haemodynamic and electrophysiological changes that cause a fatal arrhythmia. The visibility of these tragic events has increased with the recent deaths of several wellknown collegiate and professional athletes.

SCA has been reported in all races and age groups, and both genders. In older athletes, $(>35$ years old) the cause of death is usually related to coronary artery disease. In athletes under 35 years, genetic disorders account for most causes of death (Franklin et al., 1997; Frazier, 1989; Futterman and Myerburg, 1998; Goble, 1999; Maron, 1996; McManus and Babul, 1996; Virmani et al., 1997; and Wight and Salem, 1995). Maron (1990) found that $62 \%$ of all reported sudden deaths occurred in high school athletes, $22 \%$ in collegiate athletes, $9 \%$ in junior high and middle school athletes, and $7 \%$ in the 
professional athletic arena. Additionally, $65 \%$ of the high school athletes were male and more incidences occurred in basketball and football than other sports.

The National Center for Catastrophic Sport Injury Research (NCCSIR) and the NCAA Injury Surveillance System (ISS) are the primary bodies responsible for collecting incidence data for the collegiate athletic population. VanCamp et al. (1995) conducted a study of the frequency and causes of non-traumatic deaths in high school and college athletes in the United States through the NCCSIR. In this study, they found that over a 10-year period (1983-1993), 126 high school athletes (115 males, 11 females) and 34 college athletes ( 31 males, 3 females) died from non-traumatic sports deaths. The death rates in male athletes were five-fold higher than in female athletes, and two-fold higher in collegiate males than in high school males. Males were found to be at an increased risk for these deaths compared to females when adjusted for participation frequency. It was hypothesized that the combination of pathological conditions and larger heart size increases the risk of SCA for male athletes. Cardiovascular conditions were the primary cause of all deaths. This may be attributed to many factors, including the higher physical training requirements of male athletes when compared to their female counterparts in traditional sports programs (Schenck, 1999). Overall, women account for approximately $15 \%$ of all sudden deaths in athletes (AHA Statement, Maron et al., 1996).

Research investigating the causes of sudden death in athletes has been done worldwide. In the United States, Waller et al. (1992) completed a study of the annual incidence rates of sudden athletic deaths in Marion County, Indiana, home of Indianapolis "amateur sports capital of the world". Between 1985 and 1990, the overall incidence rate was $0.04 \%$ ( 18 deaths in 44,481 autopsies) and varied slightly between 
each study year. Eighty-eight percent of the 18 deaths were cardiac in origin (Waller, 1992).

Basso, Corrado, and Thiene (1999) collected 200 cases of sudden death in people (including athletes) $\leq 35$ years old from $1978-1994$. The study cites $81.5 \%$ of the deaths as cardiovascular in nature. The causes for the death were found as follows: $23 \%$ arrhythmogenic right ventricular cardiomyopathy, mitral valve prolapse $10 \%$, conduction system abnormalities $10 \%$, congenital coronary artery anomalies $8.5 \%$, myocarditis $7.5 \%$, hypertrophic cardiomyopathy $5.5 \%$, aortic rupture $5.5 \%$, dilated cardiomyopathy $5 \%$, nonatherosclerotic-acquired coronary artery disease $3.5 \%$, postoperative congenital heart disease $3 \%$, aortic stenosis $3 \%$, pulmonary embolism $2 \%$, and other causes $2 \%$. Arrest remains unexplained in six percent of the cases. It was recognized that the underlying abnormality (congenital or acquired) is frequently unnoticed in this population and only discovered upon autopsy. The investigators concluded that most of the diseases, even the asymptomatic ones, might be detected early with the proper imaging tests.

In the United Kingdom, the relationship between sudden death and vigorous activity was investigated in the game of rugby (Opie, 1975), squash (Northcote, Flannigan, and Ballantyne, 1986), and in British soliders (Lynch, 1980). From Opie's data (1975) the estimated risk of sudden death from rugby was 1:50,000 playing hours and 1:3,000 referee hours. Additional research of sudden cardiac death has been conducted in Australian aboriginal sportsmen (Young et al., 1999) and in young Japanese athletes (Kinoshita et al., 2000).

Recent research has pinpointed several cardiovascular conditions that are responsible for SCA in athletic populations (AHA, 1996). These conditions include, but 
are not limited to, hypertrophic cardiomyopathy (HCM), Marfan's Syndrome, arrhythmogenic right ventricular cardiomyopathy (ARVC), long-QT syndrome, WolffParkinson-White syndrome, myocarditis, and congenital defects, commotio cordis. Hypertrophic cardiomyopathy and coronary artery anomalies are widely recognized as the most frequent causes of sudden cardiac death (Drezner, 2000). Hypertrophic Cardiomyopathy (HCM)

Over 40 years of research has been accumulated on hypertrophic cardiomyopathy, much of it diverse and contradictory, but one theme remained consistent. HCM is the most common genetic cardiovascular disease, expressed in the young adult population at $0.2 \%(1: 500)$ and the most common cause of sudden cardiac death in young people, including competitive trained athletes (Maron and Klues, 1994; Maron, 1995; Maron, 1996; Stampfli et al., 1999). The overall annual mortality rate of HCM is approximately $1 \%$, with subsets of individuals at $5 \%$ of or more (Maron, 2002). Fifty-five percent of HCM patients do not demonstrate any of the recognized risk factors and it is uncommon to for these young adults to die suddenly (Elliot et al., 2000).

Recent studies show that $36 \%$ of young athletes who die suddenly have probable or definite HCM, making it the most common cause of sudden cardiac death in competitive athletes under age 30 (AHA, 2003; Maron et al., 1996). Those older than 30 are more likely to die from arteriosclerosis, stroke, or acute myocardial infarction. Sudden death from HCM occurs most frequently during sedentary or mild activities, but is closely related to exertive activity as well (Maron, 1996; 2000). Maron, et al. (1990) found an association between sudden cardiac death and time of day. Sudden death from HCM most frequently occurs between 3:00 and 9:00 pm, when most athletes practice. In 
addition, most of these deaths took place in the months of August through January, and maybe attributed to football and basketball seasons (Maron, 1990; cited in Schreck, 1999). Maron's research illustrates the difference between sudden cardiac death and acute myocardial infarctions, which most often occur during the morning hours.

HCM occurs in all races and both genders, but with more frequency in young Caucasian and African-American males (Schreck 1999). Maron et al (2003) demonstrated that HCM is a common cause of sudden death in young African-American male athletes who had not been diagnosed. More research is warranted to demonstrate the underlying reasons for these results.

A heart murmur, family history, new symptoms, or an abnormal ECG, may detect HCM in the athlete and echocardiography can confirm the magnitude of the disease (Maron, 2002). Athletes who participate in dynamic (and static) sports will experience hypertrophy of the left ventricle when compared to sedentary individuals ("athlete's heart"). This is a result of physical training, and when activity decreases, so does the heart muscle. In HCM patients, the heart muscle does not decrease in size with changes in exercise patterns (Mitchell, 1994; cited in Schreck, 1999).

Shephard (1996) strongly disputes the idea of HCM being a leading cause of sudden death, due to "...weak diagnostic criteria and frequent republication of a very small groups of cases..." Shepard (1996) continues to state that the development of athlete's heart is not a pathological sign, but a "desired outcome that will enhance performance on the sports field, and will allow longer independence in old age."

Identification and disqualification of athletes with $\mathrm{HCM}$ during preparticipation screenings have helped to decrease the incidence of sudden cardiac death from the 
disease, but undiagnosed, it is still a leading cause of sudden death in athletes. According to Kenny and Shapiro (1992):

Athletes who have HCM and a left ventricle thickness that is greater than $20 \mathrm{~mm}$, a left ventricular outflow obstruction greater than $50 \mathrm{mmHg}$, experience atrial or ventricular arrhythmia, or have a family history of sudden death, especially before age 40 years, should not participate in competitive sports (cited in Schreck, 1999).

It is the general recommendation that athletes with HCM, but without the above symptoms may continue to compete at low-intensity activities (Schreck, 1999).

It is important to mention that a number of athletes with HCM have been able to maintain extremely high levels of competition for many years without suffering symptoms or sudden death. Maron and Klues (1994) found that these athletes competed in distance running (including marathon), swimming, triathlon, basketball, and football while maintaining national, professional, or collegiate levels. Echocardiographic studies of these individuals indicated a left ventricular wall thickness ranging between 18 to 29 $\mathrm{mm}$ (mean $20 \mathrm{~mm})$.

Marfan's Syndrome

Marfan's Syndrome affects both genders and all races. It may affect more than 40,000 Americans. Even though it is usually inherited genetically (a parent with Marfan's has a $50 \%$ chance of passing it to their children), $30 \%$ of reported cases have no family history of the syndrome (Marfan Syndrome Fact Sheet, 1997; cited in Schreck, 1999)

In Marfan's patients, the integrity of the connective tissue throughout the body is decreased; this includes the cardiovascular system. The aorta may become weak and 
overextended during strenuous exercise, causing an aortic aneurysm or rupture of the ascending aorta, causing sudden death. Many Marfan's patients have mitral valve prolapse, where the leaflets of the valve move backwards, causing a contraction and resulting in an irregular heart rhythm. This irregular rhythm may result in a fatal arrhythmia.

Marfan's is easily detected by the physical attributes of the athlete. These attributes include tall and thin body structure, arm span greater than standing height, unusually large appendages, hyperextensible joints, scoliosis, pigeon chest, abnormally high arched palate, and nearsightedness (Marfan Syndrome Fact Sheet, 1997). The sport of basketball sees the highest incidence of Marfan's.

Marfan's can be diagnosed with a complete physical examination and cardiac monitoring. Once diagnosed, it can be controlled with medication and lifestyle modifications, including decreasing exercise intensity to avoid excess strain on the heart and blood vessels. Surgery is necessary in cases of mitral valve prolapse, but with appropriate treatments, Marfan's patients have a life expectancy comparable to the general population (Kowalski, 1998).

\section{Congenital Defects}

In the United States, coronary artery anomalies are the most common congenital defect in young athletes, accounting for approximately $19 \%$ of sudden cardiac deaths (Lipp, 2001). The most common is the left main coronary artery rising from the right sinus of Valsalva, becoming wedged between the aorta and the pulmonary artery, especially during exercise (AHA, Maron et al., 1996; Lipp, 2001). Other congenital defects include, aortic stenosis, pulmonary stenosis, left anterior descending coronary 
artery, mitral valve prolapse, bicuspid aortic valve disease, and atrial septal defect. Some diseases may cause underlying defects that are not detected unless sudden cardiac death occurs.

Arrhythmogenic Right Ventricular Cardiomyopathy / Dysplasia (ARVC, ARVD)

In the United States, HCM plays a predominant role in sudden cardiac arrest where in Europe, ARVC and atherosclerosis of the coronary arteries is more frequent (Kulbertus, 2001). In Italy, it has been estimated to cause $30 \%$ of the sudden cardiac deaths in the northeastern area (Lipp, 2001).

ARVC is characterized by the occlusion of the right ventricle with adipose and fibrous tissue. Fibrosis is typically the origin of the ventricular arrhythmias in ARVC and the best treatment is unclear (Lipp, 2001; McRae et al., 2001). Corrado et al. (2001) reported that right precordial ST-segment elevation mostly reflected underlying ARVC and therefore increased an individual's likelihood to die from non-exercise related sudden cardiac arrest.

\section{Commotio Cordis}

Case reports of commotio cordis in European medical literature date back 130 years. Link (1999) defines commotio cordis as blunt, non-penetrating chest blow that cause sudden cardiac death. Death is caused by a ventricular fibrillation that occurs when the chest is impacted during a narrow, electrically vulnerable portion of the cardiac cycle, repolarization, just before peak of the T- wave (Lateef, 2000). The lethal blows in humans must occur directly over the heart; especially low energy blows (Link et al., 2001). Baseballs, softballs, hockey pucks, and other objects are the most common cause of trauma. 
Commotio cordis was thought to be rare, but an increase in the frequency of reports has some researchers investigating the event more closely. Link et al. (2001) found that male athletes age 5-18 are particularly at risk. Maron, et al. (2002) followed by reporting that events occurred most often during organized sporting events, $62 \%$ (79 of the 128 confirmed cases), and fatal blows were inflicted at a wide range of velocities. Males were most common, accounting for $95 \%$ (122 individuals), and only $16 \%$ (21 individuals) survived, with prompt cardiopulmonary resuscitation and defibrillation the only identifiable factor in survival rate. Successful resuscitation is uncommon in cases of commotio cordis, generally because death is instantaneous.

\section{Ergogenic Aids and Supplement Use}

Kennedy and Lawrence (1993) reported the first two cases of cardiac death in athletes using anabolic steroids in Australia. Two footballers (18 and 24 years old), suffered fatal cardiac arrests during training. Upon autopsy, the younger had signs of HCM, while the older myocarditis. The first acute non-fatal myocardial infarction (MI) was reported in 1988, and the first fatal MI in 1990. Kennedy and Lawrence (1993) maintain that a casual relationship to SCA is hard to prove, but it is possible that anabolic steroid use can contribute to an increase in heart size, response to catecholamines, and inflammation causing an arrhythmogenic effect in both athletes.

In February 2003, the Food and Drug Administration's Rand Report on Ephedra and Ephedrine-containing supplements was released (Agency for Healthcare Research and Quality [AHRQ], 2003). Although there were cases of acute myocardial infarctions related to ephedrine, no direct link between ephedrine and SCA can be assumed or proven. It is concluded through previous controlled trials that ephedrine and/or ephedrine 
plus caffeine supplements is associated with two to three times the risk of nausea, vomiting, anxiety, mood changes, autonomic hyperactivity, and palpitations (AHRQ, 2003).

The deaths of several collegiate and professional athletes have been attributed to Ephedra use. In August 2001, Rashidi Wheeler, a Northwestern University football player, brought national attention to the dangers of Ephedra-containing products when he collapsed and died during a workout (ACSM, 2003). The Minnesota Vikings claim that Ephedra contributed to Kory Stringer's death from heatstroke in 2001, and to the February 2003 death of Baltimore Orioles pitching prospect Steve Bechler (ACSM, 2003). The FDA has banned Ephedra and ephedrine-containing supplements, but they may still be acquired via stockpiles held by supplemental nutrition stores across the country (ACSM, 2003).

Hypothesis testing studies are necessary to assess as casual relationship between Ephedra or ephedrine consumption and serious adverse effects... (ARHQ, 2003).

\section{Myocarditis}

Myocarditis is an acute inflammatory condition that often goes unrecognized as a cause of sudden cardiac death. In 1995, Friman, Wesslen, Fohlman, Karajalainen, and Rolf of Sweden published an article on the epidemiology of infectious myocarditis, lymphocytic myocarditis, and dilated cardiomyopathy. The true incidence of infectious myocarditis is unknown. Lymphocytic myocarditis was reported at $1.06 \%$ of 12,747 routine autopsies over a 10-year period. Dilated cardiomyopathy (DCM) was found to have an estimated frequency of $7.5-10 \%$ per 100,000 per year. The most common causes 
of myocarditis were found to be the enteroviruses, in particular Coxsackie-B viruses. More recently, the cytomegaloviruses, Borrelia burgdorferi, and Chlamydia pneumoniae infections have been associated with sudden cardiac death.

Cocaine and other illicit drug use have been linked to myocarditis and SCA in addition to secondary infections resulting from rubella, scarlet fever, and staphylococcal and streptococcal bacterial infections (Isner, Estes, Thompson, Costanzo-Nordin, et al. 1986; Lipp, 2001; Virmani, Robinowitz, Smialek, and Smyth, 1988).

\section{Other Conditions}

Wolff-Parkinson-White Syndrome is found in approximately 3 in 1,000 individuals with a risk of SCA of about 1:1,000 patients-years (Estes et al., 2001). The syndrome shows itself in the surface ECG with a short PR-interval and delta waves appearing on the QRS complex from early ventricular activation (Estes et al., 2001). The ECG reading indicates a dysrhythmia. Since the rate of death is low, participation in athletics is usually unrestricted.

It has been suggested that SCA may be affected by persistent magnesium deficiency, and the resulting hyperlipaemia and hyperglycemia (Stendig-Lindberg, 1992). Brugada Syndrome, a functional electrical disorder due to structural heart disease, has also been identified as a cause of ventricular arrhythmias (Link et al., 2001).

\section{Preparticipation Screenings}

A preparticipation screening, including clinical history and medical examination, is mandatory for young athletes in Europe (Kulbertus, 2001). In the United States, the protocols for screenings are based upon the recommendations of the 26th Bethesda Conference, conducted through the American College of Cardiology, and through the 
American Heart Association (AHA) Medical/Scientific Statement for Cardiovascular Preparticipation Screening of Competitive Athletes (AHA Joint Committee, Maron et al., 1996). In general, a standard history and physical examination is the practice for cardiovascular preparticipation screenings in high school and college athletes, but no national standardization exists to date.

In 2000, Pfister, Puffer and Maron conducted a survey of NCAA schools, Division I, II, and III to assess their screening practices for cardiovascular diseases in student-athletes. They concluded that Division I schools were more likely to conduct comprehensive screenings than Division II and III schools. It was speculated that the number of student athletes, and the limited number of athletic scholarships affected the school's screening procedures.

Overall, about one percent of athletes who are screened are completely disqualified from participation (Kurowski and Chandran, 2000). Conditions that may disqualify an athlete include, hypertrophic cardiomyopathy, long QT interval syndrome, concussion, significant knee injury, sickle cell disease, and uncontrolled seizures (Kurowski and Chandran, 2000). The American Academy of Family Physicians, American Academy of Pediatrics, American College of Cardiology, American Medical Society for Sports Medicine, American Orthopedic Society for Sports Medicine, and American Osteopathic Academy of Sports Medicine have developed or endorsed recommendations for cardiovascular screenings of student athletes as part of a comprehensive sport preparticipation physical evaluation (Lyznicki, 2000). Wilson and Jungner (1968) identified the criteria for submitting a population to "presymptomatic screening" which can be applied to the athletic population. More recently, Grafe, Paul, 
and Foster (1997) offered guidelines for preparticipation screenings; a station method with multiple examiners in specialty areas (such as musculoskeletal and cardiovascular), conducted six weeks prior to the beginning of the season and at the beginning of each new level of competition, and should screen for signs and symptoms of pathological states that may lead to non-traumatic death.

Practicality and cost-effectiveness are two major factors when deciding to conduct cardiovascular screenings in a large population of athletes. When combined with the issue of effectiveness in screening to prevent sudden cardiac death, the conclusions are varied:

Noninvasive screening on an individual basis, in most instances, will identify those athletes at risk for sudden death if appropriate financial resources can be applied. History and physical examination, chest roentgenogram, 12-lead electrocardiogram, echocardiography, and exercise stress testing are useful tools in the recognition of those conditions associated with acute cardiac emergencies (Frazier, 1989).

Based on a large-scale prospective screening evaluation of student athletes at the University of Maryland, Maron et al. (1987) concluded:

A systematic preparticipation screening program (such as the present onepersonal and family history, physical examination, and 12-lead electrocardiogram) does not appear to be an efficient means of detecting clinically important cardiovascular disease in young athletes. 
In 1995, Maron, et al. re-iterated previous conclusions:

Preparticipation screening appeared to be of limited value in identification of underlying cardiovascular abnormalities (Maron et al., 1995).

In a review of issues surrounding sudden death in athletes, Soyeur (2001) states:

Low prevalence of sudden cardiac arrest during exercise, large number of people to screen, cost of examinations are limiting factors for mass screening, but the notion of screening program to prevent as much [sudden cardiac death] as possible is proposed.

Waller, Hawley, Clark, and Pless in their 1992 report of incidence of sudden athletic deaths in Marion County, Indiana, concluded:

A retrospective analysis of (Marion County, Indiana Study) preparticipation screening efforts suggests that most of the cardiac conditions responsible for death could have been detected.

Many researchers suggest that guidelines should be developed for the preparticipation screening (Drezner, 2000; Lyznicki, Nielsen, and Schneider, 2000; Maron, 1997, 1998; Rich, 1994; Seto, 2003). These guidelines may include the use of imaging devices to detect cardiovascular abnormalities. Three strategies, recommended by Fuller (2000) include specific cardiovascular history and physical examination, 12lead ECG, and two-dimensional 2D echocardiography. A 12-lead ECG is theorized as the most cost effective of the three. Fuller (2000) also makes the point that history questions need more sensitivity (at least two-fold) and echocardiography must become more cost effective (a reduction of at least 4.5 fold) to be incorporated into traditional screening protocols. 
Technological advances in the area of cardiovascular conditions have possible benefits for the high school and collegiate athletic arenas. Practicality and costeffectiveness are factors to consider, and the overall effectiveness of modalities (i.e. ECG, echocardiogram) is still under debate. A prospective study conducted over a threeyear period in northern Nevada, in high school athletes, showed that the ECG was a more effective screening tool than cardiac history questions and auscultation/inspection (Fuller et al., 1997). Some additional conclusions include:

Screening would not be as reliable in large athletic populations for conditions such as congenital coronary artery origin abnormalities (Basso et al., 2000)

The resting electrocardiogram can show details in detecting subjects at risk for lethal arrhythmias, may show the first expression of pathological cardiac adaptation to sports (Claessens et al., 2000).

Echocardiography screening for very tall athletes should be considered due to higher incidence of aortic dilatation (Kinoshita et al., 2000).

Screening tests such as electrocardiography, treadmill stress testing, and urinalysis are not indicated in the absence of symptoms or a significant history of risk factors (Kurowski and Chandran, 2000). 
Athletes with normal hearts may show electrocardiogram changes that mimic those of heart disease. The distinction between adaptive hypertrophy and pathologic hypertrophy may be difficult based solely on the electrocardiogram (Oakley, 1992).

In the past, the arguments against echocardiography have been focused on cost and the number of false positives. In recent years, the introduction of the portable echocardiography machine has decreased the cost from $\$ 400$ to between $\$ 2$ and $\$ 39$ per athlete (Schnirring, 2001). Debate continues around the effectiveness of these machines, if they may unnecessarily exclude a number of athletes, and if they actually help to save lives. In California, a non-profit group, A Heart For Sports, formed by community members to provide free portable echocardiography screening to high school and college athletes. The organization employs sonographers under the supervision of cardiologists. Similar grassroots organizations include Operation Beating Heart, at Savannah State University, Alabama, the Chad Foundation for Athletes and Artists (formed by a mother who lost her son to sudden cardiac death), and the Living Heart Network in Massachusetts, formed by a retired heart surgeon/former professional football player (Hunt, 2002).

Carek and Futrell (1999) evaluated the athletes view on preparticipation screening in two southeastern United States colleges. Sixty-six percent of athletes believed they could participate and avoid severe injuries or death without undergoing a screening, while $89 \%$ of athletes believe that the screenings do help to prevent major injuries (including cardiac events). Women athletes were found to dislike questions regarding eating disorders, sexual health, smoking, and alcohol use more than the men. Carek and 
Futrell thus concluded that the screenings provide an important service to the athlete's health and may also serve as a site for health-related education and counseling.

In 2003, there is variation and inconsistency in the states requirements for preparticipation screenings. Seto (2003) recommends a national adoption of a more uniform screening process based on the American Heart Association recommendations. Seto also proposes that if a national protocol were developed, it would help to close the gap between the recommended and the reality of current screening practices. In the NCAA, schools within Division I, with larger programs and scholarship abilities, were found more likely to have comprehensive preparticipation screenings than Division II and III schools (Pfister, Puffer, and Maron, 2000). This research called for a "change and improvement" in the cardiovascular screening process for college athletes (Pfister, et al., 2000).

\section{Emergency Planning}

Involvement in sports may exacerbate pre-existing health problems, cause injury, or even death. The sporting environment can be harmful to the athlete in many ways. The goal of the preparticipation screening is to ensure the future safety of the athlete when training and competing. Unfortunately, preparticipation screenings cannot detect all causes of sudden cardiac death, or prevent those that may occur as a result of competition (i.e. commotio cordis). Rich (1994) suggests that a well-outlined emergency plan needs to be established when physicians, athletic trainers, or coaches are working with athletes. These plans should include on-site treatment, mechanism to contact emergency personnel, and proper transport to medical facility. 
In 2002, the National Athletic Trainers' Association (NATA) published a position statement: Emergency Planning in Athletics (Andersen, Courson, Kleiner, and McLoda, 2002). Twelve comprehensive statements were made in the recommendation; truncated to eight by the NATA for press release (2002). The truncated recommendations are as follows:

1) Each organization or institution that sponsors athletic activities must develop and implement a written emergency plan;

2) The plan should be developed by organizational or institutional personnel in consultation with local emergency medical services (EMS);

3) Personnel should be trained in CPR, and/or automated external defibrillation (AED), first aid, and prevention of disease transmission;

4) Identify emergency equipment and its location;

5) Identify communication system and method;

6) Have a specific plan for each venue;

7) Identify personnel involved with execution of plan, and;

8) Identify who will document what happens during the emergency.

All plans should be rehearsed annually and/or when new staff is incorporated.

These statements were created under the initial recommendation of the National Collegiate Athletic Association (Brown, 1999), and the National Federation of State High School Athletic Associations (Schultz, Zinder, and Valovich, 2001). In the current climate, the institution and its personnel may be placed at risk by the lack of an emergency plan, which may lead to a legal claim (Andersen, Courson, Kleiner, and McLoda, 2002). 
Mills, Moore, and Thompson (1997) state that "primary caretakers of athletes should know the major causes of exercise-related cardiac complications and sudden cardiac death and look for these conditions during preparticipation evaluations...we strongly suggest that coaches and other athletic personnel be required to learn basic life support measures... and update their skills on an annual basis. Such efforts will help prevent additional exercise-related cardiac deaths".

Although primary prevention of cardiovascular disease has increased dramatically since the Framingham Heart Study, sudden cardiac death has no definitive prevention strategies, and must rely on the timely response and treatment by responders. In the collegiate athletic arena, the athletic training staff serves as the first line of defense against sudden death resulting from cardiac arrest.

The Cardiac Chain of Survival

Significant advances in the treatment of sudden cardiac arrest (SCA) have been made in the past three to four decades. In the 1960 's, mouth-to-mouth resuscitation and closed-chest compressions were the "gold standard" (Berry, 2001). According to Berry (2001), in 1973 training in cardiopulmonary resuscitation (CPR) was extended to the lay public, and the American Heart Association (AHA), in coordination with other scientific organizations, began to develop a standardized national curriculum for basic life support (BLS), advanced cardiac life support (ACLS), and later, pediatric advanced life support (PALS). These developments came with the advent of the paramedic, which brought cardiac medications and defibrillation out of the hospitals for the first time. Bringing the treatments to the scene of the arrest reduced the number of out-of-hospital cardiac-related deaths (White, Asplin, Bugliosi, and Hankins, 1996; White, Hankins, and Bugliosi, 
1998). The Cardiac Chain of Survival was developed to teach first responders a step-bystep approach to care of cardiac emergencies that would include CPR, defibrillation, and advanced cardiac life support (AHA, 2003; ARC, 2003). The four steps are: early recognition and access to care, early $\mathrm{CPR}$, early defibrillation, and early advanced life support.

\section{Step 1: Early Recognition and Access to Care}

Each year, out-of-hospital unexplained cardiac arrests will affect approximately 450,000 Americans (Weaver and Peberdy, 2002). The majority occurs in people with recognized heart disease, but approximately 250,000 will suffer SCA with no known signs of disease (AHA, 2003). Approximately $80 \%$ of the events will take place at home, with almost $60 \%$ being witnessed (Eisenberg and Mengert, 2001). The etiology of SCA prevents challenges for the traditional lay responder because defibrillation, the restoration of the heart's natural rhythm through electrical shock, is the only definitive treatment (AHA, 2003; American Red Cross [ARC], 2003).

After the SCA is recognized, the immediate activation of emergency medical services (EMS), 911, or local emergency number, is the first step in the cardiac chain of survival. By activating EMS, the responder decreases the delay time for advanced care to arrive and take over the treatment of the victim.

\section{Step 2: Early CPR}

CPR and early defibrillation are the most critical factors in determining who survives from SCA. Brain damage starts to occur in four to six minutes after the heart stops pumping blood. When a responder performs effective CPR immediately on the SCA victim, they can double their chance of survival (AHA, 2000). If no CPR is 
administered, the victim's chances of survival are reduced by seven to ten percent with every minute delay until defibrillation (AHA, 2003).

The purpose of CPR is to circulate oxygenated blood to the vital organs (lungs, heart, and brain) until more advanced care can arrive, or the victim shows signs of circulation. CPR alone has a success rate between ten and twenty percent, largely dependent on the effectiveness of the responders breaths and compressions (AHA, 2002; ARC 2002). When combined with defibrillation, the success rate increases dramatically.

\section{Step 3: Early Defibrillation}

Studies indicate that survival rates from SCA decrease dramatically with each minute that defibrillation is delayed, and after ten minutes, there is only a five to ten percent chance of survival when defibrillated (AHA, 2003; ARC, 2003). After twelve minutes, the survival rate drops to two to five percent (AHA Guidelines, 2000). The AHA (2003) provided that in some cities with public access defibrillation (PAD) programs, when bystanders provide immediate CPR and the first shock is delivered within three to five minutes, the reported survival rates are as high as $48 \%$ to $74 \%$ (AHA, 2003).

The American Red Cross and the American Heart Association ascertain that automated external defibrillators (AEDs) are a key component in the fast response to SCA, and with the recent technological advances, and increased visibility of the devices, they will increase in importance in the future.

\section{Step 4: Early Advanced Cardiac Life Support}

Early CPR and defibrillation combined with early advanced cardiac care can produce high long-term survival rates (AHA, 2000). Advanced care refers to the 
administration of intravenous medications and advanced techniques such as tracheal intubations.

\section{Automated External Defibrillators (AEDs)}

An AED uses a microcomputer to analyze a victim's cardiac rhythm and determine if a shock is necessary. The machine is designed so users follow simple audible and visual instructions for operation. The AED will not allow a user to shock a rhythm that will not improve from defibrillation. In this sense, the machine has a built-in failsafe so that users decide only to help, not how to do it.

AEDs vary widely in their operation mode, from simple, one-button, voice activated, to those that require manual setting of the shock level and give ECG printouts (Brown and Kellermann, 2000). The machines with the manual setting mode also have an automated mode, and are most typically used in medical settings where training is provided for all users. The typical AED is the size of a small laptop computer or lunch box, weighs between four and nine pounds, and costs between $\$ 2800$ and $\$ 5000$ (Brown and Kellermann, 2000; Medtronic, 2002). Recent advances in technology have developed smaller AEDs, some similar in size to a personal data manager, or "Palm Pilot". Smaller, more portable, and affordable AEDs will theoretically increase their inclusion into private homes and first aid kits (Eisenberg, 2000).

Traditionally, AEDs were not safe for use on infants or children under eight years of age, but recent technology has developed pediatric pads that are adaptable to most existing and all new AED models (AHA, 2000, 2003; ARC, 2002, 2003). Other precautions, such as drying the chest, and keeping the victim away from conductive materials, must be taken prior to usage (AHA, 2000; ARC, 2002). Training for AED 
usage is specified as four hours, but the actual time to achieve proficiency may be as little as one hour, providing mastery of CPR (Brown and Kellermann, 2000).

\section{History of Defibrillation}

The first successful electrical defibrillation was described in 1947, when

Claude Beck used open chest massage and altering current internal

defibrillation to resuscitate a 14-year-old boy who heart was in ventricular

fibrillation (Beck, Pritchard, and Feil, 1947) Cited in Brown and

Kellerman, 2000.

In the mid-1950's, the first published reports of external defibrillation surfaced. In 1964, the development of the synchronizing defibrillation to the ECG cycle ushered in the modern day AED. The first automated external defibrillator was introduced in 1979, and in the past two decades, the use and acceptance of automated defibrillation had increased dramatically. Firefighters with basic training began using AEDs in 1986, and they were assumed to be for medical personnel only for many years.

During the late 1980's and throughout the 1990s, research emerged illustrating the benefits of training non-medical personnel (including lay responders) on the AED. In 1992, the American Heart Association (AHA), published guidelines supporting early defibrillation and stating that all Basic Life Support (BLS) personnel are trained to operate an AED. Revisions to the emergency cardiovascular care programs came again in 2000 in the International Guidelines 2000 Conference on CPR and Emergency Cardiovascular Care (ECC). AED training is now considered a standard in all AHA CPR courses, and is becoming such in the American Red Cross (ARC) curriculums. 


\section{Current Research}

AEDs improve the low survival rates from cardiac arrest when operated by trained responders (Auble, Menegazzi, and Paris, 1995; Eisenberg, Hallstrom, Copass, et al., 1984; Kellemann et al., 1993; Marenco, Wang, Link, et al., 2001; Page et al., 2000; Vukov, White, Bachman, O'Brien, 1988; and Weaver, Hill, Fahrenbruch, et al., 1988). When used promptly (within three to five minutes) with CPR, defibrillation has as success rate up to $70 \%(\mathrm{AHA}, 2000)$. In a comparison study using naïve sixth grade students and trained professionals (EMTs and paramedics), the untrained children responded at nearly the same rate as the professionals when using an AED in a mock cardiac arrest (Gundry et al., 1999). Gundry et al. (1999) also suggests that widespread use of AEDs will require modest training in the general population.

The effectiveness of AEDs is improving survival from SCA when used by trained laypersons in casinos and commercial aircraft. Cardiac arrest on an airplane is almost always fatal because of delays in emergency care. In the 1980 's, two studies examined the rate of in-flight medical events among passengers arriving at two United States airports. The studies found a similar incidence rate, approximately 30-33 events per day (Cummins and Schubach, 1989; and Speizer, Rennie and Breton, 1989). In 2000, the Federal Aviation Administration (FAA) found that rate to be approximately 13 events per day during the years 1996-1997 (DeJohn, Veronneau, Wolbrink, et al., 2000). The difference in the rates may be due to how a serious event was classified. Most in-flight events are not serious enough to warrant ground medical support (Gendreau and DeJohn, 2002). 
Some airlines have installed AEDs on aircraft since the early 1990's (Groeneveld et al., 2001). Page et al. (2000) followed an airline as they implemented their AED program from 1997-1999. Early reports of effectiveness from this program persuaded Congress to pass the Aviation Medical Assistance Act in 1998, directing the Federal Aviation Administration (FAA) to consider requiring AEDs on all passenger aircraft (House Subcommittee on Aviation, 2000). In April 2001, the FAA issued a rule requiring all commercial aircraft with at least one flight attendant to carry AEDs by 2004 (FAA, 2001).

In Las Vegas, Nevada, a study was conducted to measure the emergency medical services (EMS) response times and relate those times to the probability of survival from SCA in the city's casinos. The study was conducted in Las Vegas casino-hotels from January 1993-June 1996 in coordination with the local EMS. The hotel staff was trained on CPR and AED, and at least one AED was placed on each floor. The average time to first shock was 4.8 minutes for survivors and 5.6 for non-survivors. When the staff delivered the first shock, the survival rate was $10 \%$ higher than waiting for EMS to give first shock. The results emphasized the importance of quick response with defibrillation in SCA incidences and the inclusion of AEDs within the casino-hotel premises (Karch, Young, and Ho, 1998).

Weaver and Peberdy (2002) reported that the National Institutes of Health is sponsoring trials to provide more data about Public Access Defibrillation (PAD) in private homes. The greatest effect of these studies may be the increase in awareness of SCA and opportunity to develop PAD programs. Additional PAD programs across the 
United States are under investigation for their effectiveness and possible widespread dissemination (AHA, 2003).

\section{AED Legislation}

In 1995, the AHA released a statement on Public Access Defibrillation (PAD) to say "...early bystander CPR and rapid AED use contribute to survival of sudden cardiac arrest..." (AHA, 1995). Subsequent research on effectiveness prompted the American College of Cardiology to state that AEDs have been shown to be effective and safe in 1996. In 1998, the American College of Sports Medicine (ACSM) and the AHA joined forces to publish recommendations for AEDs in health and fitness facilities (Balady, Chaitman, Driscoll, et al., 1998). Based on the ACSM/AHA report and current trends at the time, 47 states passed Good Samaritan legislation to include the use of AEDs (ACSM/AHA, 2002). In 2000, President Bill Clinton signed into law the Cardiac Arrest Survival Act and the Rural Access to Emergency Devices Act as components of the federal Public Health Improvement Act of 2000 (ACSM/AHA, 2002).

Senators Edward Kennedy, MA and Bill Frist, TN introduced the Community Access to Emergency Defibrillation Act of 2001 on July 31, 2001. This act called for the creation of a community grant program to disseminate AED information, develop innovated programs, and create a national clearinghouse to promote AED access in schools (Congressional Record, 2001). The bill passed, earmarking $\$ 55$ million a year for five years for communities to install AEDs in public places, train first responders, encourage private companies to purchase AEDs, and promote PAD programs in schools (American Red Cross, 2002; Chmelynski, 2002). Most recently in June 2002, President

George W. Bush signed the Public Health and Bioterrorism Preparedness and Response 
Act, which incorporated The Community Access to Emergency Defibrillation Act of 2002 (American Red Cross, 2002). The act authorized the appropriation of millions of federal dollars to support the implementation of PAD programs across the country.

The incorporation of the state and federal laws expanded the Good Samaritan legal protection to users of AEDs across the United States. At the present time, Good Samaritan legal protection to lay rescuers has been expanded to all fifty states (ARC, 2003).

\section{AEDs in Health and Fitness Facilities}

In the State of New York, Governor George E. Pataki signed a new law requiring AEDs in all public schools and at sporting events (Chmelynski, 2002). Similar legislation is being considered in New Jersey, Illinois, Rhode Island, and Massachusetts, as AEDs are becoming part of the standard of care philosophy. The American Heart Association, American College of Cardiology, American Red Cross, American Public Health Association, and the American College of Sports Medicine all support increased public access to AEDs, including increased training in CPR and AED usage.

The incorporation of AEDs into health and fitness facilities (including collegiate athletic training programs) faces the issues of liability, training, location, and access (in addition to the cost factor in many programs) (ACSM/AHA, 2002; Hunt, 2002). In a 2002 report, the ACSM and AHA declared:

...It is prudent to conclude that health/fitness facilities should be considered among the sites in which PAD programs should be established (ACSM/AHA, 2002). 
AEDs are "strongly encouraged" in health and fitness facilities with membership $>2500$ and those that offer special programs such as cardiac rehabilitation or physical therapy (ACSM/AHA, 2002). This recommendation may be extended to the collegiate athletic programs when one considers the number of individuals served by the athletic facilities. These individuals include the athletes, coaches, training staff, officials, spectators, and others who may use the facilities for various reasons. The inclusion of these individuals increases the likelihood that the athletic training staff may respond to a cardiopulmonary emergency in a non-athlete.

\section{AEDs in Collegiate Athletic Training Programs}

The National Athletic Trainer's Association (NATA), does not have a position statement for the incorporation of AEDs into athletic training programs, but does endorse a comprehensive emergency plan. At the present time, the inclusion of AEDs is left for each program to decide. Ron Courson, Head Athletic Trainer at the University of Georgia, and a leading advocate of AED programs, implicated an AED protocol as part of the emergency plan for the athletic training program in 1995.

I feel that AEDs definitely have a role in sports medicine. ATCs [certified athletic trainers] are often the first responders to athletic emergencies.

Time to defibrillation is the critical component in successfully treating sudden cardiac arrest (citied in Hunt, 2002).

As the NATA and the NCAA investigate the issue of AEDs in athletic training programs, the notion of "standard of care" for each athlete must be considered. The lay responder is the most important link in the cardiac chain of survival (AHA, 2000). Providing basic life support and access to defibrillation can be considered a community 
responsibility (AHA, 2000). Good Samaritan legislations have made the AED a tool of the lay responder in many states (ACSM/AHA, 2002; ARC, 2002). The NATA Board of Certification now requires AED certification in addition to CPR to sit for the certification exam (NATA, 2003). In addition, the accreditation body for all clinical athletic training education programs has included an AED clinical proficiency to the 2004-2005 requirements (NATA, 2003).

The athletic training staff, as trained responders, is held to a higher standard of care than lay responders in the traditional model of care (originated by the American Heart Association, 1992, revised 2000). Under this model, the athletic training program should provide the highest standard of care possible to their athletes, incorporating proven techniques and devices to their arsenal. The perception of, and issues surrounding, Automated External Defibrillators in these programs are under investigation. 


\section{METHODOLOGY}

\section{Research Question}

The primary research question will be as follows: What factors, if any, are associated with the determination of Automated External Defibrillator (AED) ownership and use in collegiate athletic training programs?

\section{Purpose}

The purpose of this research will be (a) to establish a descriptive picture of AED ownership and use, and (b) determine the predictability of ownership and use based upon factors identified from the data obtained in collegiate athletic training programs. These data will help to set a baseline for the current and future implications for AEDs in collegiate athletic training programs.

Procedures

\section{Participant Selection}

Head certified athletic trainers (ATCs) at 325 National Collegiate Athletic Association (NCAA) Division I institutions will be asked to participate. Both active and provisional institutions will be included. There will be no restrictions for demographic variables such as age, gender, and race.

The subjects will be directly contacted by email beginning September 15, 2003. Email addresses will be obtained from the National Athletic Trainers Association (NATA) directory by professional contacts within the field (Ron Courson, ATC, University of Georgia; Scott Richter, ATC, University of Montana. Surveys will be collected through December 15, 2003. 
An ideal number of responses will be considered at 300 completed surveys (approximately $30 \%$ return rate).

\section{Instrumentation}

The Automated External Defibrillator (AED) Survey for Collegiate Athletic Training Programs will be designed by the researcher to investigate the existence, use, and perceived need for AEDs within the athletic training room setting. The survey will be constructed based on the topics of the athletic training profession, emergency care by the training staff, cardiovascular preparticipation screenings, and AEDs use and placement in training rooms. The survey's validation will be encouraged through consecutive reviews completed by ATCs in the State of Montana, NATA District 10, and professional contacts (Ron Courson, ATC and Scott Richter, ATC).

The survey will be prepared in HTML format in a secure website http://www.soe.umt.edu/hhp/aedsurvey designed in coordination with The University of Montana School of Education Teacher Resource Center Computer Staff. Access to the survey will be restricted by a login and password provided to each ATC within the email announcement.

\section{Data Collection}

The collection of survey data will proceed utilizing email and an interactive website, both sponsored by the School of Education at The University of Montana. The ATCs will be notified of the methods through direct email. All emails will be sent from the address starr.wharton@umontana.edu. The first email will contain a cover letter with pertinent background and instructions, including the direct link to the survey site, and the login and password needed to access the site. A second email will be sent one week after 
the first to encourage participation and provide a general "thank you" to those who have already participated. A third email will be sent three weeks after the first containing a shortened cover letter and another thank you to participants. A final email will be sent seven weeks after the first, similar in content to the second email. Participants will have the option to enter their email address after they complete the online survey to forgo receiving the reminders. This option will be offered after the survey has been submitted to the database, to ensure confidentiality. The researcher will have a record of email addresses, but will not have a corresponding survey for each address.

\section{Confidentially and reliability}

To ensure confidentially and reliability, the following steps will be taken:

A) Only the Head ATC at each institution will be asked to complete the survey, with the assertion the students are undesirable participants.

B) No potentially identifying factors, other than the institution's NCAA Division Membership and NATA District Membership, will be used in the survey.

C) Once the data are submitted by the ATC, no changes can be made. This will be ensured by internal security controls set in the website and the database.

D) Each survey will be automatically routed into a secure database established by the School of Education Teacher Resource Center. The database will be accessible by login and password only, and will include controls to prevent manipulation. The database will be compatible to the Microsoft Excel Program, and the GB Stat Computer Program to allow the researcher to download individual or multiple data sets for analysis. 


\section{Statistical Procedures}

Each question of the survey will receive a letter code for identification in the database. This database map will be created prior to the distribution of the first email. All statistical tests will be run using the GB Stat Computer Program.

\section{Null Hypothesis}

There will be no experimentally important or statistically consistent predictability of AED ownership utilizing relevant predictor variables.

\section{A Priori Statements}

Level of consistency

A p-value $\leq .05$ will be defined as the level of statistical consistency between relevant predictor and criterion variables. Level of predictability

The level of experimentally important predictability will be established as at least $70 \%$ based upon all cases.

\section{Statistic}

Frequencies and cross-tabs will be conducted on relevant data. Other analysis will be reported if appropriate and relevant. A Discriminate Function Analysis will be utilized to test the level of predictably between relevant predictor and criterion variables, and to test statistical reliability. 


\section{Limitations}

The limitations to this research will be the following:

A) There will be no control of the target population's present knowledge and views of Automated External Defibrillators, and the role that they may play in the athletic training programs.

B) There will be no control over who may complete the survey, i.e. the head ATC may delegate the survey to a graduate assistant or co-worker.

C) There will be no control for the rate of return and participation rate.

D) There will be no control of the subject's ability and access to information that will allow them to complete the survey accurately, i.e. a novice ATC may not possess information as that of a veteran.

E) There will be no control over unforeseen computer failures, viruses, operation errors, or other events that may inhibit completion of the survey and database function.

\section{Delimitations}

The delimitations to this research will be the following:

A) Only Head ATC's will be asked to complete the survey.

B) Only NCAA sanctioned institutions will be targeted; NAIA institutions will not be included.

C) The survey format will be on Internet only, with no options for paper completion.

D) The survey will ask for specific information that not all ATC's may have access to or knowledge of.

E) The timing of the research will incorporate the fall season, traditionally hectic months for the collegiate ATC. 


\section{Assumptions}

The primary assumption of the research is that all human life is of equal value, and each human, when faced with a life-threatening emergency, deserves an equal chance of survival. A further assumption will be that medical professionals (including ATCs) want to provide the highest standard of care to all individuals.

"Sport medicine professionals and sport scientists have particular opportunities and responsibilities to act as an athlete's advocate-- and to protects their health and well-being" (Pipe, 2001). 


\section{RESULTS}

\section{Research Question}

The primary research question was: What factors, if any, are associated with the determination of Automated External Defibrillator (AED) ownership and use in collegiate athletic training programs?

\section{Purpose}

The purpose of this research was (a) to establish a descriptive picture of AED ownership and use, and (b) determine the predictability of ownership and use based upon factors identified from the data obtained in collegiate athletic training programs.

\section{Data Collection}

Data collection took place from September 15, 2003 through December 15, 2003. Head Certified Athletic Trainers (ATC) at NCAA Division I Collegiate Athletic Training Programs were sent an email requesting participation in an online survey involving AEDs in Collegiate Athletic Training Programs. Subsequent reminder emails were sent at onemonth intervals, equaling a total of three emails to each Head ATC. Email addresses were obtained using the individual school websites, and the 2003 NATA online and hard copy membership directory. A total of 325 Division I schools were targeted. The membership directory confirmed each email address in the case of a failure to contact (i.e. delivery failure, unknown address, return to sender, etc). Failure to contact after three attempts and confirmation of the email address occurred with 49 of the targeted programs. The delivery failure rate was $15 \%$. 


\section{Summary Data}

A total of 100 completed surveys were collected from 276 NCAA Division I Collegiate Athletic Training Programs. The response rate was 36\%. Frequencies were conducted to obtain profile data.

\section{Institution and Program Profile}

Programs from Division IA, IAA, and IAAA as well as all ten NATA Districts completed the survey (Figure 1 and 2). The number of athletes in the programs ranged from 20 to 1100 , average 448.97 , SD 200.78 . The number of facilities used by the athletics program for competition and practice ranged from 1 to 20 , average $9.51, \mathrm{SD}$ 4.19. Forty-three of the schools were CAAHEP accredited education programs, with 39 of the Head ATCs serving as a clinical instructor in the program. Those ATCs spent an average of $11.47 \%$ of their time as a clinical instructor. No outreach hours outside the collegiate setting were reported. Adult CPR/AED was the most commonly required certification to work in the training room (Figure 3).

\section{Figure 1}

Respondents by NCAA Division

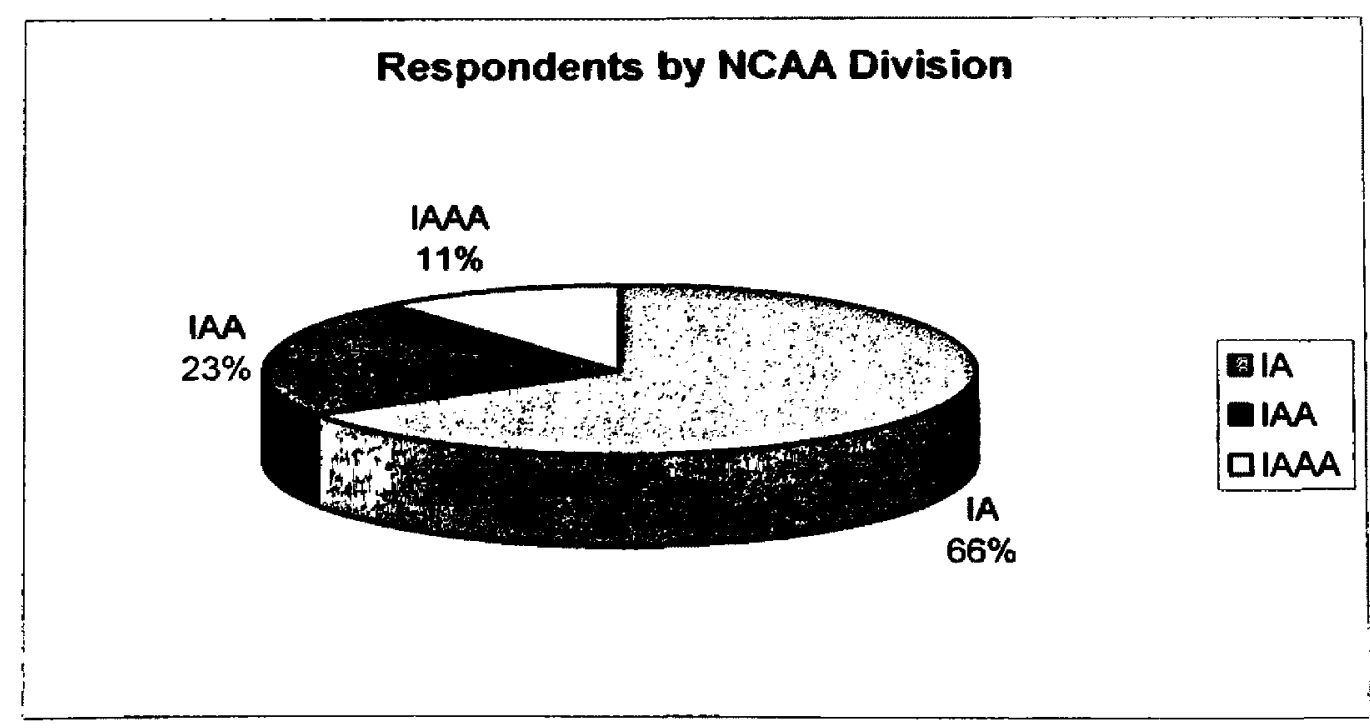




\section{Figure 2:}

Respondents by NATA District

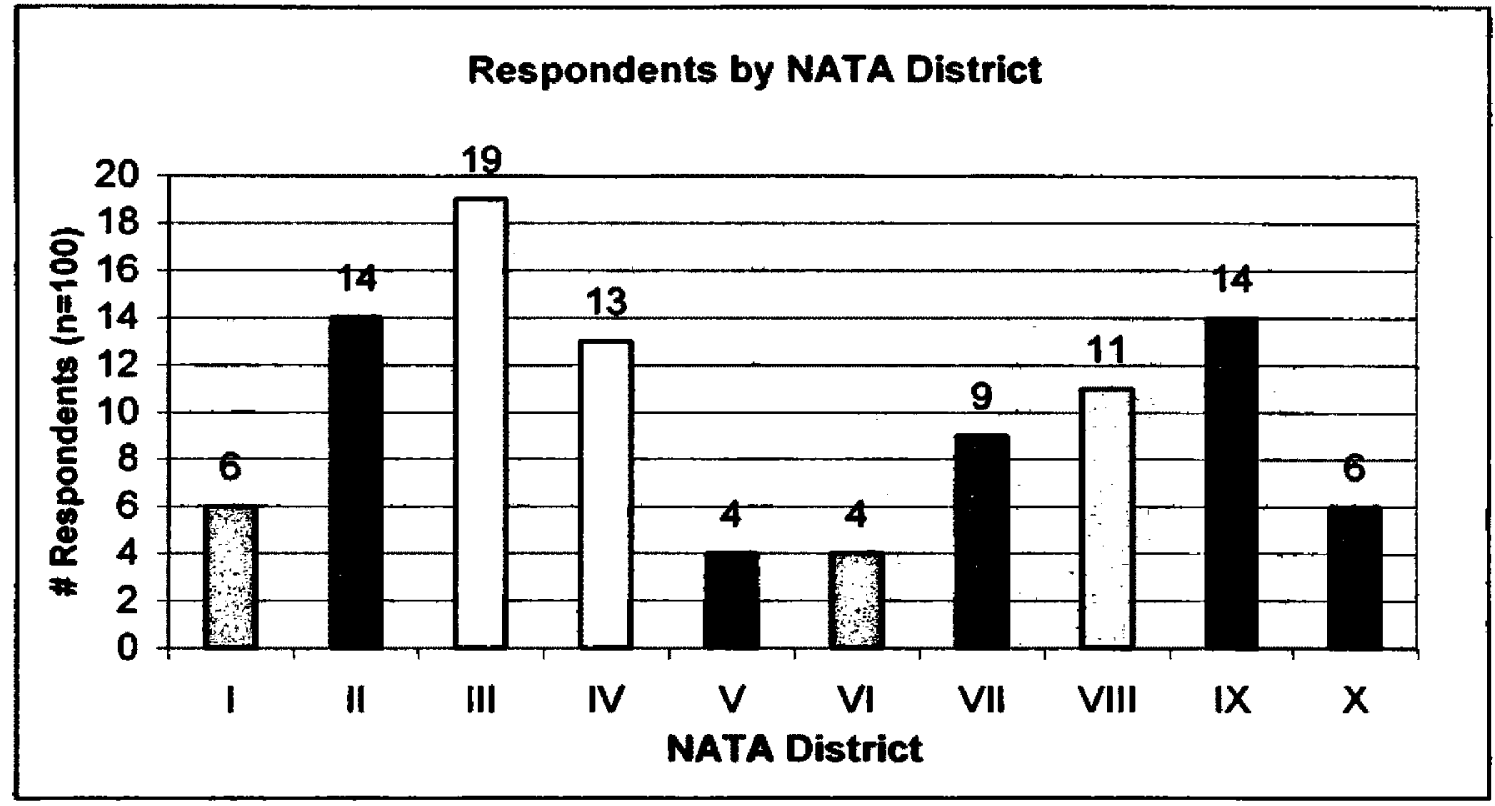

\begin{tabular}{|l|l|}
\hline \multicolumn{1}{|c|}{ District } & \multicolumn{1}{|c|}{ Member States/Provinces } \\
\hline I & $\begin{array}{l}\text { Connecticut, Maine, Massachusetts, New Hampshire, Rhode } \\
\text { Island, Vermont, Quebec, New Brunswick, Nova Scotia }\end{array}$ \\
\hline II & Delaware, New Jersey, New York, Pennsylvania \\
\hline III & $\begin{array}{l}\text { Maryland, North Carolina, South Carolina, Virginia, West } \\
\text { Virginia, District of Columbia }\end{array}$ \\
\hline IV & $\begin{array}{l}\text { Illinois, Indiana, Michigan, Minnesota, Ohio, Wisconsin, } \\
\text { Manitoba, Ontario }\end{array}$ \\
\hline V & $\begin{array}{l}\text { lowa, Kansas, Missouri, Nebraska, North Dakota, Okalahoma, } \\
\text { South Dakota }\end{array}$ \\
\hline VI & Arkansas, Texas \\
\hline VII & Arizona, Colorado, New Mexico, Utah, Wyoming \\
\hline VIII & California, Hawaii, Nevada, Guam \\
\hline IX & $\begin{array}{l}\text { Alabama, Florida, Georgia, Kentucky, Louisiana, Mississippi, } \\
\text { Tennessee, Puerto Rico, U.S. Virgin Islands }\end{array}$ \\
\hline X & $\begin{array}{l}\text { Alaska, Idaho, Montana, Oregon, Washington, Alberta, British } \\
\text { Columbia, Saskatchewan }\end{array}$ \\
\hline
\end{tabular}


Figure 3:

\section{Required Certifications}

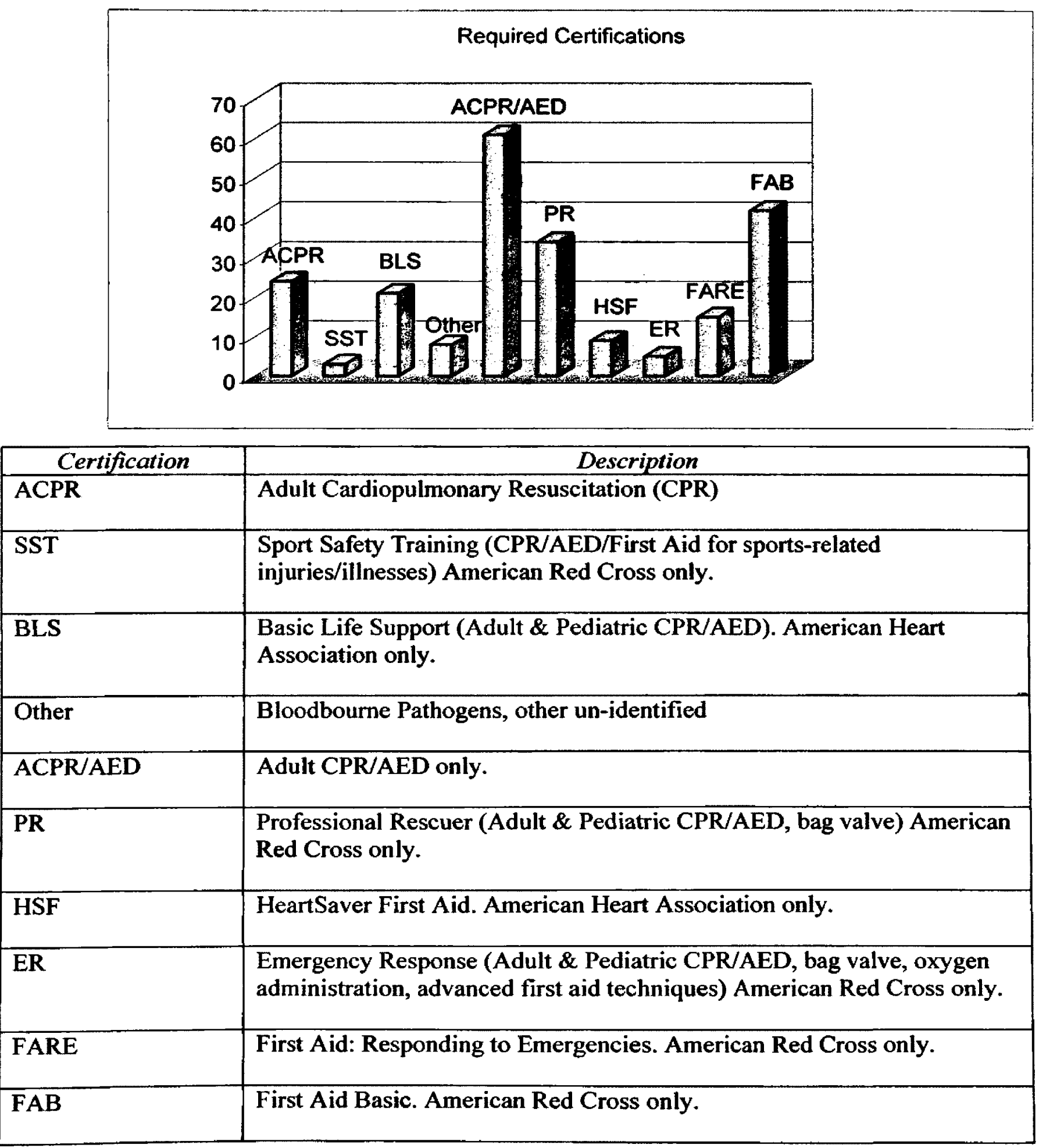


EMTs, paramedics, and/or emergency medical vehicles were regularly on site during practices for football at one school. No emergency personnel or vehicles were regularly on site during competition for the sports of fencing, golf, rifle, rowing, tennis, track and field, and water polo (see Table 1).

Table 1:

\# of Institutions with emergency personnel/vehicles at Athletic Competitions ( $\mathrm{n}=$ 100)

\begin{tabular}{|l|c|c|c|}
\hline \multicolumn{1}{|c|}{ Sport } & EMT & Paramedic & $\begin{array}{c}\text { Emergency } \\
\text { Medical Vehicle }\end{array}$ \\
\hline Baseball & 6 & 7 & 0 \\
\hline Basketball & 32 & 28 & 2 \\
\hline Cross-country & 6 & 11 & 2 \\
\hline Fencing & 0 & 0 & 0 \\
\hline Field Hockey & 1 & 1 & 0 \\
\hline Football & 39 & 35 & 40 \\
\hline Golf & 0 & 0 & 0 \\
\hline Gymnastics & 5 & 8 & 4 \\
\hline Ice Hockey & 3 & 3 & 4 \\
\hline Lacrosse & 4 & 4 & 4 \\
\hline Rifle & 0 & 0 & 0 \\
\hline Rowing & 0 & 0 & 0 \\
\hline Skiing & 1 & 1 & 0 \\
\hline Soccer & 11 & 10 & 8 \\
\hline Softball & 2 & 1 & 1 \\
\hline Swimming & 1 & 1 & 0 \\
\hline Tennis & 0 & 0 & 0 \\
\hline Track/Field & 0 & 0 & 0 \\
\hline Volleyball & 7 & 2 & 3 \\
\hline Water Polo & 0 & 0 & 0 \\
\hline Wrestling & 2 & 1 & 1 \\
\hline Other & 0 & 1 & 2 \\
\hline
\end{tabular}

\section{Head Certified Athletic Trainer Profile}

Surveys were completed by both genders (males $=80$, and females $=20$ ) with a range of years in the profession from 4 to 34 averaging 18.87 years overall, 17.85 
females, and 19.13 males respectively. Fourteen of the twenty total females were Division IA Head ATCs. Five of the six respondents from NATA District I were female.

A Masters Degree was the most commonly reported highest degree earned, equaling 83 of the 100 responses. Fourteen had a Bachelors degree as the highest earned, while four had earned Doctorates. Thirty-three of the Head ATCs were certified CPR/AED/FA instructors and none of them served as the primary instructor for the program.

\section{Preparticipation Screening Profile}

Preparticipation screening protocols were reported in 75 of the responses. Fifty percent of the programs screened all returning athletes in addition to the incoming athletes. Medical staff and certified program staff conducted the screenings at 61 of the schools. Medical staff alone conducted screenings in 26 programs and certified staff alone in 10 programs. Certified and non-certified staff conducted the screenings in one program and two programs reported other screening places. The types of screenings regularly conducted may be seen in Table 2 . 
Table 2:

Preparticipation Screening Profile

\begin{tabular}{|l|c|}
\hline \multicolumn{2}{|l|}{ What types of screening(s) do you regularly conduct? (Please check all } \\
that apply) \\
\hline Screening Type & $\frac{\# \text { programs }}{(\mathrm{n}=100)}$ \\
\hline Cardiac History Questions & 87 \\
\hline Cardiorespiratory Endurance Tests (i.e. VO 2 Max) & 0 \\
\hline ECG/EKG & 7 \\
\hline Echocardiogram & 5 \\
\hline \begin{tabular}{l} 
Graded Exercise Test (GXT) \\
\hline Heart Auscultation
\end{tabular} & 62 \\
\hline $\begin{array}{l}\text { Other (any explanation reported) } \\
\text { "Athletic Physical" } \\
\text { "Cardiologist on site for any red flagged athletes" } \\
\text { "physicals from personal physician" } \\
\text { "EKG and echo on all murmurs or positive cardiac Hx" } \\
\text { "Echo if warranted by other testing" } \\
\text { "Echo for MBB only" }\end{array}$ & 5 \\
\hline
\end{tabular}

Cardiopulmonary Emergencies Profile

Twenty-nine programs reported one or more cardiopulmonary emergency in the past three years. Of the 100 total responses, 62 had verified their number of emergencies. The other 38 were estimates. In Table 3, a breakdown of emergencies and deaths in different groups is reported. The total number of emergencies equals 36 . Fourteen of the programs reported an emergency that resulted in death. 


\section{Table 3}

Cardiopulmonary Emergencies and Deaths By Group $(n=100)$

\begin{tabular}{|c|c|c|c|c|c|c|}
\hline \multicolumn{7}{|c|}{ \# Cardiopulmonary Emergencies in Past 3 Years } \\
\hline $\begin{array}{c}\# \\
\text { Events } \\
\end{array}$ & Athletes & Spectators & \begin{tabular}{|c|} 
Coaches \\
ITrainers \\
IStaff
\end{tabular} & Officials & Other & Other Explanation \\
\hline 0 & 87 & 91 & 96 & 97 & 93 & $\begin{array}{l}\text { housekeeping employee in } \\
\text { the Dept. }\end{array}$ \\
\hline 1 & 8 & 4 & 3 & 3 & 6 & rec person in building \\
\hline 2 & 4 & 3 & 1 & & 1 & recreational athlete \\
\hline 3 & 1 & 1 & & & & university professor \\
\hline 12 & & 1 & & & & $\begin{array}{l}\text { elderly walkers using the } \\
\text { indoor track in the indoor } \\
\text { facility }\end{array}$ \\
\hline & & & & & & tryout \\
\hline & & & & & & educator \\
\hline & & & & & & Non NCAA visiting athlete \\
\hline \multicolumn{7}{|c|}{ \# Cardiopulmonary Deaths in Past 3 Years } \\
\hline \# Deaths & Athletes & Spectators & $\begin{array}{l}\text { Coaches } \\
\text { ITrainers } \\
\text { IStaff }\end{array}$ & Officials & Other & Other Explanation \\
\hline 0 & 86 & 86 & 88 & 89 & 85 & $\begin{array}{l}\text { Understand individual did } \\
\text { not have shockable rhythm }\end{array}$ \\
\hline 1 & 4 & 4 & 2 & 1 & 5 & tryout \\
\hline 2 & 1 & 1 & 1 & 1 & 1 & \\
\hline 3 & 1 & 1 & 1 & 1 & 1 & \\
\hline
\end{tabular}

\section{Emergency Planning and AED Profile}

A formal level of protocol for the management of cardiopulmonary emergencies in the athletic training room was most common in 69 schools. Informal protocols were reported in 20 schools and 11 had no protocol. The use of an Automated External Defibrillator (AED) was included in $\mathbf{7 8}$ of the schools protocols (informal or formal). Eighty-three respondents reported that AEDs are extremely beneficial. Ten respondents 
said AEDs are not beneficial, and 7 were unsure. The hours that the Head ATC reported as necessary for proper training ranged from 0 to 10 , with 1 hour being the most common $(n=28)$. Seventy-nine of the programs reported having one or more AED, with a range from 1 to 13 total AEDs distributed among their facilities. See Figure 4 for the barriers identified by programs that had fewer AEDs than they deemed necessary.

Figure 4

Barriers to AED Ownership

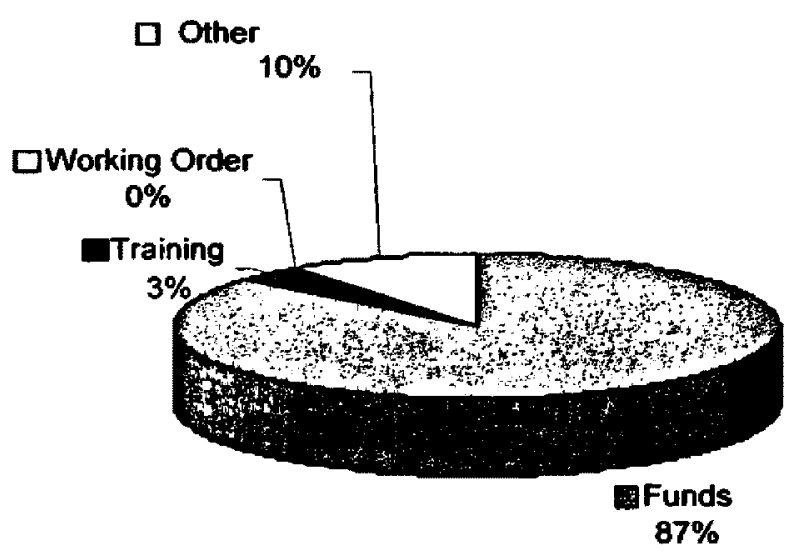

Barriers to AED Ownership

Sixty-seven of the respondents said that they would purchase an AED, 19 said that they would not, and 14 were unsure. For further explanation from the respondents of why/why not, see Appendix A- Summary Results. When asked who should be responsible for purchasing the AED, 39 said the Intercollegiate Athletics Program, 38 the Institution, 19 the Athletic Training Program, and 4 other (Appendix A). When asked if the program could afford to purchase an $\mathrm{AED}, 52$ programs said yes, and 48 no. The amount that they could afford to spend to purchase an AED ranged from $\$ 0(n=43)$ to $\$ 30,000(\mathbf{n}=1)$, average $\$ 2089.5$, as seen in Figure 5 . 
Figure 5

Amount Program Can Afford to Purchase An AED

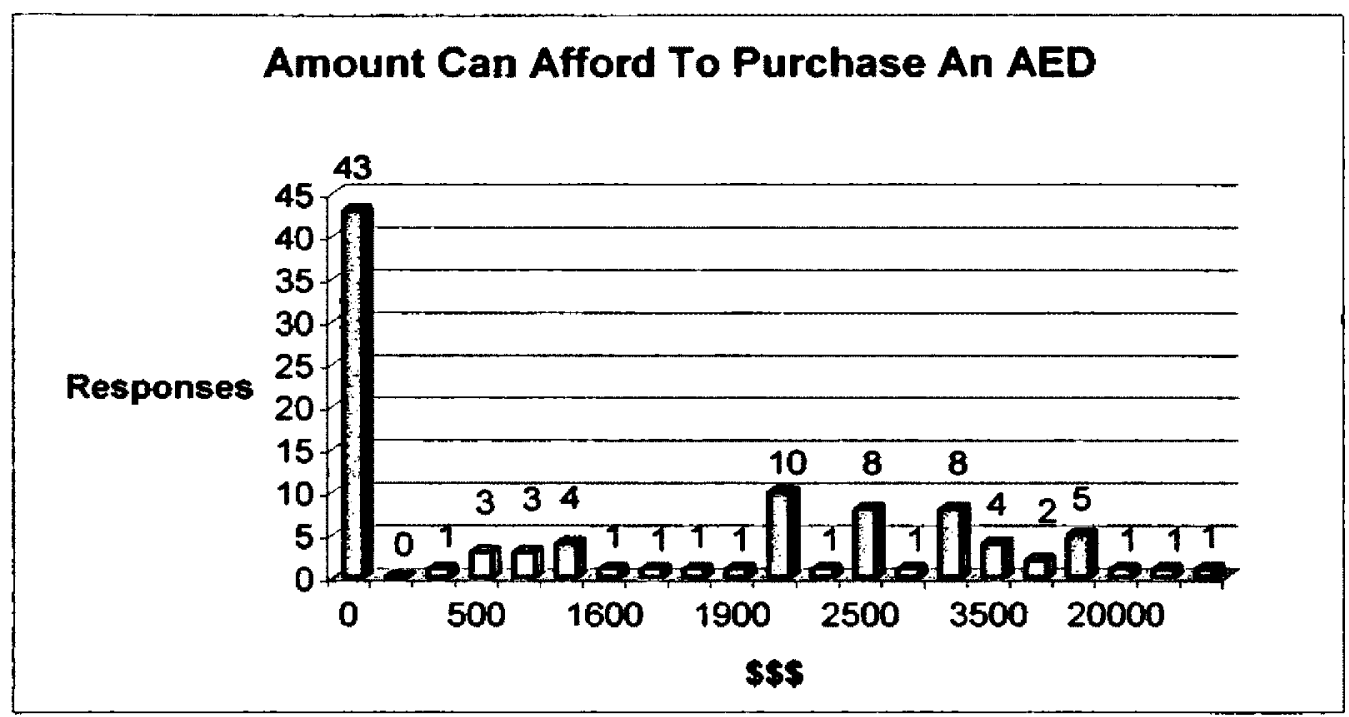

For those who own an AED, the number of years they have owned one ranged from 0 to 9 with mean equal to $6.25 y$ rs. Seventy-five percent of females and $80 \%$ of males own an AED. Of the 79 AED owners, five reported having used the AED in the past three years. The AED was used once on an athlete and official, and twice on each a spectator and in the other category. The others were reported as a "recreational athlete" and a "university professor". Of the emergencies where an AED was used, four resulted in death. Three deaths were athletes; one was in the other category described as a "tryout".

\section{Statistics- Cross-tabs}

Cross-tabs were conducted for AED ownership and willingness to purchase utilizing relevant predictor variables. Relevant contingency tables with a p-value $\leq .05$ were considered consistent. See Tables 4 and 5. 


\begin{tabular}{|c|c|c|c|c|c|}
\hline \multicolumn{5}{|c|}{ Table 4: Cross-Tab Results: AED Ownership x Variables } & \\
\hline $\begin{array}{r}\text { Of all below, } \% \text { that } \\
\text { AED } \\
\end{array}$ & n/don' & own & $\begin{array}{r}\text { Of all that own/don" } \\
\% \text { of belov }\end{array}$ & own Al & \\
\hline $\begin{array}{l}\text { Who conducts pre-par } \\
\text { screenings? }\end{array}$ & $\begin{array}{c}\text { No } \\
\text { AED }\end{array}$ & AED & $\begin{array}{l}\text { Who conducts pre-par } \\
\text { screenings? }\end{array}$ & $\begin{array}{c}\text { No } \\
A E D\end{array}$ & AED \\
\hline Cert AT Staff & 80 & 20 & Cert AT Staff & 38 & 3 \\
\hline Cert \& UnCert AT Staff & 0 & 100 & Cert \& UnCert AT Staff & 0 & 1 \\
\hline Medical \& Cert AT Staff & 15 & 85 & Medical \& Cert AT Staff & 43 & 66 \\
\hline Medical Staff & 15 & 85 & Medical Staff & 19 & 28 \\
\hline Other & 0 & 100 & Other & 0 & 3 \\
\hline$p<.0001$ & & & $p<.0001$ & & \\
\hline
\end{tabular}

\begin{tabular}{|c|c|c|c|c|c|}
\hline $\begin{array}{c}\text { Who should buy the } \\
\text { AED? }\end{array}$ & $\begin{array}{c}\text { No } \\
\text { AED }\end{array}$ & AED & $\begin{array}{c}\text { Who should buy the } \\
\text { AED? }\end{array}$ & $\begin{array}{c}\text { No } \\
\text { AED }\end{array}$ & AED \\
\hline Athletic Training Program & 53 & 47 & Athletic Training Program & 48 & 11 \\
\hline $\begin{array}{c}\text { Intercollegiate Athletics } \\
\text { Program }\end{array}$ & 18 & 82 & $\begin{array}{c}\text { Intercollegiate Athletics } \\
\text { Program }\end{array}$ & 33 & 41 \\
\hline Institution & 8 & 92 & Institution & 14 & 44 \\
\hline Other & 25 & 75 & Other & 5 & 4 \\
\hline P.00134 & & & P.00134 & & \\
\hline
\end{tabular}

\begin{tabular}{|c|c|c|c|c|c|}
\hline $\begin{array}{c}\text { NCAA Division } \\
\text { Membership }\end{array}$ & $\begin{array}{c}\text { No } \\
\text { AED }\end{array}$ & AED & $\begin{array}{c}\text { NCAA Division } \\
\text { Membership }\end{array}$ & $\begin{array}{c}\text { No } \\
\text { AED }\end{array}$ & AED \\
\hline IA & 24 & 76 & IA & 76 & 63 \\
\hline IAA & 4 & 96 & IAA & 5 & 28 \\
\hline IAAA & 36 & 64 & IAAA & 19 & 9 \\
\hline P.05427 & & & P.05427 & & \\
\hline
\end{tabular}

\begin{tabular}{|c|c|c|c|c|c|}
\hline $\begin{array}{c}\text { Pre-par screening } \\
\text { protocol for all incoming } \\
\text { athletes? }\end{array}$ & $\begin{array}{c}\text { No } \\
\text { AED }\end{array}$ & AED & $\begin{array}{c}\text { Pre-par screening } \\
\text { protocol for all incoming } \\
\text { athletes? }\end{array}$ & $\begin{array}{c}\text { No } \\
\text { AED }\end{array}$ & AED \\
\hline No & 44 & 56 & No & 52 & 18 \\
\hline Yes & 13 & 87 & Yes & 48 & 82 \\
\hline p.00111 & & & p.00111 & & \\
\hline
\end{tabular}




\begin{tabular}{|c|c|c|c|c|c|}
\hline \multicolumn{6}{|c|}{ Table 4: Cross-Tab Results: AED Ownership x Variables } \\
\hline \multicolumn{3}{|c|}{$\begin{array}{c}\text { Of all below, \% that own/don't own } \\
\text { AED }\end{array}$} & \multicolumn{3}{|c|}{$\begin{array}{l}\text { Of all that own/don't own AED, } \\
\% \text { of below }\end{array}$} \\
\hline $\begin{array}{c}\text { AED included in } \\
\text { Cardiopulmonary } \\
\text { Emergencies Protocol? }\end{array}$ & $\begin{array}{c}\text { No } \\
\text { AED }\end{array}$ & $A E D$ & $\begin{array}{c}\text { AED included in } \\
\text { Cardiopulmonary } \\
\text { Emergencies Protocol? }\end{array}$ & $\begin{array}{c}\text { No } \\
\text { AED }\end{array}$ & $A E D$ \\
\hline No & 96 & 5 & No & 100 & 1 \\
\hline Yes & 0 & 100 & Yes & 0 & 99 \\
\hline$p<.0001$ & & & $p<.0001$ & & \\
\hline
\end{tabular}

\begin{tabular}{|c|c|c|c|c|c|}
\hline $\begin{array}{c}\text { Can your program afford } \\
\text { an AED? }\end{array}$ & $\begin{array}{c}\text { No } \\
\text { AED }\end{array}$ & AED & $\begin{array}{c}\text { Can your program afford an } \\
\text { AED? }\end{array}$ & $\begin{array}{c}\text { No } \\
\text { AED }\end{array}$ & AED \\
\hline No & 31 & 69 & No & 71 & 42 \\
\hline Yes & 12 & 86 & Yes & 29 & 58 \\
\hline$P .01561$ & & & p.01561 & & \\
\hline
\end{tabular}

\begin{tabular}{|c|c|c|c|c|c|}
\hline $\begin{array}{c}\text { Protocol for the } \\
\text { management of } \\
\text { cardiopulmonary } \\
\text { emergencies (level) }\end{array}$ & $\begin{array}{c}\text { No } \\
\text { AED }\end{array}$ & AED & $\begin{array}{c}\text { Protocol for the } \\
\text { management of } \\
\text { cardiopulmonary } \\
\text { emergencies (level) }\end{array}$ & $\begin{array}{c}\text { No } \\
\text { AED }\end{array}$ & AED \\
\hline None & 100 & 0 & None & 52 & 0 \\
\hline Informal & 10 & 90 & Informal & 10 & 23 \\
\hline Formal & 12 & 88 & Formal & 38 & 77 \\
\hline$p<.0001$ & & & $\mathbf{p}<.0001$ & & \\
\hline
\end{tabular}

\begin{tabular}{|c|c|c|c|c|c|}
\hline $\begin{array}{c}\text { How beneficial would the } \\
\text { AED be in the event of a } \\
\text { cardiopulmonary arrest? }\end{array}$ & $\begin{array}{c}\text { No } \\
\text { AED }\end{array}$ & AED & $\begin{array}{c}\text { How beneficial would the } \\
\text { AED be in the event of } a \\
\text { cardiopulmonary arrest? }\end{array}$ & $\begin{array}{c}\text { No } \\
\text { AED }\end{array}$ & AED \\
\hline Not at all & 100 & 0 & Not at all & 48 & 0 \\
\hline Unsure & 0 & 100 & Unsure & 0 & 9 \\
\hline Extremely Beneficial & 13 & 87 & Extremely Beneficial & 52 & 91 \\
\hline$p<.0001$ & & & $p<.0001$ & & \\
\hline
\end{tabular}




\section{Table 5: Cross-Tab Results: Willingness to Purchase $x$ Variables}

*All numbers are percentages. $N=100$

\begin{tabular}{|c|c|c|c|c|c|c|c|}
\hline \multicolumn{4}{|c|}{$\begin{array}{c}\text { Of all below, \% that will not/unsure/will } \\
\text { buy }\end{array}$} & \multicolumn{4}{|c|}{$\begin{array}{c}\text { Of all will not/unsure/will buy, } \% \text { of } \\
\text { below }\end{array}$} \\
\hline $\begin{array}{c}\text { How beneficial } \\
\text { would the AED be in } \\
\text { the event of a } \\
\text { cardiopulmonary } \\
\text { arrest? }\end{array}$ & $\begin{array}{l}\text { Will } \\
\text { Not }\end{array}$ & Unsure & Will & $\begin{array}{c}\text { How beneficial } \\
\text { would the AED be in } \\
\text { the event of a } \\
\text { cardiopulmonary } \\
\text { arrest? }\end{array}$ & $\begin{array}{l}\text { Will } \\
\text { Not }\end{array}$ & Unsure & WIII \\
\hline Not at all & 100 & 0 & 0 & Not at all & 53 & 0 & 0 \\
\hline Unsure & 14 & 29 & 57 & Unsure & 5 & 14 & 6 \\
\hline Extremely Beneficial & 10 & 15 & 76 & Extremely Beneficial & 42 & 86 & 94 \\
\hline$p<.0001$ & & & & $p<.0001$ & & & \\
\hline
\end{tabular}

\begin{tabular}{|c|c|c|c|c|c|c|c|}
\hline $\begin{array}{c}\text { Pre-par screening } \\
\text { protocol for all } \\
\text { incoming athletes? }\end{array}$ & $\begin{array}{c}\text { Will } \\
\text { Not }\end{array}$ & Unsure & Will & $\begin{array}{c}\text { Pre-par screening } \\
\text { protocol for all } \\
\text { incoming athletes? }\end{array}$ & $\begin{array}{c}\text { Will } \\
\text { Not }\end{array}$ & Unsure & Will \\
\hline No & 40 & 4 & 56 & No & 53 & 7 & 21 \\
\hline Yes & 12 & 17 & 71 & Yes & 47 & 93 & 79 \\
\hline P.0047 & & & & p.0047 & & & \\
\hline
\end{tabular}

\begin{tabular}{|c|c|c|c|c|c|c|c|}
\hline $\begin{array}{c}\text { Is the number of } \\
\text { cardiopulmonary } \\
\text { emergencies at your } \\
\begin{array}{c}\text { facility(s) an } \\
\text { estimate or verified } \\
\text { number? }\end{array}\end{array}$ & $\begin{array}{c}\text { Will } \\
\text { Not }\end{array}$ & Unsure & Will & $\begin{array}{c}\text { Is the number of } \\
\text { cardiopulmonary } \\
\text { emergencies at } \\
\text { your facility(s) an } \\
\text { estimate or verified } \\
\text { number? }\end{array}$ & $\begin{array}{c}\text { Will } \\
\text { Not }\end{array}$ & Unsure & Will \\
\hline Estimate & 32 & 13 & 55 & Estimate & 63 & 36 & 31 \\
\hline Verified & 11 & 15 & 74 & Verified & 37 & 64 & 69 \\
\hline $\mathbf{p ~ . 0 4 0 8 6}$ & & & & p.04086 & & & \\
\hline
\end{tabular}

\begin{tabular}{|c|c|c|c|c|c|c|c|}
\hline $\begin{array}{c}\text { AED included in } \\
\begin{array}{c}\text { Cardiopulmonary } \\
\text { Emergencies } \\
\text { Protocol? }\end{array}\end{array}$ & $\begin{array}{c}\text { Will } \\
\text { Not }\end{array}$ & Unsure & Will & $\begin{array}{c}\text { AED included in } \\
\text { Cardiopulmonary } \\
\text { Emergencies } \\
\text { Protocol? }\end{array}$ & $\begin{array}{c}\text { Will } \\
\text { Not }\end{array}$ & Unsure & Will \\
\hline No & 50 & 14 & 36 & No & 58 & 21 & 12 \\
\hline Yes & 10 & 14 & 77 & Yes & 42 & 79 & 88 \\
\hline $\mathbf{P . 0 0 0 1 1}$ & & & & $\mathbf{P . 0 0 0 1 1}$ & & & \\
\hline
\end{tabular}




\begin{tabular}{|c|c|c|c|c|c|c|c|}
\hline Table 5: Cross & o & $\begin{array}{l}\text { Sults: } \\
\text { number }\end{array}$ & $\begin{array}{l}\text { Iling } \\
\text { repe }\end{array}$ & $\begin{array}{l}\text { gness to Purchas } \\
\text { grcentages. } N=100\end{array}$ & $x$ & riables & \\
\hline $\begin{array}{l}\text { Of all belo } \\
\text { not/unst }\end{array}$ & $\begin{array}{l}\mathrm{v}, \% \mathrm{t} \\
\mathrm{re/wil}\end{array}$ & $\begin{array}{l}\text { at will } \\
\text { buy }\end{array}$ & & $\begin{array}{r}\text { Of all will not/un } \\
\text { b }\end{array}$ & $\begin{array}{l}\text { sureh } \\
\text { low }\end{array}$ & ill buy, & $\%$ of \\
\hline \begin{tabular}{c|} 
Funds a barrier to \\
purchasing?
\end{tabular} & $\begin{array}{l}\text { Will } \\
\text { Not }\end{array}$ & Unsure & Will & \begin{tabular}{|c|} 
Funds a barrier to \\
purchasing?
\end{tabular} & $\begin{array}{l}\text { Will } \\
\text { Not }\end{array}$ & Unsure & Will \\
\hline No & 39 & 18 & 43 & No & 100 & 64 & 31 \\
\hline Yes & 0 & 10 & 90 & Yes & 0 & 38 & 69 \\
\hline$p<.0001$ & & & & $p<.0001$ & & & \\
\hline $\begin{array}{l}\text { Can you afford to } \\
\text { purchase an AED? }\end{array}$ & $\begin{array}{l}\text { Will } \\
\text { Not }\end{array}$ & Unsure & Will & \begin{tabular}{|l|}
$\begin{array}{c}\text { Can you afford to } \\
\text { purchase an AED? }\end{array}$ \\
\end{tabular} & $\begin{array}{l}\text { Will } \\
\text { Not }\end{array}$ & Unsure & Will \\
\hline No & 29 & 19 & 52 & No & 74 & 64 & 37 \\
\hline Yes & 10 & 10 & 81 & Yes & 26 & 36 & 63 \\
\hline p.00833 & & & & P. .00833 & & & \\
\hline
\end{tabular}

Statistics: Discriminate Function Analysis

The Discriminate Function Analysis (DFA) was run to test the level of predictably between relevant predictor and criterion variables. The level of experimentally important predictability was established as at least $70 \%$ based upon all cases.

The DFA was run with the predictor variable AED ownership and interval level data criterion variables as follows: percent of time as a clinical instructor, years in the profession, number of athletes, number of facilities, number of athletic training staff that are CPR instructors, number of cardiopulmonary emergencies faced in past 3 years, number of hours required for proper AED training, and the amount that the program can afford to purchase an AED. See Table 6 for a summary of DFA results. 
Table 6

Discriminate Function Analysis (DFA) Results

** Important predictability level $=70 \% ; 50 \%=$ Chance

\begin{tabular}{|c|c|c|}
\hline Predictor Variable & Criterion Variable(s) & \% of correct prediction \\
\hline \multirow{8}{*}{$\begin{array}{l}\text { AED Ownership } \\
\text { (own or not) }\end{array}$} & $\%$ time $\mathrm{CI}$ & 64 \\
\hline & Yrs in profession & 61 \\
\hline & \# Athletes & 49 \\
\hline & \# Facilities & 52 \\
\hline & \# staff CPR instructors & 42 \\
\hline & \# CP emergencies & 40 \\
\hline & \# training hours & 55 \\
\hline & $\$$ program can afford & 63 \\
\hline $\begin{array}{l}\text { AED Ownership } \\
\text { (own or not) }\end{array}$ & All variables & 71 \\
\hline \multirow{8}{*}{$\begin{array}{l}\text { AED Ownership } \\
\text { (own or not) }\end{array}$} & All except \# Athletes & 71 \\
\hline & All except \# CP emergencies & 70 \\
\hline & All except \# facilities & 70 \\
\hline & All except \% time CI & 69 \\
\hline & All except Yrs in profession & 69 \\
\hline & All except $\$$ program can afford & 68 \\
\hline & $\begin{array}{l}\text { All except \# staff CPR } \\
\text { instructors }\end{array}$ & 68 \\
\hline & $\begin{array}{l}\% \text { time } \mathrm{CI}, \text { Yrs in profession, \# } \\
\text { training hours, } \$ \text { program can } \\
\text { afford }\end{array}$ & 68 \\
\hline
\end{tabular}




\section{DISCUSSION}

The primary research question was: What factors, if any, are associated with the determination of Automated External Defibrillator (AED) ownership and use in collegiate athletic training programs?

\section{Purpose}

The purpose of this research was (a) to establish a descriptive picture of AED ownership and use, and (b) determine the predictability of ownership and use based upon factors identified from the data obtained in collegiate athletic training programs.

\section{Institution and Program Profile}

There is a good distribution of data by NCAA Division and NATA District, with the most from Division IA $(n=66)$ and District III $(n=19)$. Consistent differences were found between Division membership and AED ownership. In Division IAA, $96 \%$ of the programs owned an AED, versus $76 \%$ in IA programs and $64 \%$ in IAAA programs. Of all the programs that do not own an AED, $76 \%$ were IA. There were no consistent differences between Division and barriers to ownership (funds, training, working order, other); whether or not the program could afford an AED; and the intent to purchase an AED.

Forty-three programs were part of a CAAHEP education program. No consistent differences were found between AED ownership or intent to purchase and the CAAHEP status. The programs all required that staff have some level of emergency care certifications, some more than one type, and $75 \%$ of the programs had one or more staff certified as a CPR/AED/First Aid instructor. Instructor certification did not have a great 
influence on the predication of AED ownership within the program, as the correct prediction was only $42 \%$ with that variable alone.

The number of athletes and the number of facilities served by the programs were found to have an AED ownership predictability assumed by chance; $49 \%$ and $52 \%$ respectively; but when removed as factors to the whole, the predictability increased to $70 \%$. This indicates that the size of the athletic program has no bearing on AED ownership.

Referring to Table 1, it was not surprising to see that only one program had emergency personnel or vehicles on site for practices, as that is common practice for most institutions. Football had the largest coverage by emergency personnel, followed by basketball and soccer as would be expected in all three NCAA Divisions.

\section{Head Certified Athletic Trainer Profile}

More males than females completed the survey, 14 of the 20 females were Division IA Head ATCs. The average amount of time in the profession differed by less than 2 years between males and females and was not a factor in the predictability of AED ownership. Seventy-five percent of the females and $80 \%$ of males owned an AED. This difference was not large and gender was not consistent when looking at AED ownership or intent to purchase. The amount of time spent as a clinical instructor for CAAHEP programs and the CPR/AED/FA instructor status did not show consistent differences with AED ownership or intent to purchase. The level of education was also not consistent as a factor in AED ownership or intent to purchase. Therefore, it may be concluded that gender, years in the profession, clinical and CPR/AED/FA instructor status, and education level have little bearing when looking at AED ownership or intent to purchase. 


\section{Preparticipation Screening Profile}

Seventy-five percent of the programs reported having preparticipation screening protocols in place for all incoming athletes. Half of the programs had a protocol that included returning athletes as well. The programs with protocols in place for all incoming athletes differed consistently in the ownership of AEDs and the intent to purchase. Of all those who have a protocol, $87 \%$ own an AED and $71 \%$ are willing to purchase one. But of all those who are unsure if they will purchase, $93 \%$ have a protocol. This is an interesting result because it appears as though having a protocol in place does not mean the program is willing to purchase, yet most programs with protocols already have an AED. There were no consistent differences between the protocol and barriers to purchase and whether the program could afford an AED.

There was a consistent difference between who conducted the screenings and AED ownership. A majority of the programs conduct preparticipation screenings with certified and medical staff $(n=61)$, and $85 \%$ of those programs own an AED. When medical staff alone conducted the screenings, $85 \%$ of those programs also own an AED. For all those who do not own an AED, certified and medical staff do $43 \%$ of the screenings and $38 \%$ are done by certified staff alone. It appears as though the inclusion of the medical staff in the preparticipation screening process may have an influence on AED ownership, although it has no consistent influence on the intent to purchase.

Cardiac history questions were asked as part of the screening in 87 of the 100 programs, with heart auscultations being common in 62 of the programs. No programs conducted cardiorespiratory endurance tests or graded exercise tests, and twelve did ECG/EKGs or echocardiograms as part of their screenings. Four of the comments in the 
"other" section did report that an echocardiogram or ECG/EKG may be conducted in certain situations (Table 2). There is a current push for echocardiograms or ECG/EKGs to be included into the preparticipation screening process in hopes to catch an underlying heart condition before it results in sudden cardiac arrest or death. The results from this question seem to show that some programs are taking that step as a secondary measure if other screening procedures warrant it. It will be interesting to see how this may change in the next few years as the cost of the portable echocardiogram machine decreases.

\section{Cardiopulmonary Emergency Profile}

Cardiopulmonary emergencies occurred at 29 of the 100 programs over the past three years. The number of these emergencies by program ranged from one to twelve in different demographic groups (Table 3). Most of the events happened with athletes, although at one program 12 events occurred with spectators. The number of emergencies is not a variable for predictability of AED ownership, but whether that number is an estimate or verified does show a consistent difference with AED ownership and intent to purchase. Fourteen of the 29 emergencies resulted in death.

Of all those who do not own an AED, $68 \%$ estimated their number of emergencies. Of all those who do own AED, $70 \%$ verified their number of emergencies. It may be concluded that having an AED makes the program more likely to verify the number of emergencies. This may be due to the fact that if they have used the AED on the emergency, they are more likely to record and remember it than if they did not. It also may depend on what demographic the emergency occurred in, and whether or not the Head ATC was part of the program at the time of the emergency. 
The programs that estimated their number of emergencies were less likely to purchase an AED. $63 \%$ of all the programs that said they would not purchase estimated their number of emergencies. $64 \%$ of those who verified their number were unsure about purchasing. This may be thought to be a result of whether the AED is beneficial and the barriers to purchasing. There was consistency of responses at the .01 level when looking at estimated or verified emergencies and the perceived benefit of the AED; of all those that thought the AED was not beneficial in the event of a cardiopulmonary emergency, $80 \%$ estimated their number of emergencies. There was no consistency with results between the estimated or verified numbers, barriers to purchasing, and whether the program could afford to purchase and AED.

\section{Emergency Planning and AED Profile Emergency Protocol}

The level of protocol for the management of cardiopulmonary emergencies as part of the emergency plan for the program was consistent different between programs that owned an AED and the intent to purchase one. Of the 11 programs that had no protocol for the management of cardiopulmonary emergencies, none of them owned an AED. In addition, for all those that own an AED, all have a protocol, either informal or formal, in place. For all those protocols that included an AED, $100 \%$ own one. For all those who do not own an AED, $100 \%$ do not have them included in their protocol. The protocol results are measures indicating internal validity in the survey.

For all those who are unsure if they will purchase, $79 \%$ have an AED included in the protocol. For all those who will not purchase, $42 \%$ of have an AED included in the protocol. While there is no consistency between AED in the protocol and barriers to 
purchasing, some of the comments in the reasons why/why not purchase may indicate why so many that will not purchase have the AED included (Appendix A-Summary Results- Other Barriers and Why/Why Not Purchase). Two programs mentioned that the campus police have AEDs in the squad cars and will respond quickly to any emergency. This is true of the emergency medical services in the area as well, which may be a part of the emergency plan, therefore included AEDs even if the program does not own or intend to purchase any.

\section{AED Beneficial?}

Whether or not the AED is beneficial in the event of a cardiopulmonary emergency is one of the most important questions in the survey and it was found to be consistent in differences when looking at both ownership and intent to purchase. Of all those who believe that an AED would not be beneficial, $100 \%$ do not own and will not purchase. Of all those who are unsure if an AED would be beneficial, $100 \%$ own one. These two results indicate internal validity for the survey. Of all those who believe the AED is extremely beneficial, $87 \%$ own one and $76 \%$ would purchase one. The remaining $13 \%$ represent the target marketing audience: those who think that the AED is extremely beneficial but do not own one. These are the programs that are willing to purchase an AED but are held back because of a barrier of some kind. Then there is another $10 \%$ that think the AED is extremely beneficial, but would not purchase

\section{Barriers to Purchasing}

The respondents were asked to identify one or more of the following barriers to purchasing an AED: funds, training, working order, other (with explanation). Funding was the barrier for most, accounting for $87 \%$ of the barrier answers. Funding was a 
consistent barrier when looking at intent to purchase, but was very interesting in how it worked. Of all those who said they would not purchase, $100 \%$ said the funds was not a barrier. This means that other barriers must be present in those 19 programs. Working order was not reported as a barrier for any programs, and training was only a factor for two programs. Other barriers included concerns about administration and decision makers, and that they had the campus police to respond in the case of an emergency.

For all those who said that funding was a barrier, $90 \%$ said that they would purchase. These 46 programs are a target audience to find out what it would take for them to be able to purchase. Unfortunately, there was no consistency in results between the funds barrier and whether the program could afford to purchase.

\section{Afford to Purchase?}

There was consistency between intent to purchase, AED ownership, and whether the program could afford to purchase. Of all those who currently own an AED, 79\% were unsure if they would purchase another one, and $42 \%$ said that they would not purchase another one. Reasons for these answers ranged from having enough to funding not being available (Appendix A - Summary Table).

Of the 100 respondents, almost half said that they could not afford to purchase. Of all those that said they would not purchase, $74 \%$ said they could not afford. The other $26 \%$ that said they would not purchase, but can afford to represents a target audience. Of all those who do not own an AED, $71 \%$ said they could not afford to purchase. Of all those that can afford an AED, $86 \%$ have them. The remaining 12 are a target group for why they have the funds but do not feel the need to purchase. 
When asked how much could the program afford to purchase an AED, the answers ranged from 0 to $\$ 30,000$, average $\$ 2089.50$, which is close to the average cost of an AED in the present market. The amount that the program could afford had little bearing on the predictability of AED ownership and therefore is not a single indicator of ownership.

\section{Who Should Purchase?}

The question of who should be responsible for purchasing the AED was consistent for ownership and intent to purchase. The Intercollegiate Athletics Program (n $=39)$ and the Institution $(n=38)$ were close with the Athletic Training Program $(n=19)$ and Other $(n=4)$ accounting for a minority. For all those that thought the Institution should be responsible, $92 \%$ had an AED. Of all those who do not own an AED, $48 \%$ thought the Athletic Training Program should be responsible. In an interesting result, of all those who think the Athletic Training Program should purchase, 53\% would not do so. If the Intercollegiate Athletics Program should purchase, then $77 \%$ would say yes to that decision. The reasons for this refer back to the reasons for why/why not purchase. Reasons listed in the other category may be seen in Table 7. 


\section{Table 7:}

Who Should Purchase An AED? Other Explanations

\begin{tabular}{|l|}
\hline "both the institution and the athletics program" \\
"it is part of our equip. and training requirement, we are responsible for teaching all \\
coaches and GA personnel CPR \& First aid (required by our AD for Coaches) and we \\
teach the AED program in those sports that currently have AED's placed there" \\
"I feel that the athletic training program, athletic program and the institution should pay \\
for AEDs, because it mutually beneficial to all parties involved" \\
\hline "all the above" \\
$\begin{array}{l}\text { "Depends on the reason for using the device, if it is to be used for spectators that is the } \\
\text { responsibility of the athletic training department." }\end{array}$ \\
\hline "Public safety issue, primary usage will be for campus students and community."
\end{tabular}

Who Owns an AED?

Those programs that own an AED have done so for an average of 6.25 years, and purchased it for many reasons. Five programs have used them thus far, with four resulting in a death. AED ownership was predicted using Discriminate Function Analysis and the interval level criterion variables $(n=8)$. An important predictability level was set apriori as $70 \%$ of all cases. None of the individual variables met this level of importance. When combined, all of the variables resulted in a correct predictability equal to $71 \%$. When the number of athletes variable was removed, the correct predictability remained $71 \%$. When the number of cardiopulmonary emergencies variable was removed, the corrected predictability was $70 \%$, as it was when the number of facilities was removed. Yet the removal of two or more variables reduced the correct predictability to $69 \%$ or below. As 
seen in Table 6, the percentages remained in the high 60 range, but did not reach 70 . Thus we can conclude that the best way to predict AED ownership is by the use of all 8 variables or by removing the number of athletes variable.

\section{Null Hypothesis}

There will be no experimentally important or statistically consistent predictability of AED ownership utilizing relevant predictor variables.

The null hypothesis is rejected because there was important predictability of the AED ownership found.

\section{Recommendations for Future Research}

This research is for NCAA Division I schools only and is not generalizable to the entirety of Division I, nor to Division II or III. It is an option to target Division I schools again, focusing on the Districts that had the lowest response rates. Since the survey will not change, the data may be compared to the present data, but there has been a great deal of education, AED grants, and media coverage in the months since the start of the original data collection, so the data may be skewed by time passage. At the present time, the survey is being distributed to Division II and III institutions for completion. It will be interesting to see the differences between the three divisions.

A marketing scheme should be developed for the following target groups identified:

1) Those who think that the AED is extremely beneficial but do not own one. These are the programs that are willing to purchase an AED but are held back because of a barrier of some kind.

2) Those that think the AED is extremely beneficial, but would not purchase. 
3) Those who said that funding was a barrier but that they would purchase.

4) Those that can afford to purchase, but do not feel the need to.

This marketing scheme should build off of what is already in place within the NATA and NCAA Recommendations for AEDs in Collegiate Athletic Training Programs and include the AED manufacturers. A grant program should be put in place for the programs that want to purchase but do not have funds to do so. Ideally the survey should be conducted yearly to develop a trend pattern in purchasing and hopefully in use, changes in protocol, and changes in attitude regarding AED benefits in the case of a cardiopulmonary emergency.

\section{Conclusion}

This research provides a descriptive picture of the ownership and utilization of AEDs in Division I Collegiate Athletic Training Programs, but it also illustrates the underlying debate regarding AEDs. When predicating AED ownership, no single variable stood out as important, but when combined, all eight variables did show an important level of predictability ( $71 \%)$. Therefore, it may be concluded that the variables that predict AED ownership are extremely broad and do not exist singularly. For instance, the number of cardiopulmonary events in the past three years may not be an important variable alone, but when combined with the personal views of the Head Athletic Trainer, may become an extremely predictive factor. The views of the Head Athletic Trainer may be influenced by education, personal experiences, or even fear. These influences are hard to overcome, with the exception of education. Through education within the profession, and to the athletic departments and institutions, the predisposed ideas of AEDs may be reevaluated. 
There may be no clear predictive factor to AED ownership until they are required in every NCAA athletic training room. The NCAA and the NATA should use this research to educate ATCs and support future legislation for AEDs in collegiate athletic training programs. 


\section{Automated External Defibrillators (AEDs) In Collegiate Athletic Training Programs \\ Survey}


Survey website address:

http://www.soe.umt.edu/hhp/survey.php

Dipartment of Healtb and Human Performance

Automated External Defibrillators (AEDs) In Collegiate Athletic

Training Programs

Please Log In:

Note: Cookies must be enabled for this page.

User Name:

Password:

$\log$ In 


\section{Important: To be completed by the Head Certified Athletic Trainer only. No students please! Only one survey per institution please!}

Please answer all questions. Questions asking about numbers should be answered with integers (i.e.: "0" not " 0.5 " or "none"). Your responses are confidential, and no personal or identifying data will be collected.

Are you the Head Certified Athletic Trainer of your institution?
$r$ Yes
$r$ No

Begin Survey 


\section{Institution/Program Information}

NCAA Division Membership: IA $^{r}$ IAA ${ }^{r}$ IAAA $r$ II ${ }^{r}$ III $r$

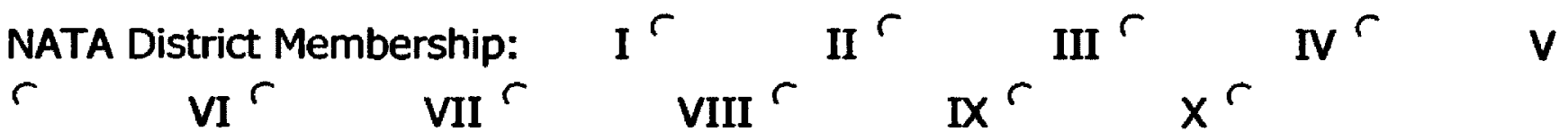

Is the athletic training room part of an accredited Athletic Training Education Program at the institution?
$r$ Yes
No

If applicable, what percentage of your time is spent as a clinical instructor for the athletic training education program? $\longdiv { 0 } \%$

$\Gamma$ I'm not a clinical instructor

Demographics (please complete)

Male ${ }^{r}$

Female $^{r}$

Years in the profession of athletic training: $\longdiv { 0 }$

Degrees earned?

Other credentials (i.e. EMT)

During the entire academic year, how many total athletes are in the athletic program? 0

How many separate athletic facilities, for both practice and competition, are used by the athletic program throughout the year? Please include practice fields, gymnasiums, stadiums, etc. even if they are used for only one sport. 0

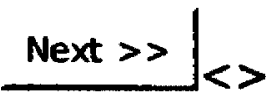




\section{Institution/Program Information, continued}

What certifications are required by the staff to work in the athletic training room with athletes? (Please check all that apply)

\begin{tabular}{|c|c|c|c|c|c|c|}
\hline Adult CPR & $\Gamma$ & $\begin{array}{l}\text { Sport Safety } \\
\text { Training }\end{array}$ & $\Gamma$ & $\begin{array}{l}\text { BLS } \\
\text { Healthcare } \\
\text { Provider }\end{array}$ & $\Gamma$ & $\begin{array}{l}\text { Other } \\
\text { (please } \\
\text { specify } \\
\text { below) }\end{array}$ \\
\hline $\begin{array}{l}\text { Adult } \\
\text { CPR/AED }\end{array}$ & $\Gamma$ & $\begin{array}{l}\text { CPR for the } \\
\text { Professional } \\
\text { Rescuer }\end{array}$ & $\Gamma$ & $\begin{array}{l}\text { Heartsaver } \\
\text { Facts AED/ } \\
\text { CPR }\end{array}$ & & \\
\hline $\begin{array}{l}\text { Emergency } \\
\text { Response }\end{array}$ & $r$ & $\begin{array}{l}\text { First Aid- } \\
\text { Responding to } \\
\text { Emergencies }\end{array}$ & $\Gamma$ & Basic First Aid & & \\
\hline
\end{tabular}

How many individuals on the athletic training room staff are currently certified as instructors in First Aid, CPR/AED, or other courses listed above? 0

Are you currently a certified instructor in First Aid, CPR/AED, and/or related courses?

$r$ Yes $r$ No

If YES, are you the primary instructor for the athletic training room staff in these courses?

$r$ Yes $r$ No (If you are not a certified instructor, select "No".) 


\section{Institution/Program Information, continued}

At which athletic events* is an EMT, paramedic, and/or emergency medical vehicle regularly on site? (Please check all that apply)

* NCAA EMT Paramedic Emergency EMT Paramedic Emergency

Sanctioned (Practices) (Practices) Medical (Competitions) (Competitions) Medical

Sports

Vehicle

(Practices)

Baseball

Basketball

Cross

Country

Fencing

Field

Hockey

Football

Golf

Gymnastics $\Gamma$

Ice Hockey $\Gamma$

Lacrosse

* NCAA

EMT
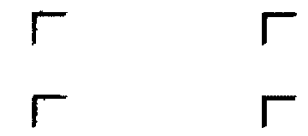

(

Vehicle

(Competitions)

Sanctioned (Practices) (Practices) Medical

Sports

Vehicle

(Practices)

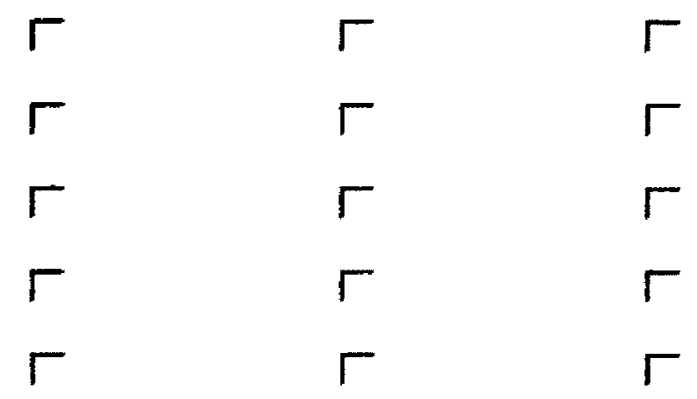

EMT Paramedic Emergency (Competitions) (Competitions) Medical

Vehicle

(Competitions) 


\begin{tabular}{|c|c|c|c|c|c|c|}
\hline Tennis & $\Gamma$ & $\Gamma$ & $\Gamma$ & $\Gamma$ & $\Gamma$ & $\Gamma$ \\
\hline Track/Field & $\Gamma$ & $\Gamma$ & $\Gamma$ & $\Gamma$ & $\Gamma$ & $\Gamma$ \\
\hline Volleyball & $\Gamma$ & $\Gamma$ & $\Gamma$ & $\Gamma$ & $\Gamma$ & $\Gamma$ \\
\hline Water Polo & $\Gamma$ & $\Gamma$ & $\Gamma$ & $\Gamma$ & $\Gamma$ & $\Gamma$ \\
\hline Wrestling & $\Gamma$ & $\Gamma$ & $\Gamma$ & $\Gamma$ & $\Gamma$ & $\Gamma$ \\
\hline Other & $\Gamma$ & $\Gamma$ & $\Gamma$ & $\Gamma$ & $\Gamma$ & $\Gamma$ \\
\hline $\begin{array}{l}* \text { NCAA } \\
\text { Sanctioned } \\
\text { Sports }\end{array}$ & $\begin{array}{c}\text { EMT } \\
\text { (Practices) }\end{array}$ & $\begin{array}{l}\text { Paramedic } \\
\text { (Practices) }\end{array}$ & $\begin{array}{c}\text { Emergency } \\
\text { Medical } \\
\text { Vehicle } \\
\text { (Practices) }\end{array}$ & $\begin{array}{c}\text { EMT } \\
\text { (Competitions) }\end{array}$ & $\begin{array}{c}\text { Paramedic } \\
\text { (Competitions) }\end{array}$ & $\begin{array}{c}\text { Emergency } \\
\text { Medical } \\
\text { Vehicle } \\
\text { (Competitions) }\end{array}$ \\
\hline
\end{tabular}




\section{Preparticipation Screenings}

Does the athletic training program have a preparticipation cardiovascular screening protocol in place for all of the incoming athletes?
$r$ Yes
$r$ No

What type of screening(s) do you regularly conduct? (Please check all that apply)
$\ulcorner$ Cardiac history $\Gamma$ questions ECG/EKG $\Gamma \quad$ Other (please specify below)
$\Gamma$ Heart auscultation $\Gamma$ Graded exercise test (GXT)
$\Gamma$ Echocardiagram $\Gamma$ Cardiorespiratory endurance tests $\left(\mathrm{VO}_{2 \max }\right.$, etc. $)$

Who conducts the preparticipation screenings?
$r$ Certified Athletic Training Staff
$\checkmark$ Certified and non-certified Athletic
Training Staff
$r$ Medical Staff and Certified Athletic Training Staff
$r$ Medical Staff $r$ Other

Is the above screening protocol conducted on all returning athletes (i.e. red-shirt freshmen) in addition to all incoming athletes (i.e. true freshmen, transfers)?
$r$ Yes
$r$ No 


\section{Cardiopulmonary Emergencies}

How many cardiopulmonary emergencies, if any, have you encountered in the past three (3) years?

0

Is this number

$r$ an estimate

or

$r$ a verified value?

If possible, please indicate in which group(s):

Athletes: 0

Coaches/Athletic Trainers/Staff: $\longdiv { 0 }$

Officials: 0

Spectators: $\sqrt{0}$

Other: (number) 0

Other: (Explain)

How many of the above cardiopulmonary emergencies, if any, resulted in death? 0

If possible, please indicate in which group(s):

Athletes: 0

Coaches/Athletic Trainers/Staff: $\longdiv { 0 }$

Officials: 0

Spectators: $\longdiv { 0 }$

Other: (number) 0

Other: (Explain) 


\section{Emergency Planning and AEDs}

Does the athletic training room have a protocol in place for the management of cardiopulmonary emergencies?

$r$ Formal Protocol $r$ Informal Protocol $r$ No Protocol

Does this protocol include the use of Automated External Defibrillators (AEDs) by the athletic training staff?

$r$ Yes $r$ No

How beneficial to do you believe an AED would be in the event of a cardiopulmonary arrest at your facility(s)?

$r$ Extremely beneficial $r$ Unsure $r$ Not beneficial at all

How many hours of training should an individual responder receive to responsibly administer treatment with an AED? 0

How many total AEDs do you have distributed among all your facilities?

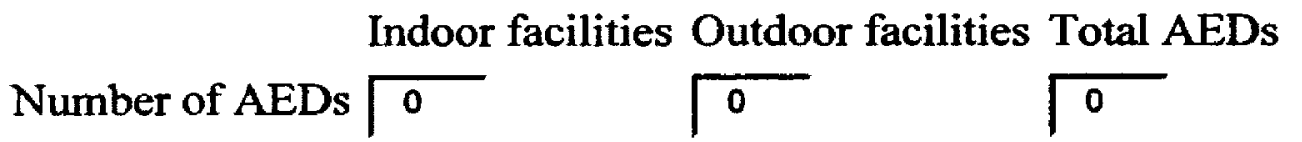

If you have fewer AEDs than you believe is necessary for your program, please check all that explain why:

$\Gamma$ Lack of funds

$\Gamma$ Lack of available training on proper use

$\Gamma$ Not in working order

$\ulcorner$ Other (please specify)

Would your program be willing to purchase an AED(s) in the future?
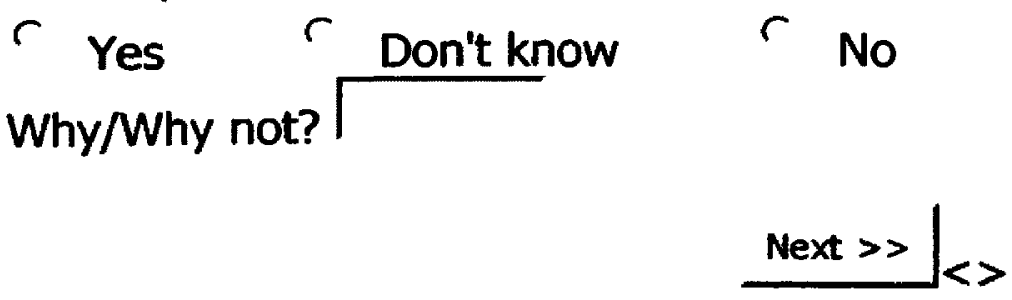


\section{Emergency Planning and AEDs, continued}

Who should be responsible for purchasing an AED?

$r$ The athletic training program

$r$ The Intercollegiate Athletics Program

$r$ The Institution

$r$ Other (explain)

Can your program afford to purchase an AED?
$r$
Yes
$r$
No

How much would the program be able to spend to purchase an AED? $\$ 0$ Next $>>\left.\right|_{<>}$ 


\section{Emergency Planning and AEDs, continued}

How many years ago did your program first purchase an AED? $\sqrt{0}$ years

If possible, please explain why an AED was purchased

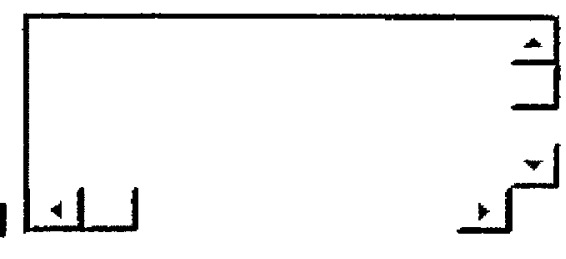

How many occasions in the past three years has the athletic training staff used an AED on an individual in cardiopulmonary arrest? 0

If possible, please indicate in which group(s):

Athletes: 0

Coaches/Athletic Trainers/Staff: 0

Officials: 0

Spectators: $\longdiv { 0 }$

Other: (number) $\longdiv { 0 }$

Other: (Explain)

How many of these occasions resulted in death? 0

If possible, please indicate in which group(s):

Athletes: 0

Coaches/Athletic Trainers/Staff: 0

Officials: 0

Spectators: 0

Other: (number) $\longdiv { 0 }$

Other: (Explain)

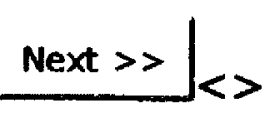


Thank you for your participation! Your answers have been recorded.

If you have any questions or concerns regarding this survey and how this data will be used, please contact Starr Wharton at starr.wharton@

If you wish, you may enter your e-mail address below, to be removed from our "reminder" mailing list. Your e-mail address will not be associated with your survey answers in any way. All survey replies are fully confidential.

Health \& Human Performance at UM-Missoula

The e-mail address to which the survey URL was sent:

Please remove me! 


\section{APPENDIX A}

\section{Summary Data Tables}




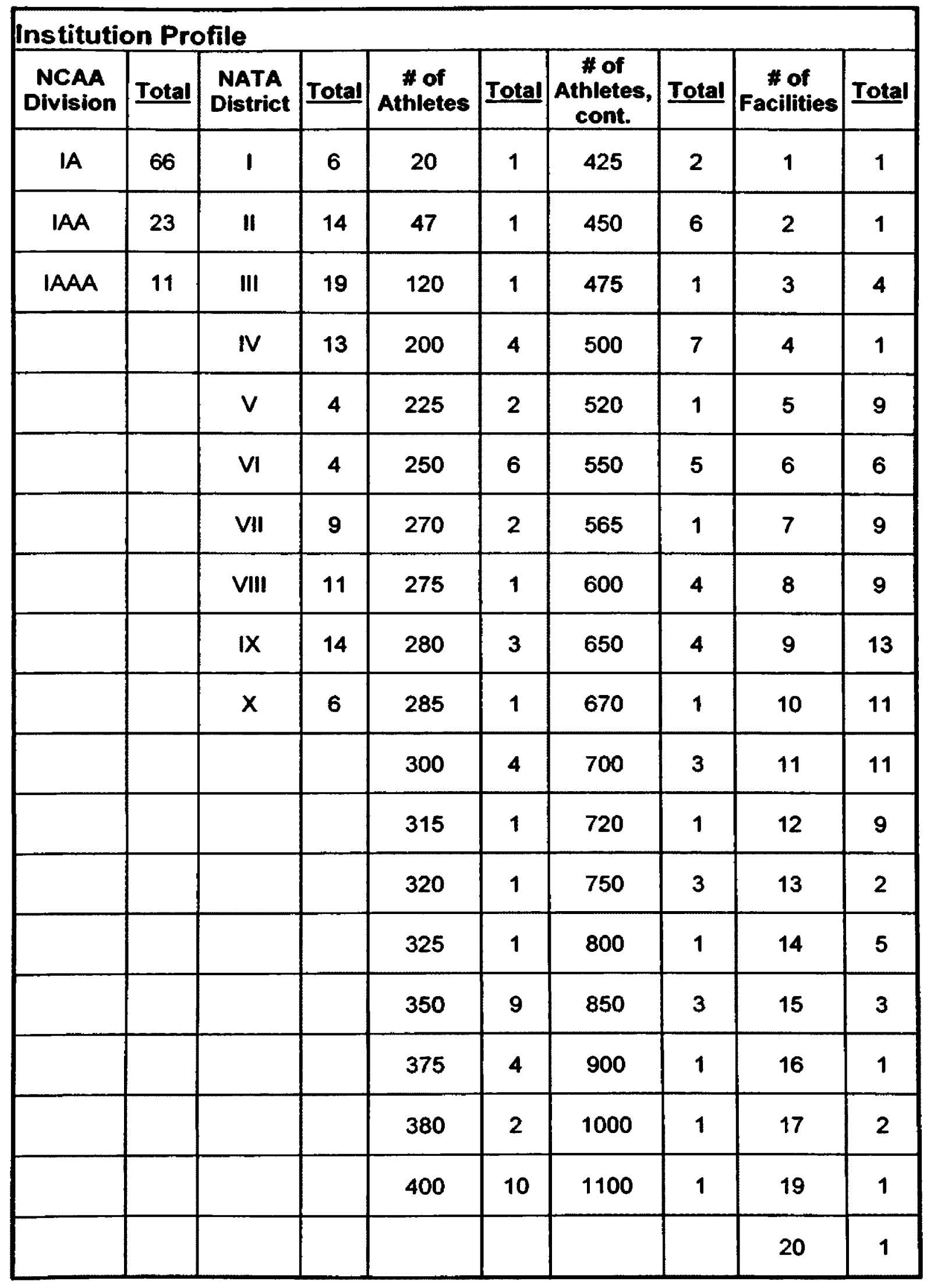




\begin{tabular}{|c|c|c|c|c|c|c|c|}
\hline \multicolumn{8}{|c|}{ Head ATC Profile } \\
\hline $\begin{array}{l}\text { Highest } \\
\text { Degree } \\
\text { earned } \\
\end{array}$ & Total & $\begin{array}{c}\text { Add'i } \\
\text { Credentials } \\
\text { listed }\end{array}$ & Total & Gender & Total & $\begin{array}{c}\text { Yrs in } \\
\text { Profession }\end{array}$ & Total \\
\hline Bach & 14 & ATC & 1 & Male & 80 & 4 & 1 \\
\hline Master's & 83 & BLS inst & 1 & Female & 20 & 5 & 6 \\
\hline \multirow[t]{28}{*}{ PhD } & 3 & CAT & 1 & & & 6 & 3 \\
\hline & & CPT & 1 & & & 7 & 1 \\
\hline & & $\operatorname{cscs}$ & 9 & & & 8 & 2 \\
\hline & & EMT & 3 & & & 9 & 2 \\
\hline & & LAT & 6 & & & 10 & 8 \\
\hline & & OT & 1 & & & 11 & 2 \\
\hline & & OTC & 1 & & & 12 & 4 \\
\hline & & PT & 9 & & & 13 & 8 \\
\hline & & PTA & 1 & & & 14 & 1 \\
\hline & & SCS & 1 & & & 15 & 2 \\
\hline & & SFR & 1 & & & 16 & 1 \\
\hline & & Teacher & 1 & & & 17 & 1 \\
\hline & & & & & & 18 & 5 \\
\hline & & & & & & 19 & 1 \\
\hline & & & & & & 20 & 4 \\
\hline & & & & & & 21 & 6 \\
\hline & & & & & & 22 & 2 \\
\hline & & & & & & 23 & 2 \\
\hline & & & & & & 24 & 5 \\
\hline & & & & & & 25 & 4 \\
\hline & & & & & & 26 & 6 \\
\hline & & & & & & 27 & 1 \\
\hline & & & & & & 28 & 6 \\
\hline & & & & & & 29 & 7 \\
\hline & & & & & & 30 & 4 \\
\hline & & & & & & 31 & 1 \\
\hline & & & & & & 33 & 3 \\
\hline & & & & & & 34 & 1 \\
\hline
\end{tabular}


Head ATC Profile, Continued

\begin{tabular}{|c|c|c|c|}
\hline $\begin{array}{c}\text { Head ATC } \\
\text { CPR/AED/FA } \\
\text { Instructor }\end{array}$ & Total & $\begin{array}{c}\text { Head ATC primary } \\
\text { instructor for } \\
\text { program }\end{array}$ & Total \\
\hline No & 67 & No & 100 \\
\hline Yes & 33 & Yes & 0 \\
\hline
\end{tabular}

\begin{tabular}{|c|c|c|c|c|c|}
\hline \multicolumn{1}{|c|}{ Athletic Training Program Profile } \\
\hline $\begin{array}{c}\text { CAAHEP } \\
\text { Program }\end{array}$ & Total & $\begin{array}{c}\text { Clinical Inst in } \\
\text { Program }\end{array}$ & Total & Hrs outreach & Total \\
\hline No & 57 & No & 61 & 0 hrs & 100 \\
\hline Yes & 43 & Yes & 39 & & \\
\hline
\end{tabular}

\begin{tabular}{|c|c|c|c|c|c|}
\hline \multicolumn{2}{|c|}{ Preparticipation Screening Profile } \\
\hline $\begin{array}{c}\text { Does the program have a } \\
\text { Preparticipation } \\
\text { Screening Protocol? }\end{array}$ & Total & $\begin{array}{c}\text { Screen all } \\
\text { returning } \\
\text { athletes in } \\
\text { addition to } \\
\text { incoming? }\end{array}$ & Total & $\begin{array}{c}\text { Who does } \\
\text { screenings }\end{array}$ & Total \\
\hline No & 25 & No & 50 & Cert. AT Staff & 10 \\
\hline Yes & 75 & Yes & 50 & $\begin{array}{c}\text { Cert. \& non-cert. } \\
\text { AT Staff }\end{array}$ & 1 \\
\hline & & & & $\begin{array}{c}\text { Medical Staff \& } \\
\text { cert. AT Staff }\end{array}$ & 61 \\
\hline & & & & Medical Staff & 26 \\
\hline
\end{tabular}




\begin{tabular}{|c|c|c|c|c|c|c|c|c|c|c|c|}
\hline \multicolumn{8}{|c|}{ Preparticipation Screening Profile cont. Screenings Conducted } \\
\hline $\begin{array}{c}\text { History } \\
\text { Questions }\end{array}$ & Total & $\begin{array}{c}\text { Heart } \\
\text { Ausc. }\end{array}$ & Total & Echo & Total & ECG & Total & GXT & Total & $\begin{array}{c}\text { Vo2 } \\
\text { max }\end{array}$ & Total \\
\hline No & 13 & No & 38 & No & 95 & No & 93 & No & 100 & No & 100 \\
\hline Yes & 87 & Yes & 62 & Yes & 5 & Yes & 7 & Yes & 0 & Yes & 0 \\
\hline
\end{tabular}

\begin{tabular}{|c|c|c|}
\hline \multicolumn{3}{|c|}{ Screenings Conducted, cont } \\
\hline $\begin{array}{c}\text { Other } \\
\text { screening }\end{array}$ & Total & $\begin{array}{c}\text { Other } \\
\text { describe }\end{array}$ \\
\hline No & 95 & Athletic Physical \\
\hline \multirow[t]{6}{*}{ Yes } & 5 & $\begin{array}{c}\text { Cardiologist on site for any red flagged } \\
\text { athletes }\end{array}$ \\
\hline & & physicals from personal physician \\
\hline & & pulse, BP \\
\hline & & $\begin{array}{l}\text { EKG and echo on all murmurs or positive } \\
\text { cardiac } \mathrm{Hx}\end{array}$ \\
\hline & & Echo if warranted by other testing \\
\hline & & echo for MBB only \\
\hline
\end{tabular}




\begin{tabular}{|c|c|c|c|c|c|}
\hline \multicolumn{2}{|c|}{ Cardio-Pulmonary Emergencies Profile } \\
\hline $\begin{array}{c}\text { \# CP Emergencies in } \\
\text { last 3 years }\end{array}$ & Total & $\begin{array}{c}\text { is that \# Verified } \\
\text { or an Estimate? }\end{array}$ & Total & $\begin{array}{c}\text { Level of } \\
\text { Protocol for } \\
\text { Management } \\
\text { of CP } \\
\text { emergencies }\end{array}$ & Total \\
\hline 0 & 71 & Estimate & 38 & No Protocol & 11 \\
\hline 1 & 17 & Verified & 62 & Informal & 20 \\
\hline 2 & 6 & & & Formal & 69 \\
\hline 3 & 3 & & & & \\
\hline 4 & 1 & & & & \\
\hline 5 & 1 & & & & \\
\hline
\end{tabular}




\begin{tabular}{|c|c|c|c|c|c|c|}
\hline \multicolumn{7}{|c|}{ Cardio-Pulmonary Emergencies Profile, cont. By Demographic } \\
\hline \multicolumn{7}{|c|}{ \# Cardiopulmonary Emergencies in Past 3 Years } \\
\hline $\begin{array}{c}\# \\
\text { Events }\end{array}$ & Athletes & Spectators & $\begin{array}{c}\text { Coaches } \\
\text { Trainers } \\
\text { /Staff }\end{array}$ & Officials & Other & Other Explanation \\
\hline 0 & 87 & 91 & 96 & 97 & 93 & $\begin{array}{l}\text { housekeeping employee in } \\
\text { the Dept. }\end{array}$ \\
\hline 1 & 8 & 4 & 3 & 3 & 6 & rec person in building \\
\hline 2 & 4 & 3 & 1 & & 1 & recreational athlete \\
\hline 3 & 1 & 1 & & & & university professor \\
\hline \multirow[t]{4}{*}{12} & & 1 & & & & $\begin{array}{l}\text { elderly walkers using the } \\
\text { indoor track in the indoor } \\
\text { facility }\end{array}$ \\
\hline & & & & & & tryout \\
\hline & & & & & & educator \\
\hline & & & & & & Non NCAA visiting athlete \\
\hline \multicolumn{7}{|c|}{ \# Cardiopulmonary Deaths in Past 3 Years } \\
\hline \# Deaths & Athletes & Spectators & $\begin{array}{c}\text { Coaches } \\
\text { Trainers } \\
\text { /Staff }\end{array}$ & Officials & Other & Other Explanation \\
\hline 0 & 86 & 86 & 88 & 89 & 85 & $\begin{array}{l}\text { Understand individual did } \\
\text { not have shockable rhythm }\end{array}$ \\
\hline 1 & 4 & 4 & 2 & 1 & 5 & tryout \\
\hline 2 & 1 & 1 & 1 & 1 & 1 & \\
\hline 3 & 1 & 1 & 1 & 1 & 1 & \\
\hline
\end{tabular}




\begin{tabular}{|c|c|c|c|c|c|c|c|}
\hline \multicolumn{8}{|c|}{ Automated External Defibrillator (AED) Profile } \\
\hline $\begin{array}{l}\text { AED included } \\
\text { in Protocol? }\end{array}$ & Total & $\begin{array}{l}\text { AED beneficial } \\
\text { in CP } \\
\text { emergency? }\end{array}$ & Total & $\begin{array}{l}\text { \# Hours } \\
\text { required } \\
\text { for AED } \\
\text { training }\end{array}$ & Total & $\begin{array}{l}\text { Total \# } \\
\text { AEDS } \\
\text { owned }\end{array}$ & Total \\
\hline No & 22 & No & 10 & 0 & 14 & 0 & 21 \\
\hline \multirow[t]{12}{*}{ Yes } & 78 & Unsure & 7 & 1 & 28 & 1 & 9 \\
\hline & & Yes & 83 & 2 & 14 & 2 & 21 \\
\hline & & & & 3 & 12 & 3 & 12 \\
\hline & & & & 4 & 21 & 4 & 10 \\
\hline & & & & 5 & 5 & 5 & 9 \\
\hline & & & & 6 & 2 & 6 & 4 \\
\hline & & & & 8 & 2 & 7 & 5 \\
\hline & & & & 10 & 2 & 8 & 2 \\
\hline & & & & & & 9 & 3 \\
\hline & & & & & & 10 & 1 \\
\hline & & & & & & 12 & 2 \\
\hline & & & & & & 13 & 1 \\
\hline
\end{tabular}

\begin{tabular}{|c|c|c|c|c|c|c|c|}
\hline \multicolumn{7}{|c|}{ Automated External Defibrillator (AED) Profile Barriers } \\
\hline $\begin{array}{c}\text { Funds a } \\
\text { Barrier? }\end{array}$ & Total & $\begin{array}{c}\text { Training } \\
\text { Barrier? }\end{array}$ & Total & $\begin{array}{c}\text { Working } \\
\text { order } \\
\text { Barrier? }\end{array}$ & Total & $\begin{array}{c}\text { Other } \\
\text { Barriers? }\end{array}$ & Total \\
\hline No & 49 & No & 98 & No & 100 & No & 94 \\
\hline Yes & 51 & Yes & 2 & Yes & 0 & Yes & 9 \\
\hline
\end{tabular}


Automated External Defibrillator (AED) Profile Barriers, explained

Convince administration that we need more lack of understanding by the decision at different facilities makers

we have number we feel necessary to cover our sports

AEDs are placed in our university police cars with a response time of under $2 \mathrm{~min}$. If we didn't do it this way we would need an AED for each of our 19 sports because if it was with $F B$ and $S B$ needed it the response time would be longer than 2 minutes.

We do not have AED at each facility, our campus police have in every squad car, and are notified first with our emergency need to budget action plan.

\begin{tabular}{|c|c|c|c|c|c|}
\hline \multicolumn{6}{|c|}{ Automated External Defibrillator (AED) Profile Purchasing Afford } \\
\hline $\begin{array}{c}\text { Can you afford to } \\
\text { buy an AED? }\end{array}$ & Total & $\begin{array}{c}\text { How much can } \\
\text { you afford? } \\
\text { (US Dollars) }\end{array}$ & Total & $\begin{array}{c}\text { How much can } \\
\text { you afford? } \\
\text { (US Dollars) } \\
\text { cont. }\end{array}$ & Total \\
\hline No & 48 & 0 & 43 & 2400 & 1 \\
\hline Yes & 52 & 200 & 0 & 2500 & 8 \\
\hline & & 250 & 1 & 2800 & 1 \\
\hline & 500 & 3 & 3000 & 8 \\
\hline & 1000 & 3 & 3500 & 4 \\
\hline & 1500 & 4 & 4000 & 2 \\
\hline & & 1600 & 1 & 5000 & 5 \\
\hline & & 1700 & 1 & 20000 & 1 \\
\hline & & 1900 & 1 & 25000 & 1 \\
\hline
\end{tabular}




\begin{tabular}{|c|c|c|}
\hline \multicolumn{3}{|c|}{ Automated External Defibrillator (AED) Profile Purchasing } \\
\hline $\begin{array}{l}\text { Would you purchase an } \\
\text { AED? }\end{array}$ & Total & WhyMhy not Purchase? \\
\hline No & 19 & large number of venue sites \\
\hline Unsure & 14 & We feel we have sufficient units at this time \\
\hline \multirow[t]{21}{*}{ Yes } & 67 & Would like to purchase 10 more \\
\hline & & we have number necessary to cover our sports \\
\hline & & Already have 6 \\
\hline & & funds available \\
\hline & & $\begin{array}{l}\text { To continue proper medical equipment necessary to provide } \\
\text { proper medical accessibility }\end{array}$ \\
\hline & & $\begin{array}{l}\text { To provide additional medical equipment accessibility in } \\
\text { case of an emergency }\end{array}$ \\
\hline & & have plenty \\
\hline & & $\begin{array}{l}\text { The efficacy of having them in our squad cars has proven } \\
\text { sufficient thus far. }\end{array}$ \\
\hline & & risk mgmt \\
\hline & & $\begin{array}{l}\text { may purchase additional units due to scheduling changes in } \\
\text { facilities }\end{array}$ \\
\hline & & $\begin{array}{l}\text { Have } 2 \text { permanently installed, and } 2 \text { floaters for events. } \\
\text { Donl't know about additional need, Cardiac death was prior } \\
\text { to having EAD program }\end{array}$ \\
\hline & & Security \\
\hline & & We have one already \\
\hline & & we are on 5 year plan \\
\hline & & To have at more sites \\
\hline & & we just purchased new AEDI's \\
\hline & & As need arises \\
\hline & & Possibly decrease risk of death \\
\hline & & $\begin{array}{l}\text { The expense will be larger and still would not offer better } \\
\text { response than we have now. At events the police have at } \\
\text { least one on site. }\end{array}$ \\
\hline & & need the funds \\
\hline & & Funding? \\
\hline
\end{tabular}




\section{Automated External Defibrillator (AED) Profile Purchasing Why/Why not Purchase, cont.}

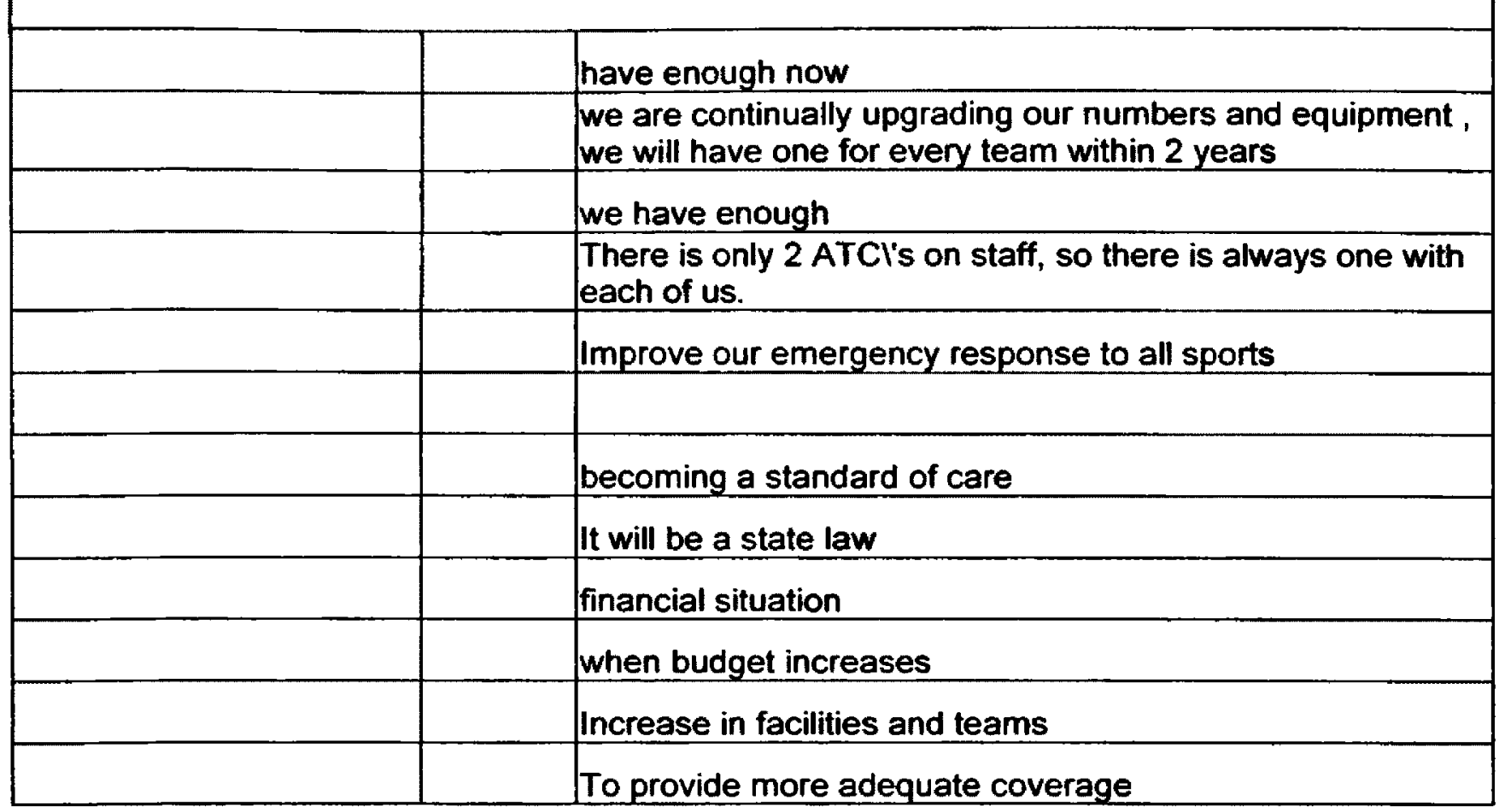

\begin{tabular}{|c|c|c|}
\hline \multicolumn{3}{|c|}{ Automated External Defibrillator (AED) Profile - Purchasing, cont. } \\
\hline $\begin{array}{l}\text { Who should be } \\
\text { responsible for } \\
\text { purchasing? }\end{array}$ & Total & Other, Explain \\
\hline Athletic Training Program & 19 & both the institution and the athletics program \\
\hline $\begin{array}{l}\text { Intercollegiate Athletics } \\
\text { Program }\end{array}$ & 39 & $\begin{array}{l}\text { it is part of our equip. and training requirement, we } \\
\text { are responsible for teaching all coaches and GA } \\
\text { personnel CPR \& First aid (required by our AD for } \\
\text { Coaches) and we teach the AED program in those } \\
\text { sports that currently have AEDI's placed there }\end{array}$ \\
\hline Institution & 38 & $\begin{array}{l}\text { Ifeel that the athletic training program, athletic } \\
\text { program and the institution should pay for AEDs, } \\
\text { because it it mutually beneficial to all parties } \\
\text { involved }\end{array}$ \\
\hline \multirow[t]{3}{*}{ Other (Explain) } & 4 & all the above \\
\hline & & $\begin{array}{l}\text { Depends on the reason for using the device, if it is } \\
\text { to be used for spectators that is the Athletic Dept's } \\
\text { responsibility. For treating athletic emergencies it } \\
\text { should be the responsibility of the athletic training } \\
\text { department. }\end{array}$ \\
\hline & & $\begin{array}{l}\text { Public safety issue, primary usage will be for } \\
\text { campus students and community. }\end{array}$ \\
\hline
\end{tabular}




\begin{tabular}{|c|c|c|c|}
\hline \multicolumn{4}{|c|}{ Automated External Defibrillator (AED) Profile How long \& why purchased? } \\
\hline $\begin{array}{c}\text { Number } \\
\text { Yrs had } \\
\text { AED } \\
\end{array}$ & Total & Why did you buy it? & Why did you buy it? cont. \\
\hline 0 & 39 & $\begin{array}{l}\text { Student Athlete transferred with heart } \\
\text { condition. }\end{array}$ & Funded through a grant \\
\hline 1 & 9 & $\begin{array}{l}\text { itl's basic equipment every AT dept } \\
\text { should have }\end{array}$ & $\begin{array}{l}\text { Perceived need, high profile incident at } \\
\text { neighboring college finally pushed approval } \\
\text { over the edge }\end{array}$ \\
\hline 2 & 16 & $\begin{array}{l}\text { safety reasons for each of our main } \\
\text { facilities }\end{array}$ & $\begin{array}{l}\text { All campus police cars have AED on our } \\
\text { campus but do to large size of campus we } \\
\text { chose to use fundraising money to purchase } \\
\text { AED for faster response time in athletic } \\
\text { venues }\end{array}$ \\
\hline 3 & 21 & To have in case of an emergency arose. & Liability issues for not having one \\
\hline 4 & 8 & $\begin{array}{l}\text { To provide state of the art cardiac } \\
\text { equipment for our athletes as well as } \\
\text { spectators at our athletic events and } \\
\text { practices that has proven to save lives. } \\
\text { Our Risk Management office endorses } \\
\text { the purchases as more Departments are } \\
\text { purchasing them as well as being utilized } \\
\text { by our campus police. }\end{array}$ & $\begin{array}{l}\text { Illinois Heart and Lung in town worked with the } \\
\text { University }\end{array}$ \\
\hline 5 & 2 & Paid for by stadium expansion & For the health and safety of our athletes \\
\hline 6 & 2 & $\begin{array}{l}\text { Needed to bring our emergency action } \\
\text { plans up to NCAA recommendations }\end{array}$ & $\begin{array}{l}\text { The need to have the best equipment } \\
\text { available for the athletes and their safety. }\end{array}$ \\
\hline 7 & 1 & $\begin{array}{l}\text { Following the death of a male lacrosse } \\
\text { player whol's heart stopped after getting } \\
\text { hit on the chest. }\end{array}$ & possibility of cardiac insult is high in our area \\
\hline 8 & 1 & $\begin{array}{l}\text { Make sure we had the proper equipment } \\
\text { needed in case of cardiac event }\end{array}$ & Booster purchased \\
\hline \multirow[t]{2}{*}{9} & 1 & $\begin{array}{l}\text { To provide proper medical equipment } \\
\text { accessibility for our students and } \\
\text { student-athletes. }\end{array}$ & safety. \\
\hline & & $\begin{array}{l}\text { To provide proper medical equipment } \\
\text { accessibility to anyone with an medical } \\
\text { emergency }\end{array}$ & liability \\
\hline
\end{tabular}




\begin{tabular}{|c|c|c|c|}
\hline \multicolumn{4}{|c|}{ Automated External Defibrillator (AED) Profile Why purchased, cont. } \\
\hline & & $\begin{array}{l}\text { risk mgmt } \\
\text { staff w cardiac hx }\end{array}$ & $\begin{array}{l}\text { It is becoming a standard of care in treating } \\
\text { cardiovascular emergencies, and we felt that } \\
\text { we were at risk legally if we did not include } \\
\text { them as part of our program. }\end{array}$ \\
\hline & & $\begin{array}{l}\text { I think it is going to be the standard of } \\
\text { care shortly for all athletic events and } \\
\text { staffs. }\end{array}$ & In the event of a cardiac emergency \\
\hline & & $\begin{array}{l}\text { Saw the need based on literature and in } \\
\text { discussion with staff and team physician. }\end{array}$ & $\begin{array}{l}\text { Public safety purchased on our campus for } \\
\text { police, IA, Campus rec, and several other } \\
\text { facility }\end{array}$ \\
\hline & & $\begin{array}{l}\text { Started at the institution level and the } \\
\text { athletic department was brought in to see } \\
\text { how they would be best utilized on } \\
\text { campus. }\end{array}$ & $\begin{array}{l}\text { We had a player who had unexplained } \\
\text { episodes of chest pain. }\end{array}$ \\
\hline & & $\begin{array}{l}\text { Because we feel that increase the } \\
\text { chance of survival }\end{array}$ & Discussed for a long time, semi at risk athlete. \\
\hline & & Basketball player with cardiac pathology & $\begin{array}{l}\text { camp with an athlete with a known heart } \\
\text { condition. Two university employees dies of } \\
\text { sudden cardiac arrest on campus. }\end{array}$ \\
\hline & & need & $\begin{array}{l}\text { athletic training education program wanted it } \\
\text { on site }\end{array}$ \\
\hline & & $\begin{array}{l}\text { To have in the athletic training room, } \\
\text { student health center and in the campus } \\
\text { police cars. }\end{array}$ & $\begin{array}{l}\text { Team Physician wanted AEDs for } \\
\text { precautionary reasons }\end{array}$ \\
\hline & & Felt it was needed. & $\begin{array}{l}\text { Due to a myocardial infarction suffered by a } \\
\text { university professor. }\end{array}$ \\
\hline & & for athletic dept. & for an athlete with an known problem \\
\hline & & $\begin{array}{l}\text { cover facilities on campus where } \\
\text { exercise takes place } \\
\text { stadium, fieldhouse, rec center, knpe } \\
\text { building }\end{array}$ & $\begin{array}{l}\text { They were not purchased. They were donated } \\
\text { to the athletics dept as part of a study of } \\
\text { effectiveness }\end{array}$ \\
\hline & & $\begin{array}{l}\text { delivery of highest quality of emergency } \\
\text { care; rural area with decreased EMS } \\
\text { response times }\end{array}$ & \\
\hline
\end{tabular}




\begin{tabular}{|c|c|l|l|}
\hline \multicolumn{2}{|c|}{ Automated External Defibrillator (AED) Use Profile } \\
\hline $\begin{array}{c}\text { How many times } \\
\text { has the AED been } \\
\text { used in past 3 } \\
\text { yrs? }\end{array}$ & Total & $\begin{array}{c}\text { \# times AED was used by } \\
\text { demographic }\end{array}$ & $\begin{array}{c}\text { \# Deaths when AED was } \\
\text { used by demographic }\end{array}$ \\
\hline 0 & 95 & $\begin{array}{l}\text { Athletes = 1 time @ one } \\
\text { school }\end{array}$ & Athletes =1 @ one school \\
\hline 1 & 4 & $\begin{array}{l}\text { Coaches, Trainers, Staff }= \\
\text { none }\end{array}$ & $\begin{array}{l}\text { Coaches, Trainers, Staff }= \\
\text { none }\end{array}$ \\
\hline 2 & 1 & $\begin{array}{l}\text { Officials = 1 time at one } \\
\text { school }\end{array}$ & Officials = none \\
\hline & & $\begin{array}{l}\text { Spectators = 2 times at one } \\
\text { school }\end{array}$ & Spectators = none \\
\hline
\end{tabular}




\section{REFERENCES}




\section{REFERENCES}

American College of Sports Medicine (ACSM). ACSM encourages young athletes to avoid Ephedra. http://www.acsm.org/publications/newreleases2003/. 13 March 2003.

Alexander RE. The automated external defibrillator: lifesaving device for medical emergencies. J Am Dent Assoc. 1999 Jun;130(6):837-45.

Alves PM, de Freitas EJ, Mathias HA, de Motta AE, Silva Re C, Muller M, Almeida SF, Stapleton E, Timerman S, Ramines JA. Use of automated external defibrillators in a Brazilian airline. A 1-year experience. Arq Bras Cardiol. 2001 Apr;76(4):310-4.

American Heart Association. 2000 heart and stroke statistical update. Dallas: American Heart Association, 2000.

American Heart Association. American Heart Association applauds Senate for completing double-play of life-saving measures. http://www.americanheart.org/advocacynews. 2002 Feb 7.

American Heart Association. Statistical fact sheet: sudden deaths from cardiac arrest. http://www.americanheart.org. 2003.

American Red Cross. AED key messages: communicator's kit for sudden cardiac arrest and public access defibrillation. http://.corpweb.redcross.org/hss/aed/aedcomm.htm. 2002 Jun 12.

American Red Cross. AED legislation update. http://corpweb.redcross.org/hss/aed/aedcomm.htm. 2001 Jun 12.

American Red Cross. Status of state legislation 2002. http://corpweb.redcross.org/hss/aed/aedcomm.htm. 2003 May 1.

Amith G. Revising educational requirements: challenging four hours for both basic life support and automated external defibrillators. New Horiz. 1997 May;5(2):167-72.

Anderson JC, Courson RW, Kleiner DM, McLodas TA. National Athletic Trainer's Association position statement: emergency planning in athletics. $J$ Ath Training. 2002 March;37(1):99-104.

Arias E, Smith BL. National Vital Statistics Report: 2001 Preliminary Data. Centers for Disease Control and Prevention. 2003 Mar 14;51(5): http://www.cdc.gov/nchs/faststats/deaths.htm. 
ATC saves life of co-worker. National Athletic Trainers' Association Press Release. 2002 May 30.

Atkins DL, Hartley LL, York DK. Accurate recognition and effective treatment of ventricular fibrillation by automated external defibrillators in adolescents. Pediatrics. 1998 Mar;101(3 Pt 1):393-7.

Automated external defibrillators: discussion. $N$ Eng $J$ Med. 2001 Mar 8;344(10):771-3.

Balady GJ, Chaitman B, Foster C, Froelicher E, Gordon N, Van Camp S. Automated external defibrillators in health/fitness facilities: supplement to the AHA/ACSM recommendation for cardiovascular screening, staffing, and emergency policies at health/fitness facilities. [AHA/ACSM Scientific Statement]. Circulation. 2002 March 5;105(9):1147-50. (printed concurrently in Medicine \& Science in Sports \& Exercise, 2002 Mar 1;34:561-4)

Basilico FC. Cardiovascular diseases in athletes. Am J Sports Med. 1999 Jan Feb;27(1):108-21.

Basso C, Corrado D, Thiene G. Cardiovascular causes of sudden death in young individuals including athletes. Cardiol Rev. 1999 May-Jun;7(3):127-35.

Basso C, Maron BJ, Corrado D, Thiene G. Clinical profile of congenital coronary artery anomalies with origin from the wrong aortic sinus leading to sudden death in young competitive athletes. J Am Coll Cardiol. 2000 May;35(6):1493-501.

Becker L, Eisenberg M, Fahrenbruch C, Cobb L. Cardiac arrest in medical and dental practices: implications for automated external defibrillators. Arch Intern Med. $2001 \mathrm{Jul} 25 ; 161(12): 1509-12$.

Berry G. Update on CPR and emergency cardiac care. JAAPA. 2001 Dec;12:18-21.

Blovin D, Topping C, Moore S, Stiell I, Afilalo M. Out-of-hospital defibrillation with AEDs:post-shock analysis should be delayaed. Ann Emerg Med. 2001 Sep;38(3):278-81.

Blue JG, Pecci MA. The collapsed athlete. Orthop Clin North Am. 2002 Jul;33(3):471-8.

Boraita Perez A, Serratosa Fernandez L. [Sudden death (IV). Sudden death in the athlete. The minimal requirements before performing a competitive sport]. Rev Esp Cardiol. 1999 Dec;52(12):1139-45.

Braunwald E. Cardiovascular medicine at the turn of the millennium: triumphs, concerns, and opportunities: Shattuck Lecture. NEJM. 1997 Nov 6;337(19): 1360-9. 
Brown J, Kellermann AL. The shocking truth about automated external defibrillators. $J A M A$. 2000 Sep 20;284(11):1438-41.

Caffrey SL, Willoughby PJ, Pepe PE, Becker LB. Public use of automated external defibrillators. NEJM. 2002 Oct 17;347(16):1242-7.

Calle PA, Monsieurs KG, Buylaert WA. Equivalence of the standard monophasic waveform shocks delivered by automated external defibrillator? Resuscitation. 2002 Apr;53(1):41-6.

Calle PA, Monsieurs KG, Buylaert WA. Unreliable post event report from an automated external defibrillator. Resuscitation. 2001 Sep;50(3):357-61.

Cantwell JD. Preparticipation physical evaluation: getting to the heart of the matter. Med Sci Sports Exerc. 1998 Oct;30(10 Suppl):S341-4.

Carek PJ, Futrell M. Athlete's view of the preparticipation physical examination. Attitudes towards certain health screening questions. Arch Fam Med. 1999 JulAug;8(4):307-12.

Carek PJ, Mainous AG $3^{\text {rd }}$. Editorial: Preparticipation cardiovascular screening for young athletes. JAMA. 2000 Aug 23-30;284(8):957-8

Cardiac Arrest Survival Act of 2000. Public Law 106-505 Sec. 401-404.

Chmelynski C. At the heart of defibrillation. The Education Digest. 2002 Oct;68(2):54-7.

Claessens P, Claessens C, Claessens M, Henderieckx J, Claessens J. Physiological or pseudophysiological ECG changes in endurance-trained athletes. Heart Vessels. 2000;15(4):181-90.

Citizen CPR. http://www.citizencpr.org. 2003.

Cobb LA, Fahrenbruch CD, Walsh TR, Copass MK, Olsufka M, Breskin M, Hallstrom AD. Influence of cardiopulmonary resuscitation prior to defibrillation in patients with out-of- hospital ventricular fibrillation. JAMA. 1999 Apr 7;281(13):1182-8.

Community Access to Emergency Defibrillation Act of 2001. Congressional RecordSenate. S1275. July 31, 2001.

Corrado D, Basso C, Buja G, Nava A, Rossi L, Thiene G. Right bundle branch block, right precordial st-segment elevation, and sudden death in young people.

Circulation. 2001 Feb 6;103(5):710-7 
Corrado D, Basso C, Nava A, Thiene G. Arrhythmogenic right ventricular cardiomyopathy: current diagnostic and management strategies. Cardiol Rev. 2001 Sep-Oct;9(5):259-65.

Courson R. University of Georgia sports medicine automated external defibrillator policies and procedures. Revised 11/12/2001.

Coward B. Automated external defibrillators used in the community. Home Health Nurse. 2000 Oct;18(9):615-9.

Cummins RO. Emergency medical services and sudden cardiac arrest: the "chain of survival" concept. Annu Rev Public Health. 1993;14:313-33.

Cummins RO. From concept to standard-of-care? Review of the clinical experience with automated external defibrillators. Ann Emerg Med. 1989 Dec;18(12):1269-75.

Cummins RO. The "chain of survival" concept: how it can save lives. Heart Dis Stroke. 1992 Jan-Feb;1(1):43-5.

Cummins RO, Theis W. Encouraging early defibrillation: the American Heart Association and automated external defibrillators. Ann Emerg Med. 1990 Nov;19(11):1245-8.

Davies CS, Colquhoun M, Graham S, Evans T, Chamberlain D. Defibrillation in public places: the introduction of a national scheme for public access defibrillation in England. Resuscitation. 2002 Jan;52(1):13-21.

Deady B, Innes G. Sudden death of a young hockey player: case report of commotio cordis. J Emerg Med. 1999 May-Jun;17(3):459-62.

Drezner JA. Sudden cardiac death in young athletes. Causes, athlete's heart, and screening guidelines. Postgrad Med. 2000 Oct;108(5):37-44, 47-50.

Defibrillation and sudden cardiac death. http://www.defib.org/defibrillation.html. June 12,2002

Ecker R, Rea TD, Meischke H, Schaffer SM, Kudenchuk P, Eisenberg MS. Dispatcher assistance and automated external defibrillator performance among elders. Acad Emerg Med. 2001 Oct;8(10):968-73.

Eisenberg MS. Is it time for over-the-counter defibrillators? JAMA. 2000 Sep 20;284(11):1435-8.

Estes NA $3^{\text {rd }}$. Editorial: Sudden death in young athletes. $N$ Eng $J$ Med. 1995 Aug $10 ; 333(6): 380-1$. 
Estes NA $3^{\text {rd }}$, Link MS, Homoud M, Wang PJ. ECG findings in active patients: differentiating the benign from the serious. Phys \& Sportsmed. 2001 Mar;29(3):67-74.

Fahrenbach MC, Thompson PD. The preparticipation sports examination. Cardiovascular considerations for screening. Cardiol Clin. 1992 May;10(2):319-28.

Federal Aviation Administration (FAA), DOT. Emergency medical equipment. Final Rule. Fed Regist. 2001 Apr 12;66(71):19028-46.

Foltz RA, Sayne MR. Automated external defibrillators in long-term care facilities are cost effective. Prehosp Emerg Care. 2000 Oct-Dec;4(4):314-7.

Frank RL, Rausch MA, Menegazzi W, Rickens M. The locations of nonresidential outof-hospital cardiac arrests in the City of Pittsburgh over a three-year period: implications for automated external defibrillator placement. Prehops Emerg Care. 2001 Jul-Sep;5(3):247-51.

Franklin BA, Fletcher GF, Gordon NF, Noakes TD, Ades PA, Balady GJ. Cardiovascular evaluation of the athlete. Issues regarding performance, screening, and sudden cardiac death. Sports Med. 1997 Aug;24(2):97-119.

Frazier JE $2^{\text {nd }}$. Acute cardiac emergencies in the injured athlete. Clin Sports Med. 1989 Jan;8(1):81-90.

Friman G, Wesslen L, Fohlman J, Karjalainen J, Rolf C. The Epidemiology of infectious myocarditis, lymphocytic myocarditis, and dilated cardiomyopathy. Eur Heart J. 1995 Dec;16 Suppl O:36-41.

Fuller CM. Cost effectiveness analysis of screening of high school athletes for risk of sudden cardiac death. Med Sci Sports Exerc. 2000 May;32(5):887-90.

Fuller CM, McNulty CM, Spring DA, Arger KM, Bruce SS, Chryssos BE, Drummer EM, Kelley FP, Newmark MJ, Whipple GH. Prospective screening of 5, 615 high school athletes for risk of sudden cardiac death. Med Sci Sports Exerc. 1997 Sep;29(9):1131-8.

Futterman LG, Lemberg L. Sudden death in athletes. Am J Crit Care. 1995 May:4(3):239-43.

Futterman LG, Meyerburg R. Sudden death in athletes: an update. Sports Med. 1998 Nov;26(5):335-50.

Garson A Jr. Arrhythmias and sudden cardiac death in elite athletes. American College of 
Cardiology, $16^{\text {th }}$ Bethesda Conference. Pediatr Med Chir. 1998 MarApr;20(2):101-3.

Gendreau MA, DeJohn C. Repsonding to medical events during commercial airline flights. NEJM. 2002 April 4;346(14):1067-73.

Gerhardt RT, Weigert R, Newell SK, Gerhardt DM, Gaither P. Field deployment of automated external defibrillators to a Federal Fire Service unit under medical direction of a military emergency service. Mil Med. 1999 Dec;164(12):877-80.

Goble MM. Sudden cardiac death in the young athlete. Indian J Pediatr. 1999 JanFeb;66(1):1-5.

Grafe MW, Paul GR, Foster TE. The preparticipation sports examination for high school and college athletes. Clin Sports Med. 1997 Oct;16(4):569-91.

Gratton M, Lindholm DJ, Campbell JP. Public access defibrillation: Where do we place the AEDs? Prehosp Emerg Care. 1999 Oct-Dec:3(4):303-5.

Groeneveld PW, Kwong J, Liu Y, Rodriguez AJ, Jones MP, Sanders GD, Garber AM. Cost- effectiveness of automated external defibrillators on airlines. JAMA. 2001 Sep 26;286(12):1482-9.

Gundry JW, Comess KA, DeRook FA, Jorgenson D, Bardy GH. Comparison of naïve sixth-grade children with trained professionals in the use of an automated external defibrillator. Circulation. 1999 Oct 19;100(16):1703-7.

Hanley K, Dowling J, Bury G, Murphy A. The role of automated external defibrillators in rural general practice. Br J Gen Pract. 1999 Apr;49(441):297-8.

Haynes BE, Mendoza A, McNeil M, Schroeder J, Smiley DR. A statewide early defibrillation initiative including laypersons and outcome reporting. JAMA. 1991 July $24-31 ; 266(4): 545-7$.

Herlitz J, Bang A, Axelsson A, Graves JR, Lindquist J. Experience with the use of automated external defibrillators in out-of-hospital cardiac arrest. Resuscitation. 1998 Apr;37(1):3-7.

Hunt V. Across the nation, attention turns to heart. NATA News. 2002 Jan:15-6.

Hunt, V. Evaluating automated medicine: the AED's place in health care. NATA News. 2002 Jan:10-14.

Jarin JM, Ansell BA, Larsen MD, Cummins RO. Automated external defibrillators: skill 
maintenance using computer-assisted learning. Acad Emerg Med., 1998 Jul;5(7):709-17.

Jordeans L, Missault L, Pelleman G, Duprez D, De Backer G, Clement DL. Comparison of athletes with life-threatening ventricular arrhythmias with two groups of healthy athletes and a group of normal control subjects. Am J Cardiol. 1994 Dec 1;74(11):1124-8.

Karch SB, Graff J, Young S, Ho CH. Response times and outcomes for cardiac arrests in Las Vegas casinos. Am J Emerg Med. 1998 May;16(3):249-53.

Karczmarewicz A, Janusek D, Buckowski T, Gutkowski R, Kulakowski P. Influence of mobile phones on accuracy of ECG interpretation algorithm in automated external defibrillator. Resuscitation. 2001 Nov;51(2):173-7.

Kellermann AL, Hackman BB, Somes G, Kreth TK, Nail L, Dobyns P. Impact of firstresponder defibrillation in an urban emergency medical services system. JAMA. 1993 Oct 13;270(14):1708-13.

Kennedy MC, Lawrence C. Anabolic steroid use and cardiac death. Med J Aust. 1993 Mar 1;158(5):346-8.

Kenny A, Shapiro LM. Sudden cardiac death in athletes. Br Med Bull. 1992 Jul;48(3):534-45.

Kinoshita N, Mimura J, Obayashi C, Katsukawa F, Onishi S, Yamazaki H. Aortic root dilatation among young competitive athletes: echocardiographic screening of 1929 athletes between 15 and 34 years of age. Am Heart J. 2000 Apr;139(4):7234.

Koller A, Mertelseder S, Whyte G. Is exercise-induced myocardial injury self-abating? Med Sci Sport Exer. 2001 May;33(5):850-1.

Kowalski KM. Sudden death in sports-- new hope for athletes. Curr Hlth. 1998 Apr/May;24(8):28-9.

Kulbertus H. [Sudden death in athletes]. Rev Med Liege. 2001 May;56(5):318-25.

Kurowski K, Chandran S. The preparticipation athletic evaluation. Am Fam Physician. 2000 May 1;61(9):2683-90, 2696-8.

Kyle JM, Leaman J, Elkins GA. Planning for scholastic cardiac emergencies: the Ripley project. $W V$ Med J. 1999 Sep-Oct;95(5):258-60. 
Lateef F. Commotio cordis: an under appreciated cause of sudden death in athletes. Sports Med. 2000 Oct;30(4):301-8.

Lateef F, Anantharaman V. Bystander cardiopulmonary resuscitation in prehospital cardiac arrest patients in Singapore. Prehosp Emerg Care. 2001 OctDec;5(4);387-90.

Lewis JF, Maron BJ, Diggs JA, Spencer JE, Mehrotra PP, Curry CL. Preparticipation echocardiographic screening for cardiovascular disease in a large, predominantly black population of collegiate athletes. Am J Cardiol. 1989 Nov 1;64(16):102933.

Link MS, Homoud MK, Wang PJ, Estes NA $3^{\text {rd }}$. Cardiac arrhythmias in the athlete. Cardiol Rev. 2001 Jan-Feb;9(1):21-30.

Link MS, Maron BJ, Vanderbrink BA, Takeuchi M, Pandian NG, Wang PJ, Estes NA $3^{\text {rd }}$. Impact directly over the cardiac silhouette is necessary to produce ventricular fibrillation in an experimental model of commotio cordis. J Am Coll Cardiol. $2001 \mathrm{Feb} ; 37(2): 649-54$.

Link MS, Wang PJ, Estes NA $3^{\text {rd }}$. Ventricular arrhythmias in the athlete. Curr Opin Cardiol. 2001 Jan;16(1):30-9.

Link MS, Wang PJ, Maron BJ, Estes NA. What is commotio cordis? Cardiol Rev. 1999 Sep- Oct:7(5):265-9.

Lipp LN. Identify the young athlete at risk for sudden cardiac death. JAAPA. 2001 Aug;8:26-30.

Lyznicki JM, Nielsen NH, Schneider JF. Cardiovascular screening of student athletes. Am Fam Physician. 2000 Aug 15;62(4):765-74.

Lyznicki JM, Williams MA, Dietchman SD, Howe JP $3^{\text {rd }}$. Inflight medical emergencies. Aviat Space Environ Med. 2000 Aug;71(8):832-8.

MacAuley D. Does preseason screening for cardiac disease really work?: the British perspective. Med Sci Sport Exerc. 1998 Oct suppl;30(10): S345-S350.

Mancini ME, Richards N, Kaye W. Saving lives with AED's. Nursing. 1997 Oct;27(10):42-3.

Marenco JP, Wang PJ, Link MS, Homoud MK, Estes NA $3^{\text {rd }}$. Improving survival from sudden cardiac arrest: the role of the automated external defibrillator. JAMA. 2001 Mar 7;285(9):1193-1200. 
Maron BJ, Bodison SA, Wesley YE, Tucker E, Green KJ. Results of screening a large group of intercollegiate competitive athletes for cardiovascular disease. J Am Coll Cardiol. 1987 Dec;10(6):1214-21.

Maron BJ. Cardiovascular risks to young people on the athletic field. Ann Intern Med. 1998 Sep 1; 129(5):379-86.

Maron BJ, Carney KP, Lever HM, Lewis JF, Barac I, Casey SA, Sherrid MV. Relationship of race to sudden cardiac death in competitive athletes with hypertrophic cardiomyopathy. J Am Coll Cardiol. 2003 Mar 19;41(6):974-80.

Maron BJ, Gohman TE, Kyle SB, Estes NA $3^{\text {rd }}$, Link MS. Clinical profile and spectrum of commotio cordis. JAMA. 2002 Mar 6;287(9):1142-6.

Maron BJ. Hypertrophic cardiomyopathy: a systematic review. JAMA. 2002 Mar 13;287(10):1308-20.

Maron BJ. Hypertrophic cardiomyopathy: practical steps for preventing sudden death. Phys \& Sportsmed. 2002 Jan;30(1):19-24.

Maron BJ, Klues HG. Surviving competitive athletics with hypertrophic cardiomyopathy. Am J Cardiol. 1994 Jun 1;73(15):1098-104.

Maron BJ, Poliac LC, Roberts WO. Risk for sudden cardiac death associated with marathon running. J Am Coll Cardiol. 1996 Aug;28(2):428-31.

Maron BJ. Risk profiles and cardiovascular preparticipation screening of competitive athletes. Cardiol Clin. 1997 Aug;15(3):473-83.

Maron BJ, Shirani J, Poliac LC, Mathenge R, Roberts WC, Mueller FO. Sudden death in young competitive athletes. Clinical, demographic, and pathological profiles. $J A M A$. 1996 Jul 17;276(3):199-204.

Maron BJ, Thompson PD, Puffer JC, McGrew CA, Strong WB, Douglas PS, Clark LT, Mitten MJ, Crawford MH, Atkins DL, Driscoll DJ, Epstein AE. Cardiovascular preparticipation screening of competitive athletes: a statement for health professionals from the sudden death committee (clinical cardiology) and congenital cardiac defects committee (cardiovascular disease in the young), American Heart Association. Circulation. 1996 Aug 15;94(4):850-6.

Maron BJ. Triggers for sudden cardiac death in the athlete. Cardiol Clin. 1996 May;14(2);195-210. 
McDonald, RD, Swanson JM, Mottley JL, Weinstein C. Performance and error analysis of automated external defibrillator use in the out-of-hospital setting. Ann Emerg Med. 2001 Sep;38(3):262-7.

McInnis K, Herbert W, Herbert D, Herbert J, Ribisl P, Franklin B. Low compliance with national standards for cardiovascular emergency preparedness at health clubs. Chest. $2001 \mathrm{Jul} ; 120(1): 283-8$.

McManus BM, Babul S. Pathology of sudden death in the young. Can J Cardiol. 1996 Nov;12(11):1150-6.

McRae AT $3^{\text {rd }}$, Chung MK, Asher CR. Arrhythmogenic right ventricular cardiomyopathy: a cause of sudden death in young people. Cleve Clin J Med. 2001 May;68(5):459-67.

Meischke HW, Rea TD, Eisenberg MS, Rowe SM. Intentions to use an automated external defibrillator during a cardiac emergency among a group of seniors trained in its operation. Heart Lung. 2002 Jan-Feb;31(1):25-9.

Michal DM. Automated external defibrillators: prehospital use in advanced cardiac life support. J Emerg Nurs. 1993 Apr;19(2):96-101.

Mills JD, Moore GE, Thompson PD. The athlete's heart. Clin Sports Med. 1997 Oct;16(4):725-37.

Mistry DJ, Kramer CM. Imaging of cardiopulmonary diseases. Clin Sports Med.2003 Jan;22(1):197-212.

Monsieurs KG, Hardley AJ, Bossaert LL. European resuscitation council guidelines 2000 for automated external defibrillation. A statement from the basic life support and automated external defibrillation working group (1) and approved by the executive committee of the European resuscitation council. Resuscitation. 2001 Mar;48(3):207-9.

Montgomery WH. Prehospital cardiac arrest: the chain of survival concept. Ann Acad Med Singapore. 1992 Jan;21(1):69-72.

Mosesso VD Jr, Davis EA, Auble TE, Paris PM, Yealy DM. Use of automated external defibrillators by police officers for treatment of out-of-hospital cardiac arrest. Ann Emerg Med. 1998 Aug;32(2):200-7.

National Athletic Trainer's Association (NATA). http://www.nata.org. 2003

National Center for Early Defibrillation (NCED). http://www.early-defib.org. 2003. 
Nichol G, Hallstrom AP, Kerber R, Moss AJ, Ornato JP, Palmer D, Riegel B, Smith S, Weisfeldt ML. American heart association report on the second public access defibrillation conference, April 17-9, 1997. Circulation. 1998 Apr 7;97(13):130914.

Nichol G, Hallstrom AP, Omato JP, Riegel B, Stiell IG, Valenzuela T, Wells GA, White RD, Weisfeldt ML. Potential cost-effectiveness of public access defibrillation in the United States. Circulation. 1998 Apr 71;97(13):1315-20.

Niskamen RA. Automated external defibrillators: experiences with their use and options for their further development: Wolf Creek IV conference to explore AEDs. New Horiz. 1997 May;5(2):137-44.

Oakley CM. The electrocardiogram in the highly trained athlete. Cardiol Clin. 1992 May;10(2):295-302.

O'Hearn P. Early defibrillation: lessons learned. J Cardiovasc Nurs. 1996 Jul;10(4):2436.

Page RL, Joglar JA, Kowal RC, Zagrodzky JD, Nelson LL, Ramaswamy K, Barbera SJ, Hamdan MH, McKenas DK. Use of automated external defibrillators by an U.S. airline. $N$ Eng $J$ Med. 2000 Oct 26;343(17):1210-5.

Pelliccia A, Di Paolo FM, Maron BJ. The athlete's heart: remodeling, electrocardiogram, and preparticipation screening. Cardiol Rev. 2002 Mar-Apr;10(2):85-90.

Pelliccia A, Maron BJ. Athlete's heart electocardiogram mimicking hypertrophic cardiomyopathy. Curr Cardiol Rep. 2001 Mar;3(2):147-51.

Pellis T, Bisera J, Tang W, Weil MH. Expanding automatic external defibrillation to include automated detection of cardiac, respiratory, and cardiorespiratory arrest. Crit Care Med. 2002 Apr; 30(4 Suppl):S176-8.

Pfister, GC, Puffer JC, Maron, BJ. Preparticiaption cardiovascular screening for US collegiate student-athletes. JAMA. 2000 March 22/29;283(12):1597-1599.

Pipe A. The adverse effects of elite competition on health and well-being. Can J Appl Physiol. 2001;26 Suppl:S192-201.

Prina LD, White RD, Atkinson EJ. Automated external defibrillators and first responders: a satisfaction survey. Resuscitation. 2002 May;53(2):171-7.

Public Access Defibrillation League (PADL). http://www.padl.org. 2003.

Rich BS. Sudden death screening. Med Clin North Am. 1994 Mar;78(2):267-88. 
Riegel B. Training nontraditional responders to use automated external defibrillators. $\mathrm{Am}$ $J$ Crit Care. 1998 Nov;7(6):402-10.

Roberston RM. Editorial: partnerships for the health of the public. Circulation. 2001 Jun 19;103(24):2870.

Rothouse M. Providers brief issue: automated external defibrillators. Issue Brief Health Policy Track Serv. 1999 Jun;25:1-6.

Rogove HJ, Hughes CM. Defibrillation and cardioversion. Crit Care Clin. 1992 Oct;8(4):839-63.

Rossi L. Structural and non-structural disease underlying high-risk cardiac arrhythmias relevant to sports medicine. J Sports Med Phys Fitness. 1995 Jun;35(2):79-86.

Russ P, Nolan J, Hill E, Dawson J, Whimster F, Skinner D. The use of AEDs by police officers in the City of London. Resuscitation. 2001 Aug;50(2):141-6.

Ryan, WA. Basic life support and emergency cardiovascular care update, part 3: automated external defibrillators. Dent Today. 2001 Nov;20(11):70-3.

Sachs RG, Kerwin J. Automated external defibrillators and sudden cardiac arrest. $N J$ Med. 2001 Apr;98(4):39-41.

Sandison T, Meischke HW, Schaeffer SM, Eisenberg MS. Barriers and facilitators to the prescription of automated external defibrillators for home use in patients with heart disease: a survey of cardiologists. Heart Lung. 2001 May-Jun;30(3):210-5.

Sato Y, Weil MH, Sun S, Tang W, Xie J, Noc M, Bisera J. Adverse effects of interrupting precordial compression during CPR. Crit Care Med. 1997 May;25(2):733-6.

Schneider T, Wolcke B, Liebrich A, Kanz KG, Dick W. [New aspects of electric defibrillation]. Anaesthesist. 1998 Apr;47(4):320-9.

Schnirring L. Portable 'echo' devices offer PPE possibilities. Phys Sportmed.2001Sep;29(9):13-16.

Sebastianelli WJ. Sideline preparation for the team physician. Curr Opin Orthop. 2002 Apr;13(2):115-121.

Seder JB. When seconds count: saving cardiac arrest victims with automated external defibrillators (AED's). Tex Dent J. 2002 May;119(5):450-4. 
Seto, CK. Preparticipation cardiovascular screening. Clin Sports Med.2003 Jan;22(1):2325.

Shekelle P, Morton S, Maglione M, et al. Ephedra and ephedrine for weight loss and athletic performance enhancement: clinical efficacy and side effects. Evidence Report/Technology Assessment No. 76 (Prepared by Southern California Evidence-based Practice Center, RAND, under Contract No. 290-97-0001, Task Order No. 9). ARHQ Publication No. 03-E022 Rockville, MD: Agency for Healthcare Research and Quality. February 2003.

Shephard RJ. The athlete's heart: is big beautiful? Br J Sports Med. 1996 Mar;30(1);510.

Siegel RJ, Kimura BJ. Sudden death of young athletes can be prevented. USA Today. $2001 \mathrm{Mar} ; 129(2670): 60-1$.

Simons SM, Moriarity J. Hypertrophic cardiomyopathy in a college athlete. Med Sci Sports Exerc. 1992 Dec;24(12):1321-4.

Smith SC Jr., Hamburg RS. Automated external defibrillators: time for federal and state advocacy and broader utilization. Circulation. 1998 Apr 7;97(13):1321-4.

So Relle R. Automated external defibrillators improving survival after sudden cardiac arrest. Circulation. 2001 Mar 27;103(12):E9024-5.

So Relle R. Federal funding for automated external defibrillators in rural areas is proposed. Circulation. 2000 Oct 24;102(17):E9034-5.

Sotoodehnia N, Zivin A, Bardy GH, Siscovick DS. Reducing mortality from sudden cardiac arrest in the community: lessons from epidemiology and clinical applications research. Cardiovasc Res. 2001 May;50(2):197-209.

Soyeur, D. [Pre-competition screening of young high-level athletes]. Rev Med Liege. 2001 Apr;56(4):280-4.

Stampfli U, Wagner D, Dubach P. [Cardiovascular diseases and sports]. Schweiz Rundsch Med Prax. 1999 Apr 1;88(14):601-8.

Stapczynski JS, Burklow M, Calhoun RP, Svenson JE. Automated external defibrillators used by emergency medical technicians: report of the 1992 experience in Kentucky. J Ky Med Assoc. 1995 Apr;93(4):137-41.

Stapczynski JS, Svenson JE, Stone CK. Population density, automated external defibrillator use, and survival in rural cardiac arrest. Acad Emerg Med. 1997 Jun;4(6):552-8. 
Stendig-Lindberg G. Sudden death of athletes: is it due to long-term changes in serum magnesium, lipids, and blood sugar? J Basic Clin Physiol Pharmacol. 1992 AprJune;3(2):153-64.

Stiell IG, Wells GA, Field BJ, Spaite DW, DeMaio VJ, Ward R, Munkley DP, Lyver MB, Luinstra LG, Campeau T, Maloney J, Dagnone E. Improved out-of-hospital cardiac arrest survival through the inexpensive optimization of an existing defibrillation program: OPALS Study Phase II. JAMA. 1999 Apr 7;281(13):117581.

Stolzenberg BT, Kupas DF, Wieczorek BJ, Sole DP. Automated external defibrillator appropriately recognize ventricular fibrillation in electromagnetic fields. Prehosp Emerg Care. 2002 Jan-Mar;6(1):65-6.

Takata TS, Page RL, Joglar JA. Automated external defibrillators: technical considerations and clinical promise. Ann Intern Med. 2001 Dec 4;135(11):990-8.

Thiene $\mathrm{G}, \mathrm{Basso} \mathrm{C}$, Corrado $\mathrm{D}$. Is prevention of sudden death in young athletes feasible? Cardiologia. 1999 Jun;44(6):497-505.

Thompson PD. Athletes, athletics, and sudden cardiac death. Med Sci Sports Exerc. 1993 Sep;25(9):981-4.

Thompson PD. The cardiovascular complications of vigorous physical activity. Arch Intern Med. 1996 Nov 11;156(20):2297-302.

Valenzuela TD, Roe DJ, Nichol G, Clark LL, Spaite DW, Hardman RG. Outcomes of rapid defibrillation by security officers after cardiac arrest in casinos. $N$ Eng $J$ Med. 2000 Oct 26;343(17):1206-9.

Valgaeren G, Conraads V, Colpaert C, Rademakers F, Vrints C. Sudden death in hypertrophic cardiomyopathy: risk stratification and prevention. Acta Cardiol. 1998;53(1):23-9.

Van Camp SP, Bloor CM, Mueller FO, Cantu RC, Olson HG. Nontraumatic sports death in high school and college athletes. Med Sci Sports Exerc. 1995 May;27(5):641-7.

Vaska PL. Sudden cardiac death in young athletes: a review for nurses. AACN Clin Issues Crit Care Nurs. 1992 Feb;3(1):243-54.

Virmani R, Burke AP, Farb A, Kark JA. Causes of sudden death in young and middleaged competitive athletes. Cardiol Clin. 1997 Aug;15(3):439-66. 
Wagner CM. The use of automated external defibrillators in pediatric patients. Air Med J. 2001 Nov-Dec;20(6):13.

Waller BF, Hawley DA, Clark MA, Pless JE. Incidence of sudden athletic deaths between 1985 and 1990 in Marion County, Indiana. Clin Cardiol. 1992 Nov;15(11):851-8.

Walters G, Glucksman E, Evans TR. Training St John Ambulance volunteers to use an automated external defibrillator. Resuscitation. 1994 Jan;27(1):39-45.

Weaver WD, Peberdy M. Defibrillators in public places-one step closer to home. New Eng J Med. 2002 Oct 17;347(16):1223-4.

Weber RD. Automated external defibrillators and liability. J Mich Dent Assoc. 2002 Feb;84(2):20.

Weil MH, Tang W. Cardiopulmonary resuscitation: a promise as yet largely unfulfilled. Dis Mon. 1997 Jul;43(7):429-501.

Weiner HR. Preventing sudden death in student athletes. Compr Ther. 1999 Mar;25(3):151-4

Weinlich M, Holzer H, Flesch I, Domres B. [Legal aspects in early defibrillation by trained lay responders]. Versicherungsmedizin. 2000 Jun 1;52(2):90-2

White RD, Hankins DG, Bugliosi TF. Seven years' experience with early defibrillation by police and paramedics in and EMS system. Resuscitation. 1998 Dec;39(3):145-51.

White $\mathrm{RD}$. Technologic advances and program initiatives in public access defibrillation using automated external defibrillators. Curr Opin Crit Care. 2001 Jun; (7)3:14551 .

White RD, Hankins DG, Atkinson EJ. Patient outcomes following defibrillation with a low energy biphasic truncated exponential waveform in out-of-hospital cardiac arrest. Resuscitation. 2001 Apr;49(1):9-14.

Wight $\mathrm{JN} J \mathrm{~J}$, Salem D. Sudden cardiac death and the 'athlete's heart'. Arch Intern Med. 1995 Jul 24;155(14):1473-80.

Wilson PWF. Editorial: Physical activity, fitness, and coronary risk estimation. $J$ Cardiopulm Rehab. 2001 Mar-Apr;21:71-2. 
Young MC, Fricker PA, Thomson NJ, Lee KA. Sudden death due to ischaemic heart disease in young aboriginal sportsmen in the Northern Territory, 1982-1996. Med $J$ Aust. 1999 May 3;170(9):425-8. 